Supporting Information

\title{
De Novo Design and Facile Synthesis of 2D Covalent Organic Frameworks: A
}

\section{Two-in-One Strategy}

Yusen Li, ${ }^{\dagger}$ Qing Chen, ${ }^{\S}$ Tiantian $\mathrm{Xu},{ }^{\dagger}$ Zhen Xie, ${ }^{\dagger}$ Jingjuan Liu, ${ }^{\dagger}$ Xiang $\mathrm{Yu},{ }^{\ddagger}$ Shengqian $\mathrm{Ma},{ }^{\perp}$ Tianshi Qin, ${ }^{\S}$ Long Chen*,†

'Department of Chemistry and Tianjin Key Laboratory of Molecular Optoelectronic Science, Tianjin University, Tianjin 300072, China.

*Analytical and Testing Center, Jinan University, Guangzhou 510632, China

${ }^{\S}$ Institute of Advanced Materials (IAM), Nanjing Tech University (Nanjing Tech), Nanjing 210009, China

${ }^{\perp}$ Department of Chemistry, University of South Florida, 4202 East Fowler Avenue, Tampa, Florida 33620, United States

E-mail: long.chen@tju.edu.cn 


\section{Contents}

Section 1. Materials and Methods

Section 2. Synthetic Procedures

Section 3. Porosity, FT-IR Spectra and Solid State ${ }^{13}$ C CP/MAS NMR Spectrum of Py-COFs

Section 4. Thermogravimetric Analysis

Section 5. PXRD Profiles for Py-COFs Synthesized in Different Solvents

Section 6. BET and PSD of Py-COF $\mathrm{CHCl3}_{\mathrm{H}}$ and $\mathrm{Py}-\mathrm{COF}$ MeCN

Section 7. SEM and TEM Images of Py-COFs

Section 8. UV-visible Spectral Profiles

Section 9. Chemical Stability Tests

Section 10. The Influence of Reaction Conditions on Crystallinity and Porosity of Py-COFs

Section 11. AA (eclipsed) Stacking Structure Simulation and Atomic Coordinates of Py-COF

Section 12. Single-Crystal Structure and Crystal Data of BFBAPy

Section 13. BET Plots of $\mathrm{N}_{2}$ Isotherms for Py-COFs

Section 14. AFM Images of Py-COF Thin Films

Section 15. The Solvent Dependence Tests and Transparency of Py-COF Films

Section 16. General Procedure for the Synthesis of Py-COFs

Section 17. Contact Angle Images for Py-COF Film and Powder

Section 18. PXRD, BET and IR Pattems of Py-COF $6 \mathrm{M} \mathrm{AcOH}$ and Py-COF $12 \mathrm{M} \mathrm{HCl}$

Section 19. UPS Spectrum of Py-COF Film

Section 20. Optical Images for Py-COF Film on ITO Glass with PEDOT/PSS Coating

Section 21.Generality and Tolerance of Two-in-One Strategy

Section 22. 2D-GIWAXS of Py-COF Film

Section 23.The Investigation of Stoichiometric Imbalance in Py-COF $\mathrm{DCM}_{\mathrm{Dys}}$ Sym

Section 24. The Comparison of PXRD Patterns for Co- and Self-Condensation COFs

Section 25. Comparison of the Performance of Some Hole Transport Materials

Section 26. The ${ }^{1} \mathrm{H}$ and ${ }^{13} \mathrm{C}$ NMR Spectra of the Intermediates and Monomers

Section 27. Supporting References 


\section{Section 1. Materials and Methods}

1,6-dibromopyrene, (4-formylphenyl)boronic acid, potassium carbonate, tetrakis(triphenylphosphine)palladium(0), 4-(4,4,5,5-tetramethyl-1,3,2-dioxaborolan-2-yl)aniline, $N$-bromosuccinimide (NBS) were purchased from Adamas. All organic solvents like dimethylacetamide (DMAc), methanol (MeOH), dichloromethane (DCM), ethanol (EtOH), acetonitrile $(\mathrm{MeCN})$, chloroform $\left(\mathrm{CHCl}_{3}\right)$, tetrahyd rofuran (THF), 1,2-dichlorobenzene (o-DCB) and butyl alcohol $(\mathrm{n}-\mathrm{BuOH})$ were analytical grade reagents and used without further purification.

Single-crystal X-ray data for compound BFBAPy was collected on a Rigaku SCX-mini diffractometer with graphite monochromatic Mo-K $\alpha$ radiation $(\lambda=0.7173 \AA)$ by $\omega$ scan mode. The thermogravimetric analysis (TGA) of Py-COF was evaluated with a differential thermal analysis instrument (TA Instruments TGA Q50-1918 analyzer) over the temperature range from 20 to $800{ }^{\circ} \mathrm{C}$ in $\mathrm{N}_{2}$ atmosphere at a heating rate of $10{ }^{\circ} \mathrm{C} \mathrm{min}^{-1}$ using an empty $\mathrm{Al}_{2} \mathrm{O}_{3}$ crucible as the reference. Surface areas were measured by nitrogen adsorption and desorption at $77 \mathrm{~K}$ using a Bel Japan Inc. model BELSOPR-max analyzer and the samples were degassed at $120{ }^{\circ} \mathrm{C}$ for $8 \mathrm{~h}$ under vacuum $\left(10^{-5}\right.$ bar) before analysis. The pore size distribution was calculated from the adsorption branch with the nonlocal density functional theory (NLDFT). The Powder X-ray diffraction (PXRD) patterns were recorded on X-ray diffractometer (RIGAKU SMARTLAB 9KW) with a Cu-target tube and a graphite monochromator. The grazing-incidence XRD (GI-XRD) patterns of Py-COF films were recorded on RIGAKU SMARTLAB $9 \mathrm{KW}$ X-ray diffractometer with an incidence angle of $0.2^{\circ}$. The two dimensional grazing incidence wide angle X-ray scattering (2D-GIWAXS) was measured at Shanghai Synchrotron Radiation Facility (SSRF) on beamline BL14B1 with $\lambda=1.24 \AA$ with a MarCCD area detector at incidence angle of $0.2^{\circ}$. on Fourier transform infrared (FT-IR) spectra were recorded in transmission mode on a Bruker Alpha spectrometer using $\mathrm{KBr}$ pellets in the range 400 $4000 \mathrm{~cm}^{-1}$. The ${ }^{13} \mathrm{C}$ cross-polarization magic angle spinning (CP/MAS) spectra were recorded on Varian Infinityplus $300(300 \mathrm{MHz})$ solid state NMR spectrometer with a $4 \mathrm{~mm}$ double resonance MAS probe and at a MAS rate of $10.0 \mathrm{kHz}$ with a contact time of $2 \mathrm{~ms}$ (ramp 100) and a pulse delay of 3 s. Transmission electron microscopies (TEM) and high-resolution transmission electron microscopies (HR-TEM) were performed on a FEI model Tecani 20 microscope and a JEOL model JEM-2100F. Field emission scanning electron microscopies (FE-SEM) were performed on a JEOL model JSM-6700 microscope operating at an accelerating voltage of $5.0 \mathrm{kV}$. Elemental analysis (C, H, N) was analyzed on a Perkin-Elmer 240C elemental analyzer. The simulations of the possible structures were carried out in Accelrys Material Studio 7.0 software package. The simulated PXRD patterns were determined by the Reflex module. Pawley refinement of the experimental PXRD of Py-COF was conducted to optimize the lattice parameters iteratively until the $R_{\mathrm{wp}}$ value converges. The theoretical surface areas for Py-COF was calculated by High-Throughput-based Complex 
Adsorption and Diffusion Simulation Suite (HT-CADSS) which can be used to perform molecular dynamics (MD) and Monte Carlo (MC) simulations in various ensembles. Detail information as well as the agreement for the use of HT-CADSS software package can be obtained by visiting this website: http://jshx.buct.edu.cn/docs/2017-10/20171013105139825461.pdf. The technical details are summarized as follows: Firstly, save the atomic coordinates cif file of Py-COF as a new car file, and import into the car folder (the car folder is in directory: HT-CADSS > WorkArea > share > structure folder). Then, createing a new folder and name as "Py-COF" in WorkArea folder which is a subfolder of HT-CADSS. Then, recreate a folder named as "1bar" as a subfolder in the "Py-COF" folder and paste the 'simulation. input' file and 'Run. bat' file from the software supporter into this folder. Afterwards, run the 'simulation. input' file and input the Framework name as 'Py-COF" in "Simulation Cell Information" part and select the "Screen_UFF" as the forcefield. Finally, run the 'Run. bat' file and waiting for the process of simulation until it is finished. The simulated result is generated in the 'Out put' folder as 'SimuResults.data' file and the calculated framework surface area of Py-COF was shown in this file as $1537.12 \mathrm{~m}^{2} / \mathrm{g}$. Atomic Force Microscope (AFM) (Bruker, Multimode 8) was used to evaluate the thickness of the as synthesized Py-COF thin films. The UPS spectrum for Py-COF film was measured by a VG Scienta R4000 analyzer with a monochromatic He-I light source $21.2 \mathrm{eV}$ ). The current density-voltage (J-V) curves of devices were measured (2400 Series SourceMeter, Keithley Instruments) under simulated AM 1.5 sunlight at $100 \mathrm{~mW} \mathrm{~cm}^{-2}$ irradiance generated by a solar simulator (Class AAA, 94023A, Newport), with the intensity calibrated with a Newport standard silicon cell 91150.

The procedure for device fabrication was as described follows: [6,6]-phenyl-C61-butyric acid methyl ester $\left(\mathrm{PC}_{61} \mathrm{BM}\right)$ solution was prepared by dissolving $10 \mathrm{mg}$ of $\mathrm{PC}_{61} \mathrm{BM}$ into chlorobenzene $(\mathrm{CB}, 1 \mathrm{~mL})$ and stirring at $25{ }^{\circ} \mathrm{C}$ for $12 \mathrm{~h}$ and poly[bis (4-phenyl)(2,4,6-trimethylphenyl)amine] (PTAA, $\left.\mathrm{M}_{\mathrm{n}}=3200, \mathrm{M}_{\mathrm{w}}=4900\right)$ solution were prepared by dissolving $2 \mathrm{mg}$ of polymer into CB (1 $\mathrm{mL}$ ) and stirring at $25^{\circ} \mathrm{C}$ for $2 \mathrm{~h}$. The mixed perovskite precursor was prepared by dissolving $1.4 \mathrm{M}$ mixture of metal lead salts which are composed of $\mathrm{PbI}_{2}$ and $\mathrm{PbBr}_{2}(0.85 / 0.15$, molar ratio), and 1.3 $\mathrm{M}$ organic cation which are composed of $\mathrm{NH}_{2} \mathrm{CHNH}_{2} \mathrm{I}(\mathrm{FAI})$ and $\mathrm{CH}_{3} \mathrm{NH}_{3} \mathrm{Br}(\mathrm{MABr})(0.85 / 0.15$, molar ratio) in a co-solvent of DMSO/DMF ( $4: 1$, by volume). PTAA solution was spin-coated onto the Py-COF film on ITO substrates at $6000 \mathrm{rpm}$ for $30 \mathrm{~s}$ then $50 \mu \mathrm{L}$ mixed perovskite solution was deposited at $6000 \mathrm{rpm}$ for $30 \mathrm{~s}$ to form perovskite layer. The films were then annealed at $100{ }^{\circ} \mathrm{C}$ for one hour. Upon cooling down to room temperature, $50 \mu \mathrm{L}$ of $\mathrm{PC}_{61} \mathrm{BM}$ solution was spin-coated on the top of perovskite layer at the speed of $1000 \mathrm{rpm}$ for 45 s. Buckminsterfullerene (C60) and bathocuproine (BCP) were then thermally evaporated in a vacuum chamber and finally, a $100 \mathrm{~nm}$ silver (Ag) electrode was thermally evaporated through a metal shadow mask with an aperture area of $0.1 \mathrm{~cm}^{2}$. 


\section{Section 2. Synthetic Procedures}

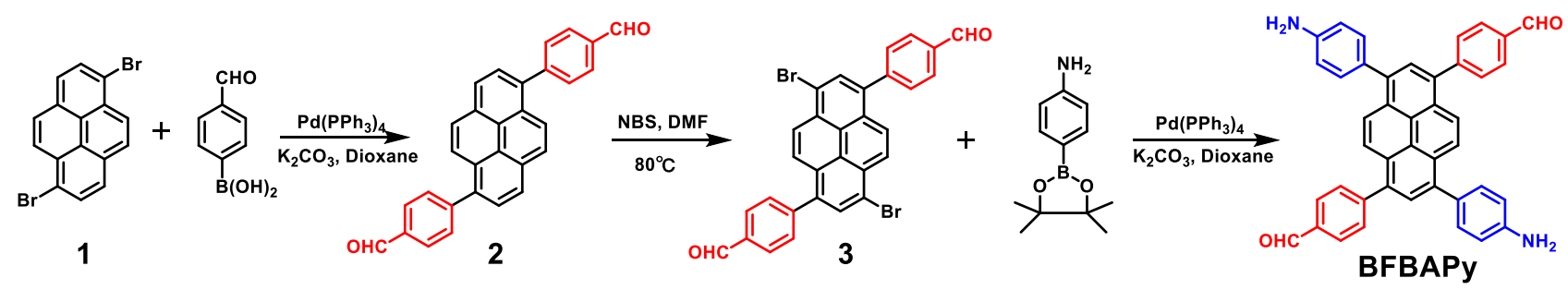

Scheme S1. Synthetic routes of compound BFBAPy.

\section{4,4'-(pyrene-1,6-diyl)dibenzaldehyde $(2)^{\mathrm{S} 1}$}

1,6-dibromopyrene (3.6 g, $10 \mathrm{mmol}$ ), (4-formylphenyl)boronic acid (4.5 g, $30 \mathrm{mmol}), \mathrm{Pd}\left(\mathrm{PPh}_{3}\right)_{4}$ $(0.36 \mathrm{~g}, 0.3 \mathrm{mmol})$ and potassium carbonate $(7.2 \mathrm{~g}, 52 \mathrm{mmol})$ were added into a $500 \mathrm{~mL}$ round-bottom flask. Then degassed dioxane $(150 \mathrm{~mL})$ and water $(30 \mathrm{~mL})$ were added. The mixture was degassed by three freeze-pump-thaw cycles, purged with $\mathrm{N}_{2}$, and stirred at $100{ }^{\circ} \mathrm{C}$ for $36 \mathrm{~h}$. After cooling to room temperature, the mixture was poured into water and filtered. The residue was washed by water, methanol, ethyl acetate and dichloromethane, then dried under vacuum to afford a yellow power $(3.5 \mathrm{~g}, 85 \%) .{ }^{1} \mathrm{H}$ NMR (400 $\left.\mathrm{MHz} \mathrm{CDCl}_{3}\right): \delta(\mathrm{ppm}) 10.18(\mathrm{~s}, 2 \mathrm{H}), 8.26(\mathrm{~d}, 2 \mathrm{H}), 8.16$ $(\mathrm{d}, 2 \mathrm{H}), 8.10(\mathrm{~d}, 6 \mathrm{H}), 8.01(\mathrm{~d}, 2 \mathrm{H}), 7.83(\mathrm{~d}, 4 \mathrm{H}) .{ }^{13} \mathrm{C} \mathrm{NMR}\left(100 \mathrm{MHz}, \mathrm{CDCl}_{3}\right): \delta(\mathrm{ppm})$ 191.98, 147.62, 136.61, 135.33, 131.35, 130.91, 129.88, 128.69, 128.02, 127.68, 125.17, 125.12, 124.94. MALDI TOF-MS: m/z Calc.410.472, found 410.282.

\section{4,4'-(3,8-dibromopyrene-1,6-diyl)dibenzaldehy de (3)}

A mixture of compound 2 (3.2 g, $7.8 \mathrm{mmol})$ and NBS (4.2 g, $16 \mathrm{mmol})$ in DMF (120 mL) were stirred under a dry argon atmosphere for $12 \mathrm{~h}$ at $80{ }^{\circ} \mathrm{C}$. Water $(200 \mathrm{~mL})$ was added to this reaction mixture. Then, the reaction mixture was filtered, washed with water and methanol, dried under vacuum to get a yellow green solid. (3.5 g, 79\%). ${ }^{1} \mathrm{H}$ NMR $\left(400 \mathrm{MHz}, \mathrm{CDCl}_{3}\right): \delta$ (ppm) 10.19 (s, $2 \mathrm{H}), 8.50(\mathrm{~d}, 2 \mathrm{H}), 8.32(\mathrm{~s}, 2 \mathrm{H}), 8.19(\mathrm{~d}, 2 \mathrm{H}), 8.11(\mathrm{~d}, 4 \mathrm{H}), 7.81(\mathrm{~d}, 4 \mathrm{H}) .{ }^{13} \mathrm{C} \mathrm{NMR}\left(100 \mathrm{MHz}, \mathrm{CDCl}_{3}\right)$ : $\delta$ (ppm) 191.82, 152.31, 137.71, 135.78, 132.11, 131.44, 131.33, 131.26, 129.97, 129.91, 128.26, 126.88, 126.58. MALDI TOF-MS: m/z Calc.568.264, found 568.114.

\section{1,6-bis(4-formylphenyl)-3,8-bis(4-aminophenyl)pyrene (BFBAPy)}

Compound 3 (3.5 g, 6.2 mmol), 4-(4,4,5,5-tetramethyl-1,3,2-dioxaborolan-2-yl)aniline (4.0 g, 18.4 $\mathrm{mmol}), \mathrm{Pd}\left(\mathrm{PPh}_{3}\right)_{4}(0.24 \mathrm{~g}, 0.2 \mathrm{mmol})$ and potassium carbonate $(6.0 \mathrm{~g}, 52 \mathrm{mmol})$ were added into a $500 \mathrm{~mL}$ round-bottom flask. Then degassed dioxane $(90 \mathrm{~mL})$ and water $(18 \mathrm{~mL})$ were added. The mixture was degassed by three freeze-pump-thaw cycles, purged with $\mathrm{N}_{2}$, and stirred at $100{ }^{\circ} \mathrm{C}$ for $36 \mathrm{~h}$. After cooling to room temperature, the mixture was poured into water and filtered. The residue was washed by water, methanol, ethyl acetate and dichloromethane, then dried under vacuum to afford a yellow power $(3.2 \mathrm{~g}, 87 \%) .{ }^{1} \mathrm{H}$ NMR (400 MHz, DMSO-d $\left.{ }_{6}\right): \delta(\mathrm{ppm}) 10.17(\mathrm{~s}, 2 \mathrm{H}), 8.26(\mathrm{~d}$, 2H), $8.11(\mathrm{~d}, 4 \mathrm{H}), 7.94(\mathrm{~m}, 6 \mathrm{H}), 7.38(\mathrm{~d}, 4 \mathrm{H}), 6.77(\mathrm{~d}, 4 \mathrm{H}), 5.39(\mathrm{~s}, 4 \mathrm{H}) .{ }^{13} \mathrm{C} \mathrm{NMR}(100 \mathrm{MHz}$, DMSO-d $)_{6}$ : $\delta$ (ppm) 193.37, 148.99, 146.94, 138.37, 135.91, 135.63, 131.74, 131.66, 130.23, 129.62, 128.30, 127.28, 126.99, 126.13, 125.91, 124.98, 114.41. MALDI TOF-MS: m/z Calc.592.698, found 592.373. 

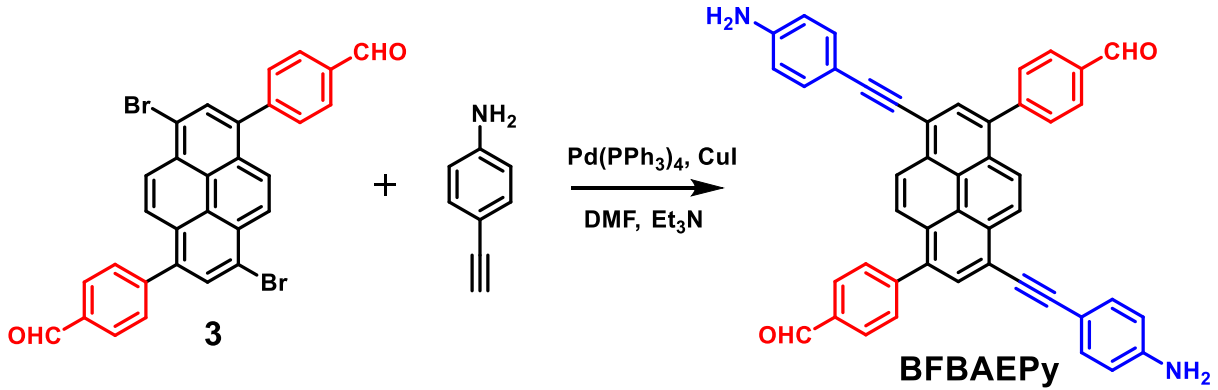

Scheme S2. Synthetic routes of compound BFBAEPy.

\section{1,6-bis(4-formylphenyl)-3,8-bis((4-aminophenyl)ethynyl))py rene (BFBAEPy)}

Compound 3 (715 mg, $1.25 \mathrm{mmol})$, 4-ethynylaniline (585 mg, $5.0 \mathrm{mmol}), \mathrm{Pd}\left(\mathrm{PPh}_{3}\right)_{4}(100 \mathrm{mg}, 0.083$ $\mathrm{mmol})$ and copper(I) iodide $(60 \mathrm{mg}, 0.31 \mathrm{mmol})$ were added into a $100 \mathrm{~mL}$ round-bottom flask. Then DMF $(35 \mathrm{~mL})$ and $\mathrm{Et}_{3} \mathrm{~N}(15 \mathrm{~mL})$ were added. The mixture was degassed by three freeze-pump-thaw cycles, purged with $\mathrm{N}_{2}$, and stirred at $120{ }^{\circ} \mathrm{C}$ for $4 \mathrm{~h}$. After cooling to room temperature, the mixture was poured into water and filtered. The residue was washed by water, methanol, ethyl acetate and dried under vacuum to afford a orange power $(700 \mathrm{mg}, 87 \%) .{ }^{1} \mathrm{H}$ NMR (400 MHz, DMSO-d 6 ): $\delta$ (ppm) 10.20 (s, 2H), 8.67 (d, 2H), $8.19(\mathrm{~m}, 8 \mathrm{H}), 7.96(\mathrm{~d}, 4 \mathrm{H}), 7.42(\mathrm{~d}, 4 \mathrm{H}), 6.62(\mathrm{~d}, 4 \mathrm{H}), 5.72(\mathrm{~s}, 4 \mathrm{H})$, ${ }^{13} \mathrm{C}$ NMR (100 MHz, DMSO-d 6 ): $\delta$ (ppm) 193.47, 150.52, 145.94, 137.01, 135.90, 133.49, 131.78, $131.75,130.90,130.79,130.36,130.27,128.00,126.21,119.43,114.18,85.90$. MALDI TOF-MS: $\mathrm{m} / \mathrm{z}$ Calc.640.742, found 640.046 .

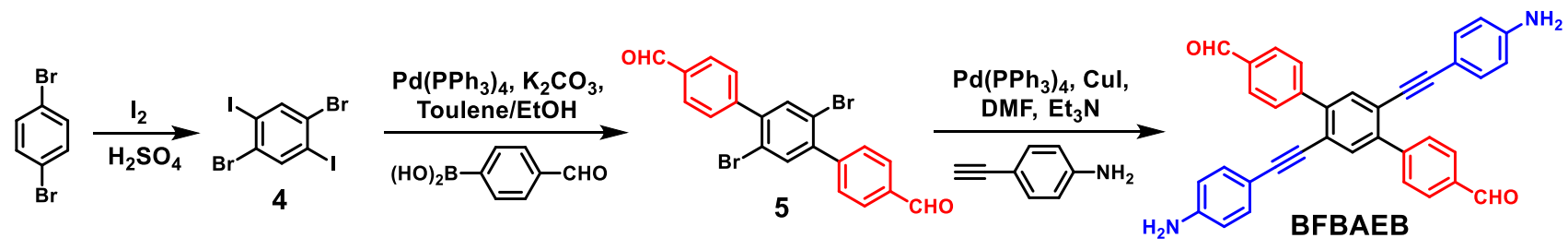

Scheme S3. Synthetic routes of compound BFBAEB.

\section{1,4-dibromo-2,5-diiodobenzene $(4)^{\mathrm{S} 2}$}

A solution of 1,4-dibromobenzene $(20 \mathrm{~g}, 84.8 \mathrm{mmol})$ in $300 \mathrm{~mL}$ of concentrated sulfuric acid was heated to $135{ }^{\circ} \mathrm{C}$. Iodine $(53 \mathrm{~g}, 20 \mathrm{mmol})$ was added portion-wise as the reaction mixture was heated. The reaction mixture was held at $135{ }^{\circ} \mathrm{C}$ for $12 \mathrm{~h}$. After cooling down to room temperature, the reaction mixture was poured into ice $(500 \mathrm{~g})$. The resulting solid precipitate was filtered and washed with a saturated solution of sodium bicarbonate and an aqueous solution of sodium thiosulphate. The solid was recrystallized from tetrahydrofuran and further from chloroform affording 1,4-dibromo-2,5-diiodobenzene as white solid, yield 59\%. ${ }^{1} \mathrm{H} \mathrm{NMR}\left(400 \mathrm{MHz}, \mathrm{CDCl}_{3}\right): \delta$ (ppm) 8.05 (s, 2H). ${ }^{13} \mathrm{C}$ NMR (100 MHz $\left.\mathrm{CDCl}_{3}\right): \delta$ (ppm) 101.37, 129.23, 142.54. MALDI TOF-MS: $\mathrm{m} / \mathrm{z}$ Calc. 487.659 , found 487.256 .

\section{1,4-Dibromo-2,5-bis(4-formylphenyl)benzene}

The mixture of 1,4-dibromo-2,5-diiodobenzene 4 (4.0 g, $8.2 \mathrm{mmol})$, (4-formylphenyl)boronic acid (3.1 g, $20.6 \mathrm{mmol}), \mathrm{Pd}\left(\mathrm{PPh}_{3}\right)_{4}(0.4 \mathrm{~g}, 0.32 \mathrm{mmol})$ and $\mathrm{K}_{2} \mathrm{CO}_{3}(4.0 \mathrm{~g}, 29.5 \mathrm{mmol})$ in a mixed solvent of toluene/ethanol $\left(\mathrm{V} / \mathrm{V}=3 / 1,160 \mathrm{~mL}\right.$, ) containing water $(1.0 \mathrm{~mL})$ was stirred for $36 \mathrm{~h}$ at $96{ }^{\circ} \mathrm{C}$. 
After removing the solvent by evaporation, the residue was diluted with water and extracted with $\mathrm{CH}_{2} \mathrm{Cl}_{2}$. The organic layers was combined and dried over anhydrous $\mathrm{MgSO}_{4}$, filtered and concentrated under reduced pressure. The residue was purified by column chromatography (DCM: $\mathrm{PE}=1: 1)$ to give compound 5 as a white solid $(2.5 \mathrm{~g}$, yield $69 \%) .{ }^{1} \mathrm{H} \mathrm{NMR}\left(400 \mathrm{MHz}, \mathrm{CDCl}_{3}\right): \delta$ (ppm) $10.11(\mathrm{~s}, 2 \mathrm{H}), 7.99(\mathrm{~d}, 4 \mathrm{H}), 7.68(\mathrm{~s}, 2 \mathrm{H}), 7.63(\mathrm{~d}, 4 \mathrm{H}) .{ }^{13} \mathrm{C} \mathrm{NMR}\left(100 \mathrm{MHz} \mathrm{CDCl}_{3}\right): \delta(\mathrm{ppm})$ $191.71,145.07,142.45,135.96,135.15,130.08,129.63,121.18$. MALDI TOF-MS: m/z Calc. 444.122 , found 443.608 .

\section{1,4-bis(4-formylphenyl)-2,5-bis((4-aminophenyl)ethynyl))benzene (BFBAEB)}

Compound 5 (555 mg, $1.25 \mathrm{mmol})$, 4-ethynylaniline (585 mg, $5.0 \mathrm{mmol}), \mathrm{Pd}\left(\mathrm{PPh}_{3}\right)_{4}(100 \mathrm{mg}, 0.083$ mmol) and copper (I) iodide $(24 \mathrm{mg}, 0.126 \mathrm{mmol})$ were added into a $100 \mathrm{~mL}$ round-bottom flask. Then DMF $(35 \mathrm{~mL})$ and $\mathrm{Et}_{3} \mathrm{~N}(15 \mathrm{~mL})$ were added. The mixture was degassed by three freezepump-thaw cycles, purged with $\mathrm{N}_{2}$, and stirred at $120{ }^{\circ} \mathrm{C}$ for $4 \mathrm{~h}$. After cooling to room temperature, the mixture was poured into water and filtered. The residue was washed by water, methanol, ethyl acetate and dried under vacuum to afford a yellow power $(370 \mathrm{mg}, 58 \%) .{ }^{1} \mathrm{H} \mathrm{NMR}(400 \mathrm{MHz}$, DMSO-d $\left.)_{6}\right): \delta(\mathrm{ppm}) 10.11(\mathrm{~s}, 2 \mathrm{H}), 8.06(\mathrm{~d}, 4 \mathrm{H}), 7.97(\mathrm{~d}, 4 \mathrm{H}), 7.70(\mathrm{~s}, 2 \mathrm{H}), 7.03(\mathrm{~d}, 4 \mathrm{H}), 6.51(\mathrm{~d}, 4 \mathrm{H})$, 5.63 (s, 4H). ${ }^{13} \mathrm{C}$ NMR (100 MHz, DMSO-d 6 ): $\delta$ (ppm) 193.36, 150.39, 145.10, 141.01, 135.98, $133.42,132.98,130.36,129.76,121.79,114.08,108.12,97.23,86.31$. MALDI TOF-MS: m/z Calc.516.600, found 516.329.

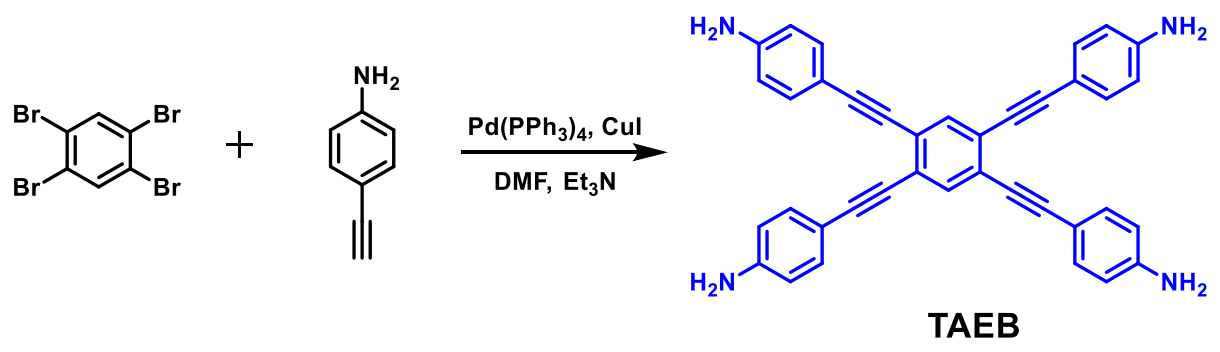

Scheme S4. Synthetic route of compound TAEB.

\section{1,2,4,5-Tetra((4-aminophenyl)ethynyl)benzene (TAEB)}

1,2,4,5-tetrabromobenzene (194 mg, $0.5 \mathrm{mmol})$, 4-ethynylaniline (351 mg, $\left.3.0 \mathrm{mmol}), \mathrm{Pd}_{(\mathrm{PPh}}\right)_{4}(20$ $\mathrm{mg}, 0.021 \mathrm{mmol})$ and copper (I) iodide $(5 \mathrm{mg}, 0.025 \mathrm{mmol})$ were added into a $50 \mathrm{~mL}$ round-bottom flask. Then DMF $(7 \mathrm{~mL})$ and $\mathrm{Et}_{3} \mathrm{~N}(3 \mathrm{~mL})$ were added. The mixture was degassed by three freezepump-thaw cycles, purged with $\mathrm{N}_{2}$, and stirred at $120{ }^{\circ} \mathrm{C}$ overnight. After cooling to room temperature, the mixture was poured into water and filtered. The residue was washed by water and recrystallized by ethyl acetate to afford a brown powder $(180 \mathrm{mg}, 67 \%){ }^{1} \mathrm{H} \mathrm{NMR} \mathrm{(400} \mathrm{MHz}$, DMSO-d $\left.\mathrm{d}_{6}\right): \delta(\mathrm{ppm}) 7.54(\mathrm{~s}, 2 \mathrm{H}), 7.23(\mathrm{~d}, 8 \mathrm{H}), 6.58(\mathrm{~d}, 8 \mathrm{H}), 5.69(\mathrm{~s}, 8 \mathrm{H}) .{ }^{13} \mathrm{C} \mathrm{NMR}(100 \mathrm{MHz}$, DMSO- $\left.\mathrm{d}_{6}\right): \delta$ (ppm) 150.45, 133.19, 124.57, 114.16, 108.30, 97.75 85.83. MALDI TOF-MS: $\mathrm{m} / \mathrm{z}$ Calc.538.216, found 538.309. 


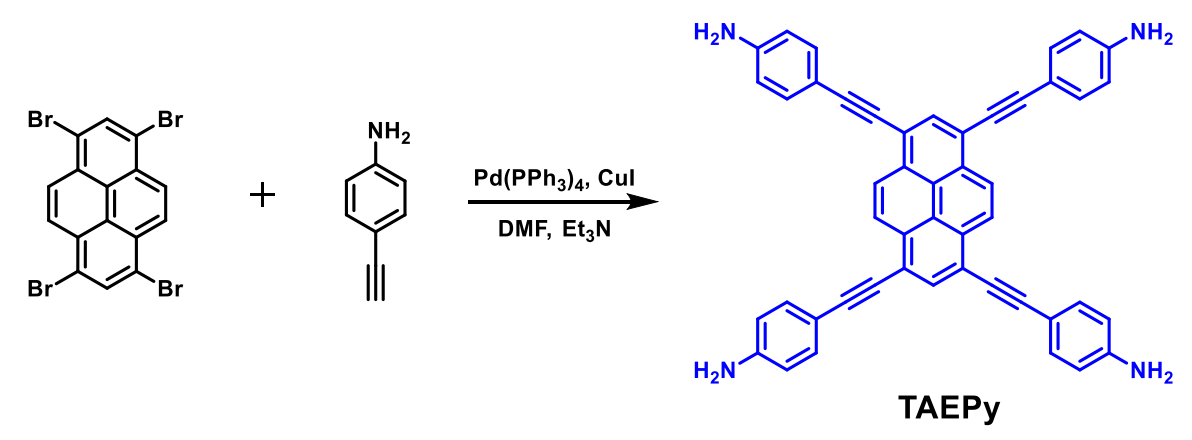

Scheme S5. Synthetic route of compound TAEPy.

\section{1,3,6,8-Tetra((4-aminophenyl)ethynyl)Pyrene (TAEPy)}

1,3,6,8-tetrabromopyrene (259 mg, $0.5 \mathrm{mmol})$, 4-ethynylaniline (351 mg, $\left.3.0 \mathrm{mmol}), \mathrm{Pd}_{(} \mathrm{PPh}_{3}\right)_{4}(20$ $\mathrm{mg}, 0.021 \mathrm{mmol})$ and copper (I) iodide $(5 \mathrm{mg}, 0.025 \mathrm{mmol})$ were added into a $50 \mathrm{~mL}$ round-bottom flask. Then DMF $(7 \mathrm{~mL})$ and $\mathrm{Et}_{3} \mathrm{~N}(3 \mathrm{~mL})$ were added. The mixture was degassed by three freezepump-thaw cycles, purged with $\mathrm{N}_{2}$, and stirred at $120{ }^{\circ} \mathrm{C}$ overnight. After cooling to room temperature, the mixture was poured into water and filtered. The residue was washed by water and recrystallized by dioxane to afford an orange powder $(245 \mathrm{mg}, 74 \%){ }^{1} \mathrm{H} \mathrm{NMR}\left(400 \mathrm{MHz}, \mathrm{DMSO}-\mathrm{d}_{6}\right)$ : $\delta(\mathrm{ppm}) 8.70(\mathrm{~s}, 4 \mathrm{H}), 8.26(\mathrm{~s}, 2 \mathrm{H}), 7.47(\mathrm{~d}, 8 \mathrm{H}), 6.66(\mathrm{~d}, 8 \mathrm{H}), 5.74(\mathrm{~s}, 8 \mathrm{H}),{ }^{13} \mathrm{C} \mathrm{NMR}(100 \mathrm{MHz}$ DMSO-d ${ }_{6}$ ): $\delta$ (ppm) 150.58, 133.54, 132.24, 130.49, 126.78, 124.27, 119.75, 114.21, 108.33, 99.35 85.48. MALDI TOF-MS: m/z Calc.662.247, found 662.235.

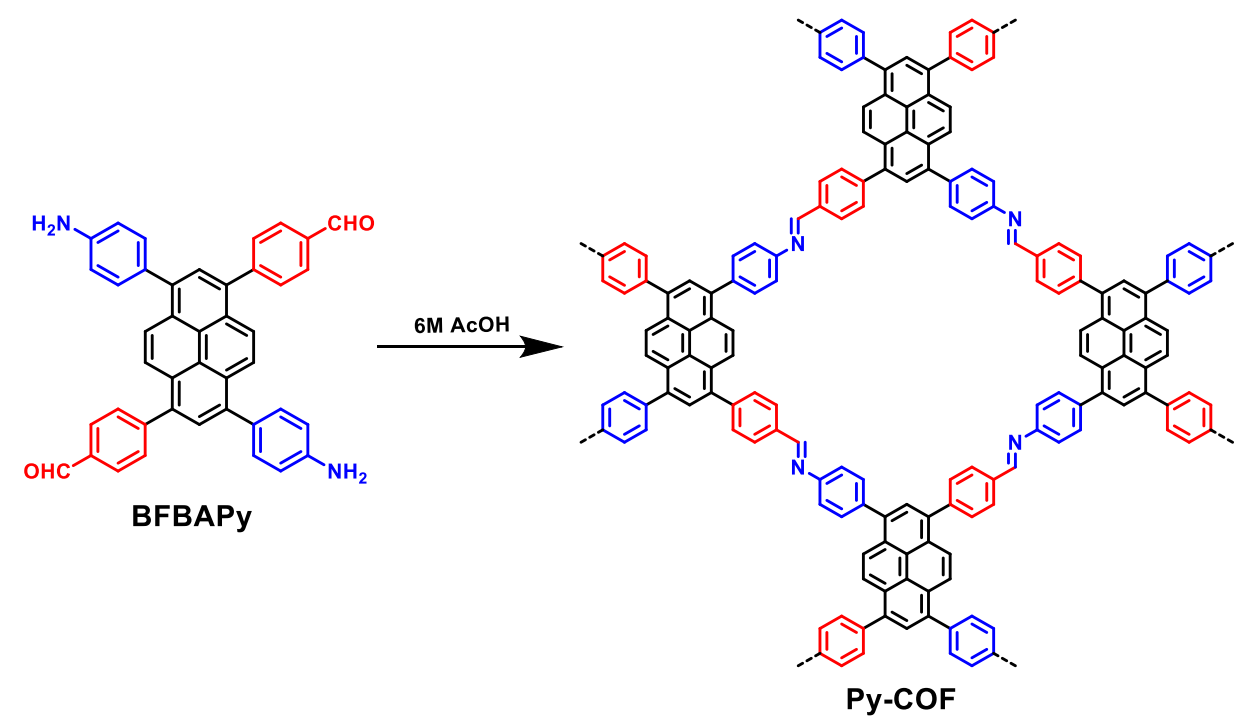

Scheme S6. Schematic illustration of the synthesis of Py-COF by self-condensation of BFBAPy

\section{Synthesis of Py-COF in mixed solvents}

BFBAPy (29.6 mg, $0.05 \mathrm{mmol})$ was added to a $10 \mathrm{~mL}$ Schlenk tube, $\mathrm{n}-\mathrm{BuOH}(1.0 \mathrm{~mL})$ and o-DCB $(1.0 \mathrm{~mL})$ were added. The mixture was sonicated for 2 minutes followed by addition of $6 \mathrm{M}$ acetic acid $(0.2 \mathrm{~mL})$. The mixture was further sonicated for another 2 minutes and degassed by three freeze-pump-thaw cycles, purged with $\mathrm{Ar}$ and heated at $120{ }^{\circ} \mathrm{C}$ for 3 days. Upon cooling to r.t., the precipitate was collected by filtration and washed by DMAc, THF and methanol, dried under vacuum to afford an orange powder $(24 \mathrm{mg}, 83 \%)$. Elemental analysis (wt.\%) calcd. For 
$\left\{\mathrm{C}_{42} \mathrm{H}_{24} \mathrm{~N}_{2}\right\}_{n}$ : C 90.62, H 4.35, N 5.03; found: C 86.33, H 5.01, N 4.22.

\section{Synthesis of Py-COF in simplex solvent}

The general method to synthesis of Py-COF in simplex solvent was almost the same as that in mixed solvents except the amount of solvents (DMAc, DCM, THF, EtOH, $\mathrm{MeCN}, \mathrm{CHCl}_{3}$ and $\mathrm{MeOH}$ ) and acetic acid were $2 \mathrm{~mL}$ and $0.2 \mathrm{~mL}$ respectively.

\section{Synthesis of Py-COF Films:}

BFBAPy (9.9 mg, $0.0167 \mathrm{mmol}$ ) was added to a Schlenk tube, and suspended in $2 \mathrm{~mL}$ dichloromethane. A glass slide holder (containing ITO glass or not) or $\mathrm{SiO}_{2} / \mathrm{Si}$ slides in the horizontal position with the ITO or $\mathrm{SiO}_{2}$ side downwards, was transferred into the tube. Acetic acid (6 M, 200 $\mu \mathrm{L}$ ) was added, the mixture was kept refluxing for $24 \mathrm{~h}$. The as-synthesized COF films were rinsed with DMAc and THF to remove residues of the reaction mixture. COF bulk material precipitated beneath the film substrate holder was collected by filtration and washed by DMAc, THF and methanol.

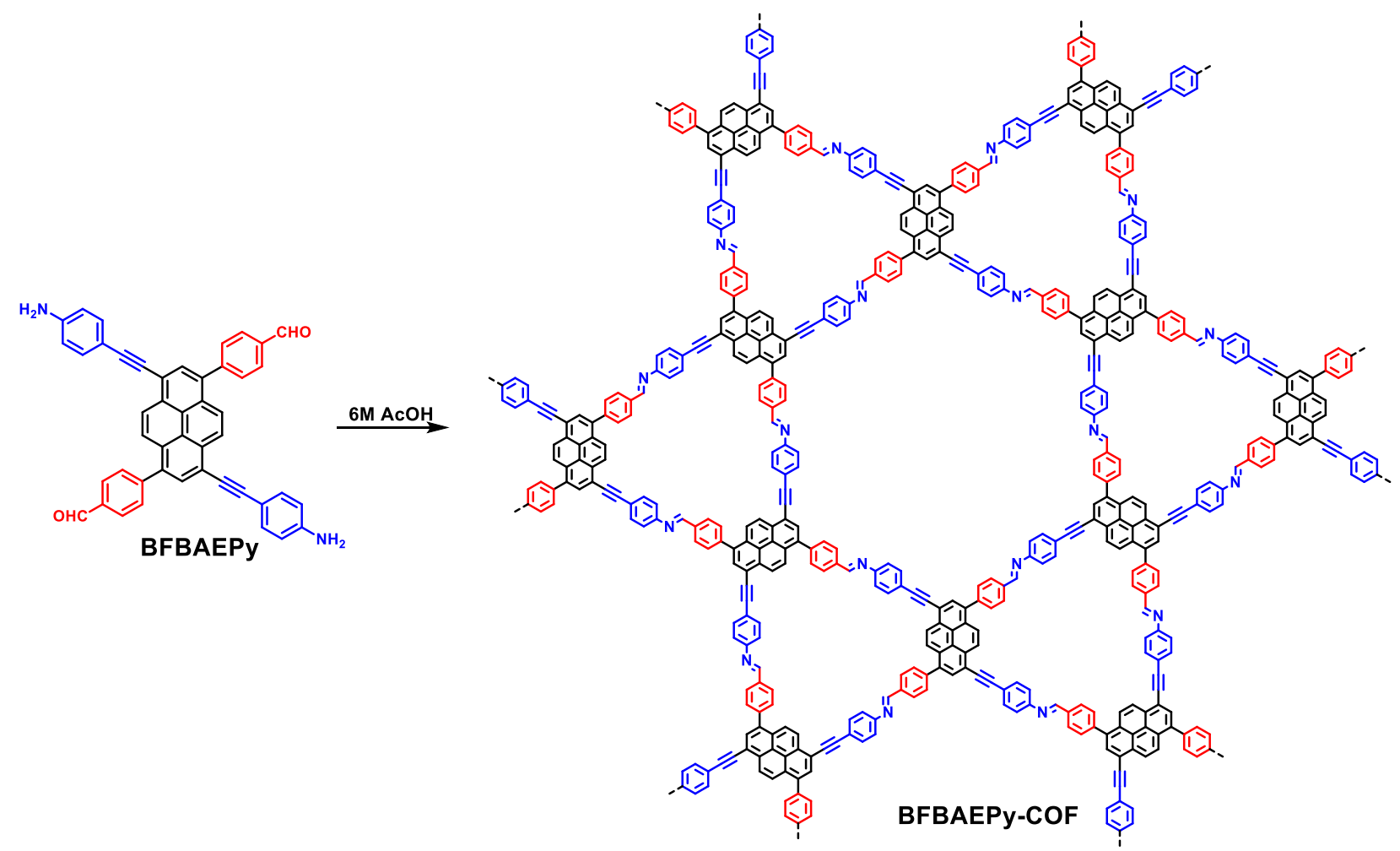

Scheme S7. Schematic representation of the synthesis of BFBAEPy-COF.

\section{Synthesis of BFBAEPy-COF}

BFBAEPy (32.0 mg, $0.05 \mathrm{mmol})$ was added to a $10 \mathrm{~mL}$ Schlenk tube, $\mathrm{n}-\mathrm{BuOH}(1.0 \mathrm{~mL})$, or THF $(1.0 \mathrm{~mL})$ or dioxane $(1.0 \mathrm{~mL})$ were added separately for three individual experiments. The mixture was sonicated for 2 minutes followed by addition of $6 \mathrm{M}$ acetic acid $(0.1 \mathrm{~mL})$. The mixture was further sonicated for another 2 minutes and degassed by three freeze-pump-thaw cycles, purged with $\mathrm{Ar}$ and heated to reflux for 3 days. Upon cooling to room temperature, the precipitate was collected by filtration and washed by DMAc, THF and methanol, dried under vacuum to afford a red-brown powder (26 mg, 86\%). 


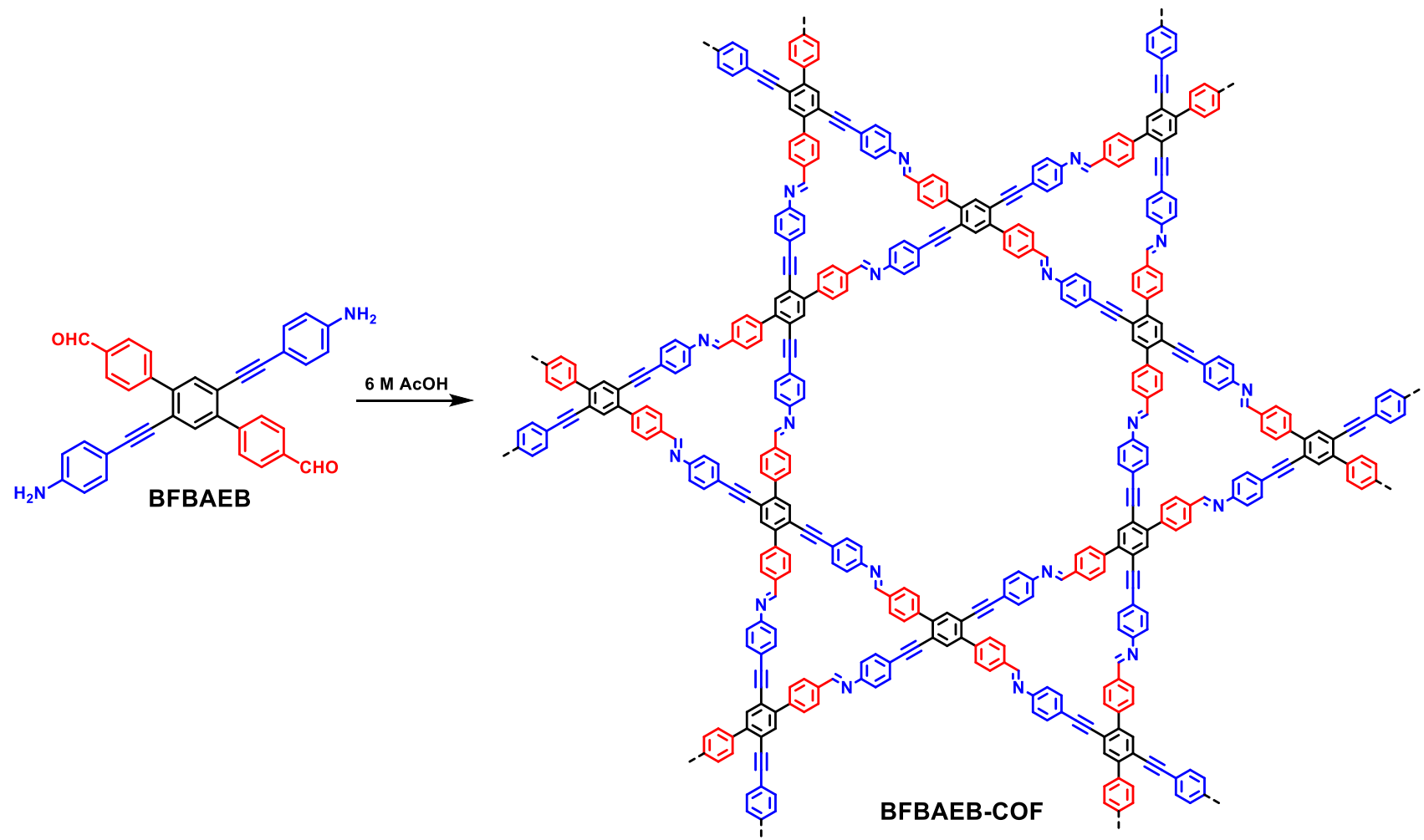

Scheme S8. Schematic representation of the synthesis of BFBAEB-COF.

\section{Synthesis of BFBAEB-COF}

BFBAEB (25.8 mg, $0.05 \mathrm{mmol})$ was added to a $10 \mathrm{~mL}$ Schlenk tube, $\mathrm{n}-\mathrm{BuOH}(1.0 \mathrm{~mL})$, or THF (1.0 $\mathrm{mL})$ or dioxane $(1.0 \mathrm{~mL})$ were added separately for three individual experiments. The mixture was sonicated for 2 minutes followed by addition of $6 \mathrm{M}$ acetic acid $(0.1 \mathrm{~mL})$. The mixture was further sonicated for another 2 minutes and degassed by three freeze-pump-thaw cycles, purged with Ar and heated to refulx for 3 days. Upon cooling to r.t., the precipitate was collected by filtration and washed by DMAc, THF and methanol, dried under vacuum to afford a brown powder (21 mg, 87\%). 


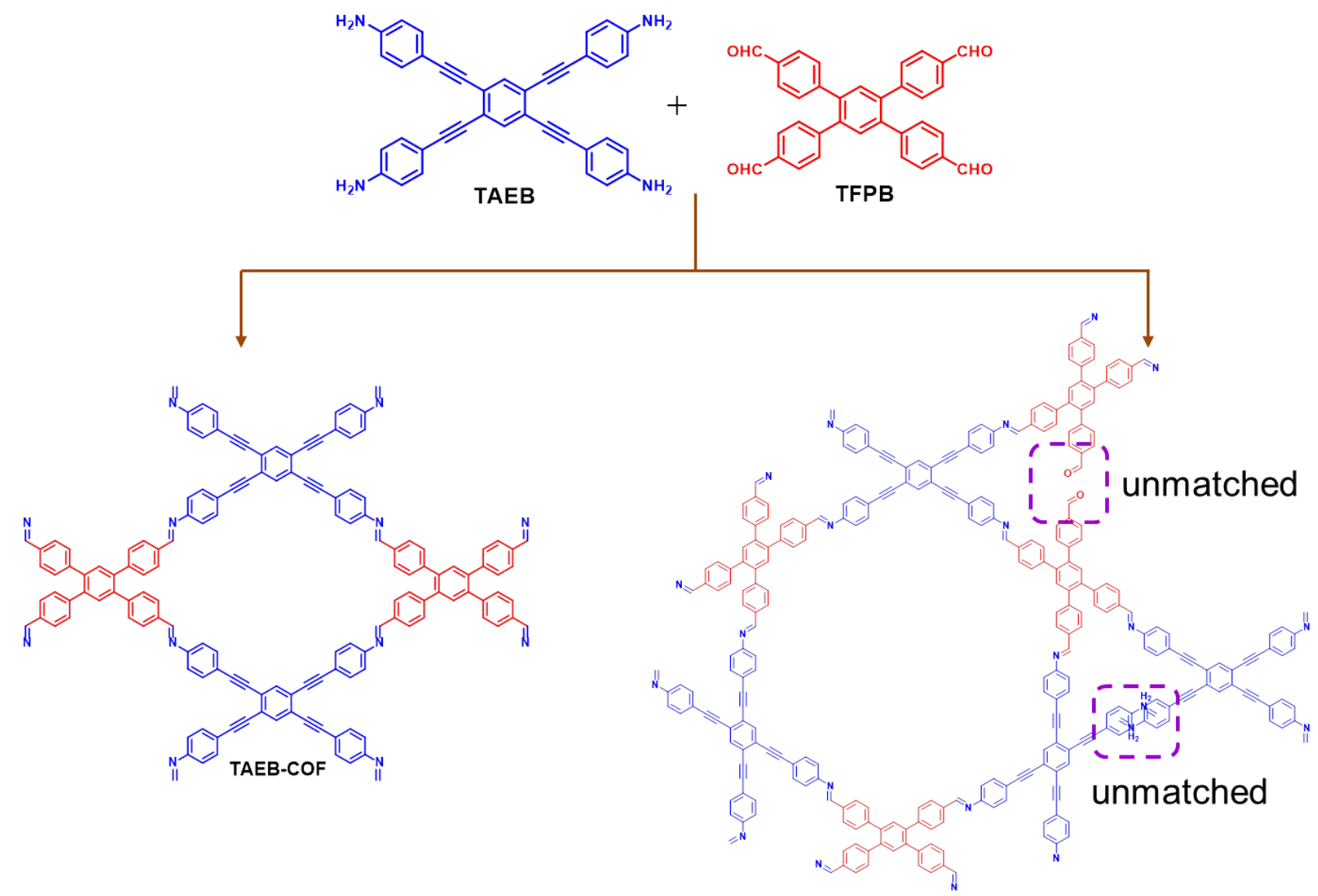

Scheme S9. Schematic representation of the synthesis of TAEB-COF. Theoretically, TAEB and TFPB cannot form the 2D Kagome structure.

\section{Synthesis of TAEB-COF}

TAEB-COF was synthesized by the co-condensation of TAEB and TFPB. ${ }^{\text {S3 }}$ TAEPy $(13.5 \mathrm{mg}, 0.025$ mmol) and TFPB $(12.4 \mathrm{mg} 0.01 \mathrm{mmol})$ were added to a $10 \mathrm{~mL}$ Schlenk tube, then mesitylene $(0.5$ $\mathrm{mL})$ and dioxane $(0.5 \mathrm{~mL})$ were added. The mixture was sonicated for 2 minutes followed by addition of $6 \mathrm{M}$ acetic acid $(0.1 \mathrm{~mL})$. The mixture was further sonicated for another 2 minutes and degassed by three freeze-pump-thaw cycles, purged with Ar and heated at $120{ }^{\circ} \mathrm{C}$ for 3 days. Upon cooling to room temperature, the precipitate was collected by filtration and washed by DMAc, THF and methanol, dried under vacuum to afford a dark brown powder (10.2 $\mathrm{mg}, 81 \%)$. Unfortunately, crystalline TAEB-COF could not be obtained in many solvent systems. All the obtained powders are amorphous (Figure S35) which indicates the difficulty in co-condensation synthesis of TAEB-COF. 


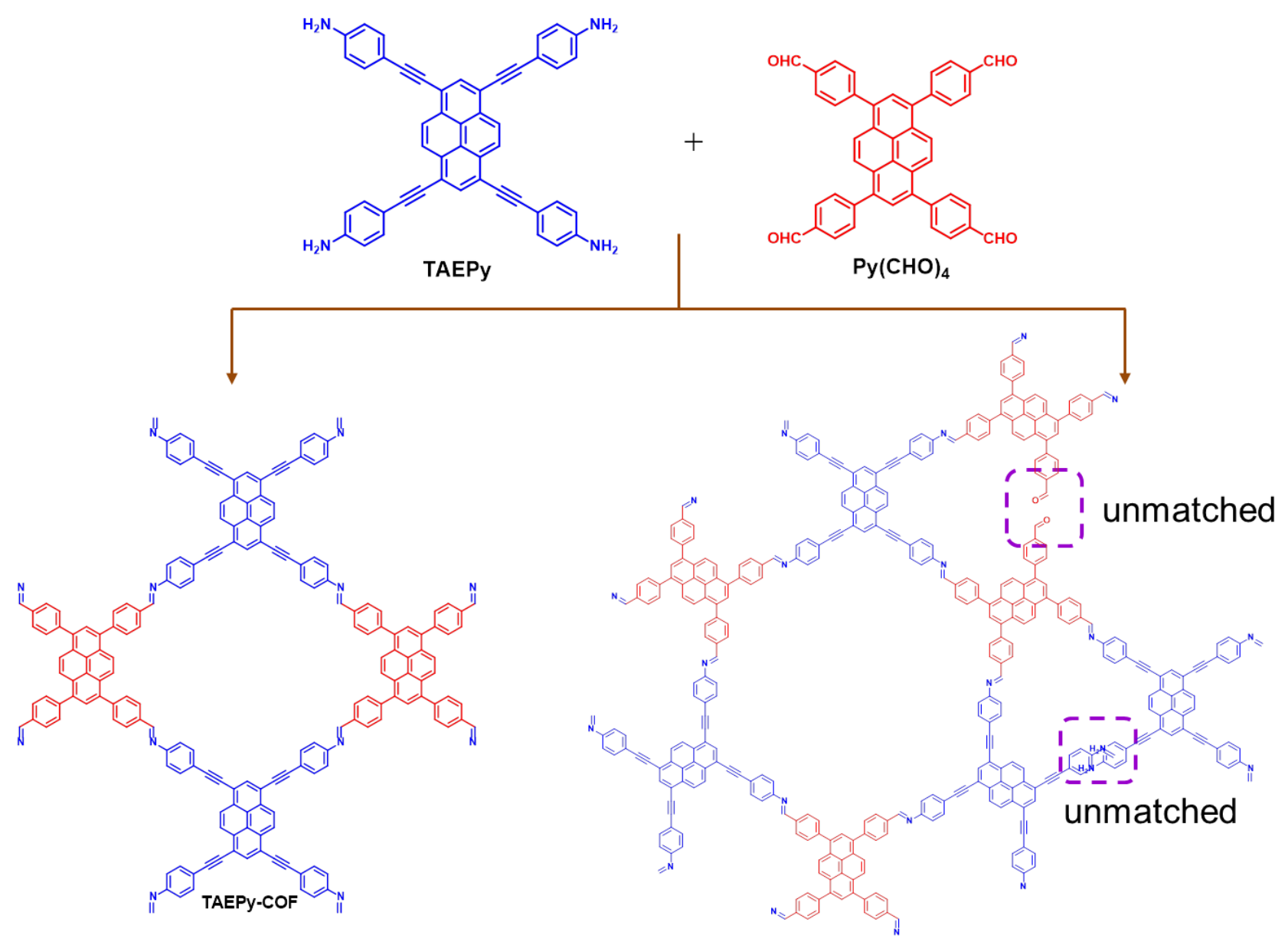

Scheme S10. Schematic representation of the synthesis of TAEPy-COF. Theoretically, TAEPy and $\mathrm{Py}(\mathrm{CHO})_{4}$ cannot form the 2D Kagome structure.

\section{Synthesis of TAEPy-COF}

TAEPy-COF was synthesized by the co-condensation of TAEPy and Py(CHO $)_{4}{ }^{\text {S4 }}$ TAEPy $(6.6 \mathrm{mg}$, $0.01 \mathrm{mmol})$ and $\mathrm{Py}(\mathrm{CHO})_{4}(6.2 \mathrm{mg} 0.01 \mathrm{mmol})$ were added to a $10 \mathrm{~mL}$ Schlenk tube, then mesitylene $(0.5 \mathrm{~mL})$ and benzyl alcohol $(0.5 \mathrm{~mL})$ were added. The mixture was sonicated for 2 minutes followed by addition of $6 \mathrm{M}$ acetic acid $(0.1 \mathrm{~mL})$. The mixture was further sonicated for another 2 minutes and degassed by three freeze-pump-thaw cycles, purged with Ar and heated at $120{ }^{\circ} \mathrm{C}$ for 3 days. Upon cooling to room temperature, the precipitate was collected by filtration and washed by DMAc, THF and methanol, dried under vacuum to afford a red powder $(10.2 \mathrm{mg}, 81 \%)$. 
Section 3. Porosity, FT-IR Spectra and Solid State ${ }^{13}$ C CP/MAS NMR Spectrum of Py-COFs

Table S1. Porosity and yields of Py-COFs synthesized from different solvents

\begin{tabular}{|c|c|c|c|c|}
\hline Solvents & Notation of Py-COF & $\begin{array}{l}\text { BET surface areas } \\
\left(\left(\mathrm{m}^{2} / \mathrm{g}\right)\right.\end{array}$ & PSDa $^{a}(\mathbf{n m})$ & Yield $(\%)$ \\
\hline Dichloromethane (DCM) & Py-COFDCM & 1370 & 1.45 & 89.1 \\
\hline Dimethylacetamide (DMAc & Py-COF & 1320 & 1.45 & 88.7 \\
\hline Chloroform (CHCl3) & $\mathrm{Py}-\mathrm{COF}_{\mathrm{CHCls}}$ & 1070 & 1.23 & 86.9 \\
\hline Methanol (MeOH) & Py-COF & 1240 & 1.36 & 84.6 \\
\hline Ethanol (EtOH) & $\mathrm{Py}-\mathrm{COF}_{\mathrm{EtOH}}$ & 1200 & 1.24 & 82.6 \\
\hline Tetrahydrofuran (THF) & Py-COF & 1360 & 1.20 & 87.7 \\
\hline Acetonitrile (MeCN) & Py-COF MeCN & 1020 & 1.35 & 80.1 \\
\hline $\begin{array}{l}\text { 1,2-dichlorobenzene (o-DC } \\
\text { /Butyl alcohol (n-BuOH) }\end{array}$ & Py-COF & 1320 & 1.41 & 79.0 \\
\hline
\end{tabular}
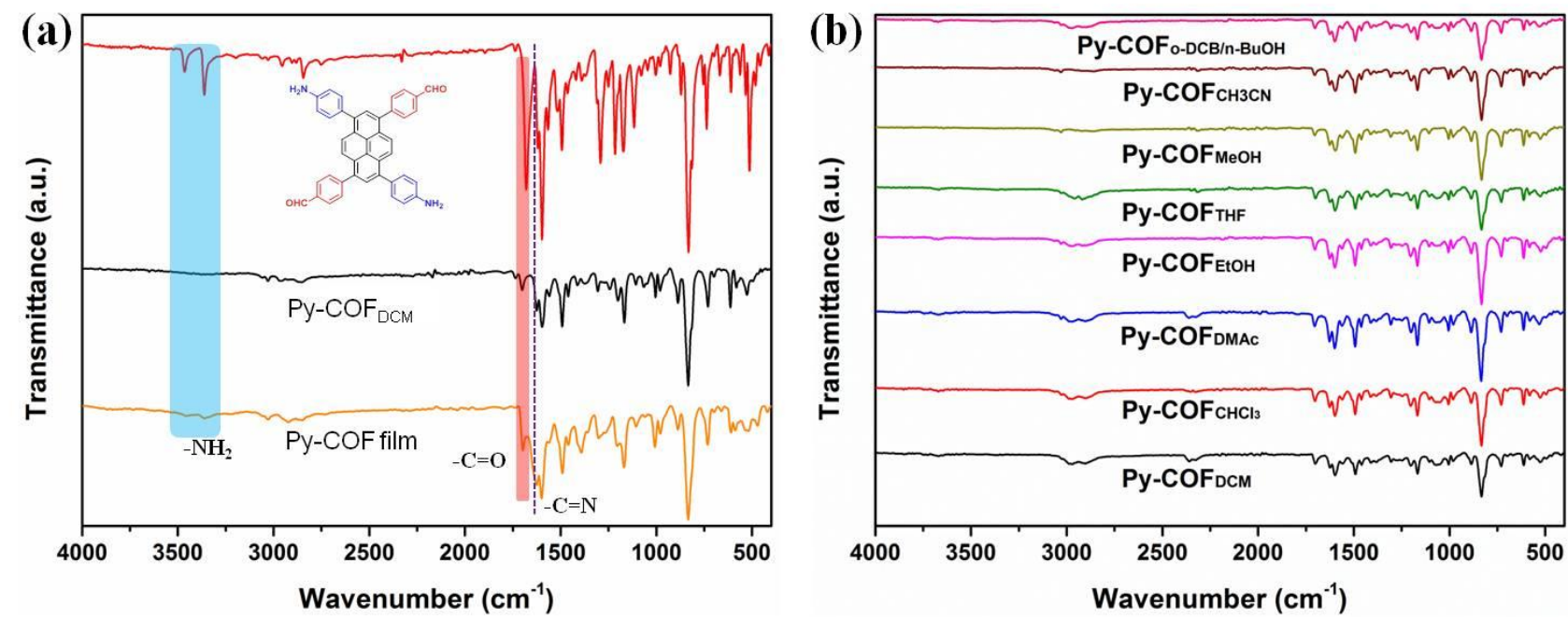

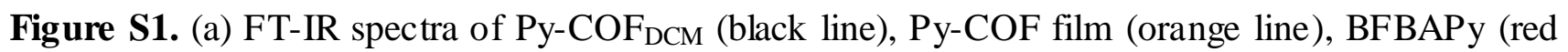
line). The appearance of a new band at $1626 \mathrm{~cm}^{-1}$ in Py-COF confirmed the formation of imine linked $\mathrm{C}=\mathrm{N}$. (b) FT-IR spectra of Py-COF synthesized in different solvents, they are are nearly identical. 


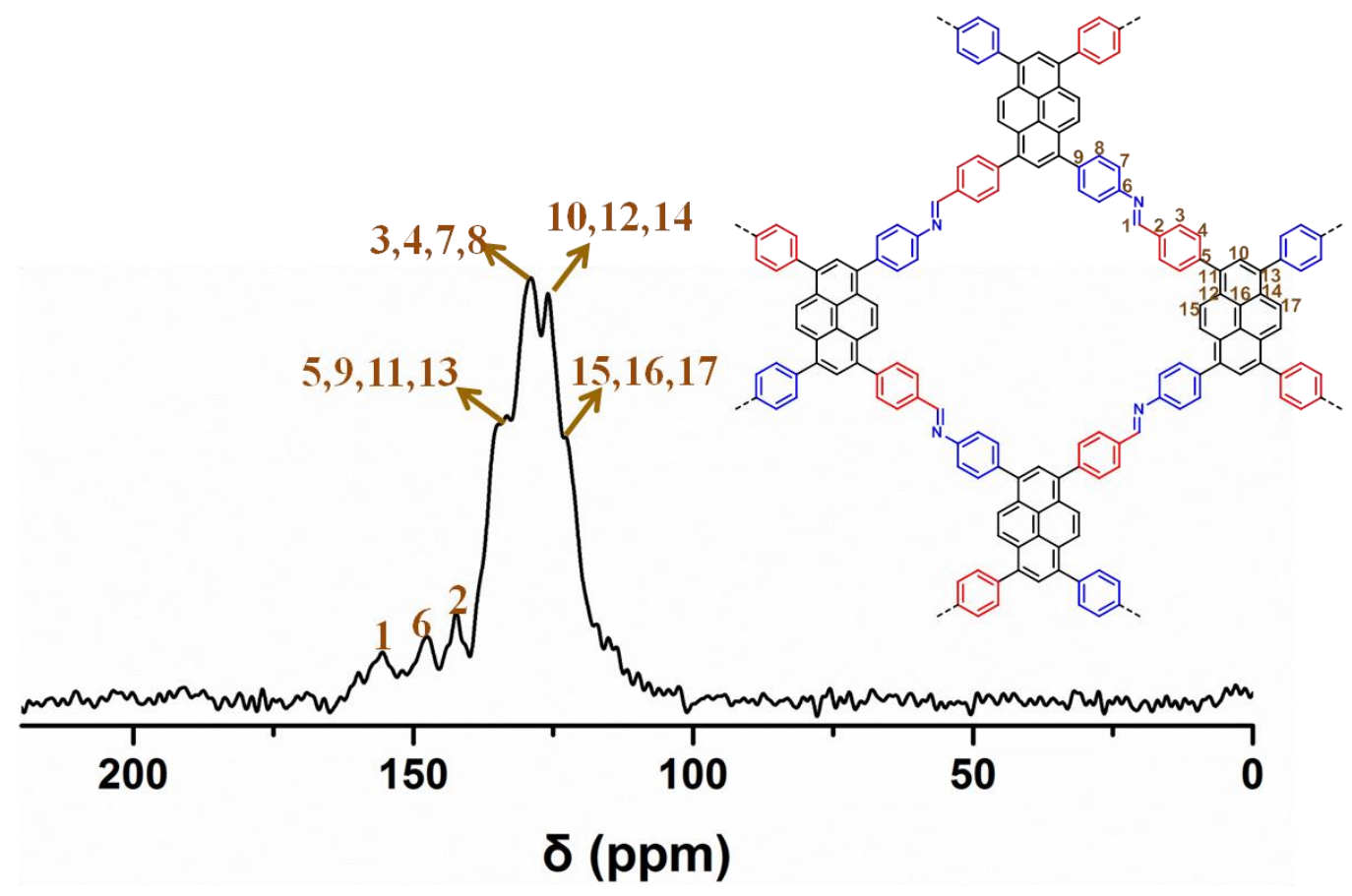

Figure S2. Solid state ${ }^{13} \mathrm{C}$ CP/MAS NMR spectrum of Py-COF powder.

Section 4. Thermogravimetric Analysis

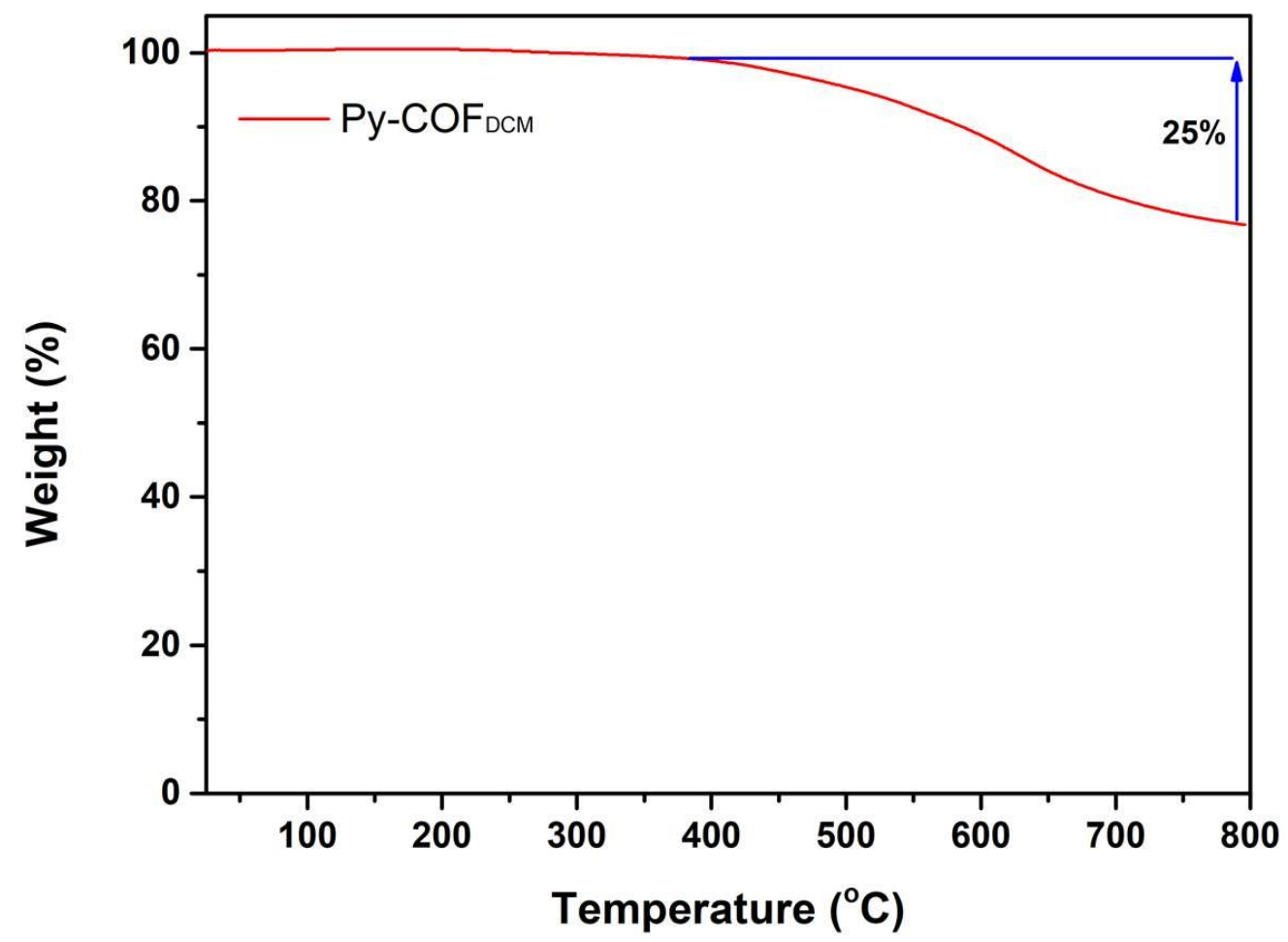

Figure S3. Thermogravimetric analysis curve for $\mathrm{Py}-\mathrm{COF}_{\mathrm{DCM}}$ powder. 


\section{Section 5. PXRD Profiles for Py-COF Synthesized in Different Solvents}

(a)

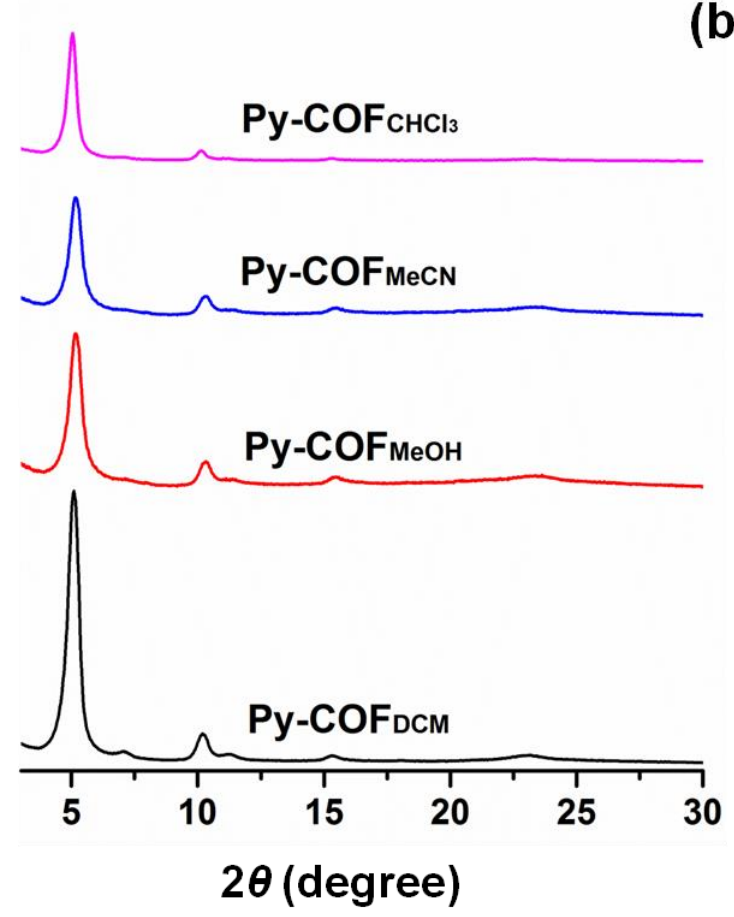

(b)

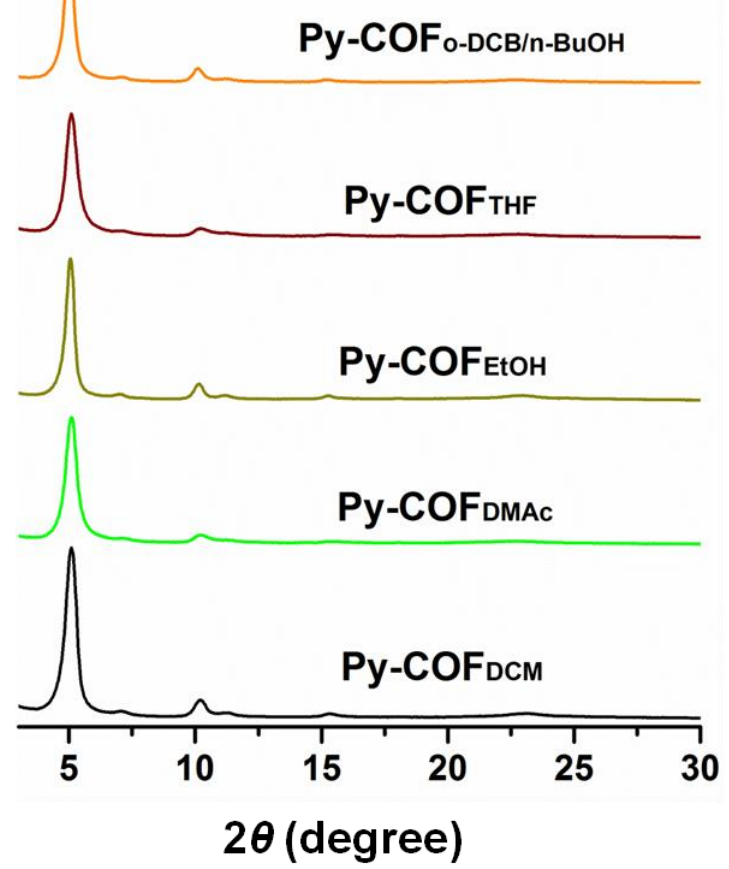

Figure S4. Powder X-ray diffraction patterns of Py-COF powders synthesized in different solvents (black for DCM, red for $\mathrm{MeOH}$, blue for $\mathrm{MeCN}$, magenta for $\mathrm{CHCl}_{3}$, green for DMAc, dark yellow for $\mathrm{EtOH}$, wine for $\mathrm{THF}$ and orange for $o-\mathrm{DCB} / n-\mathrm{BuOH}$ mixed solvents). 


\section{Section 6. BET and PSD of Py-COF $\mathrm{CHCl}_{3}$ and $\mathrm{Py}-\mathrm{COF}$ MeСN}

(a)

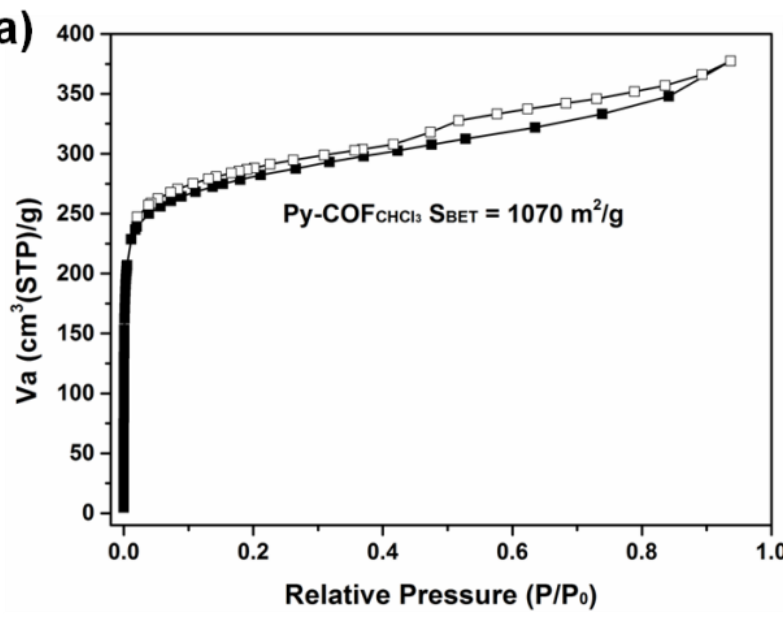

(c)

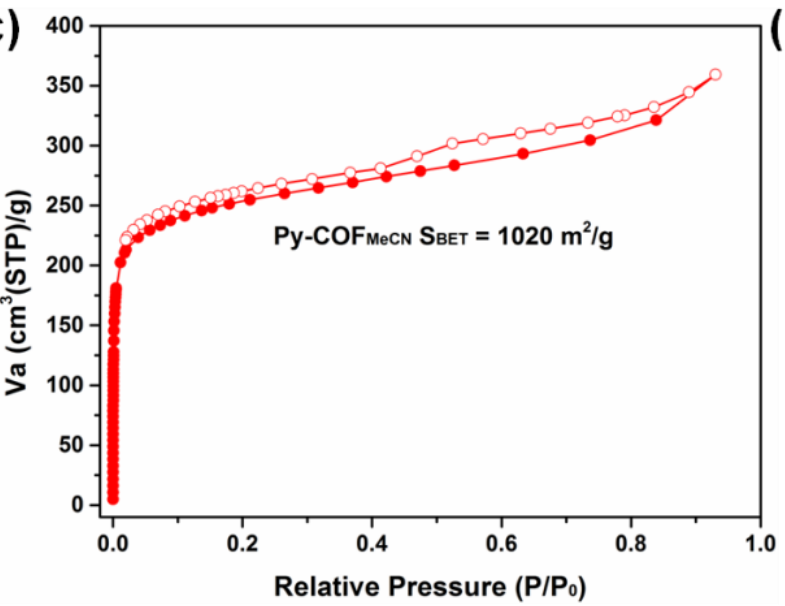

(b)

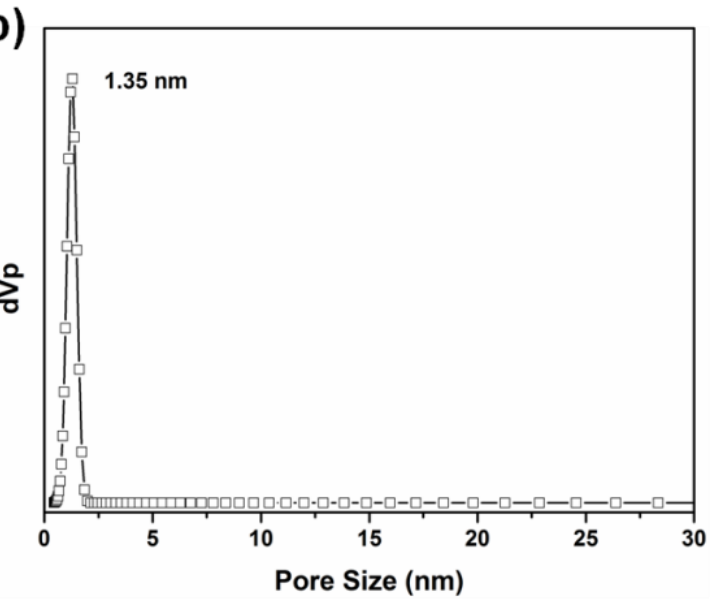

(d)

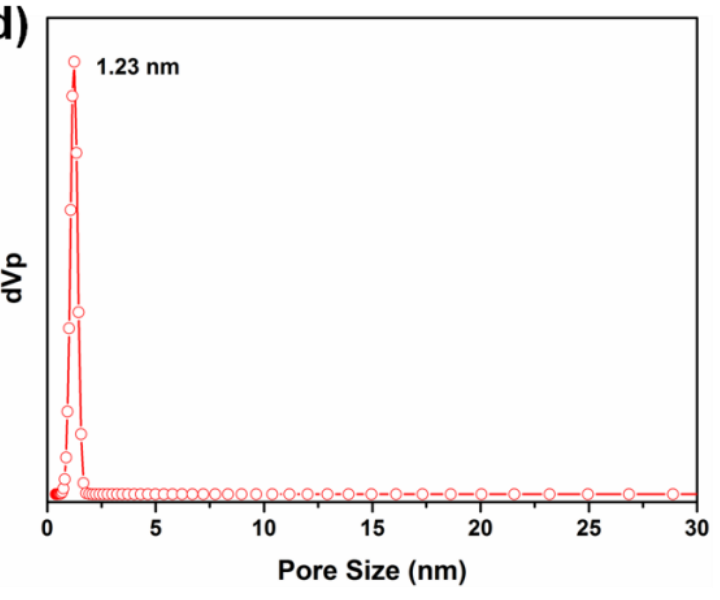

Figure S5. Nitrogen adsorption (solid) and desorption (open) isotherms at $77 \mathrm{~K}$ for (a) $\mathrm{Py}-\mathrm{COF}_{\mathrm{CHCl}}$ and (c) Py-COFMeCN; pore size distribution for (b) $\mathrm{Py}-\mathrm{COF}_{\mathrm{CHCl}}$ and (d) $\mathrm{Py}-\mathrm{COF}$ MeCN. 


\section{Section 7.SEM and TEM Images of Py-COFs}

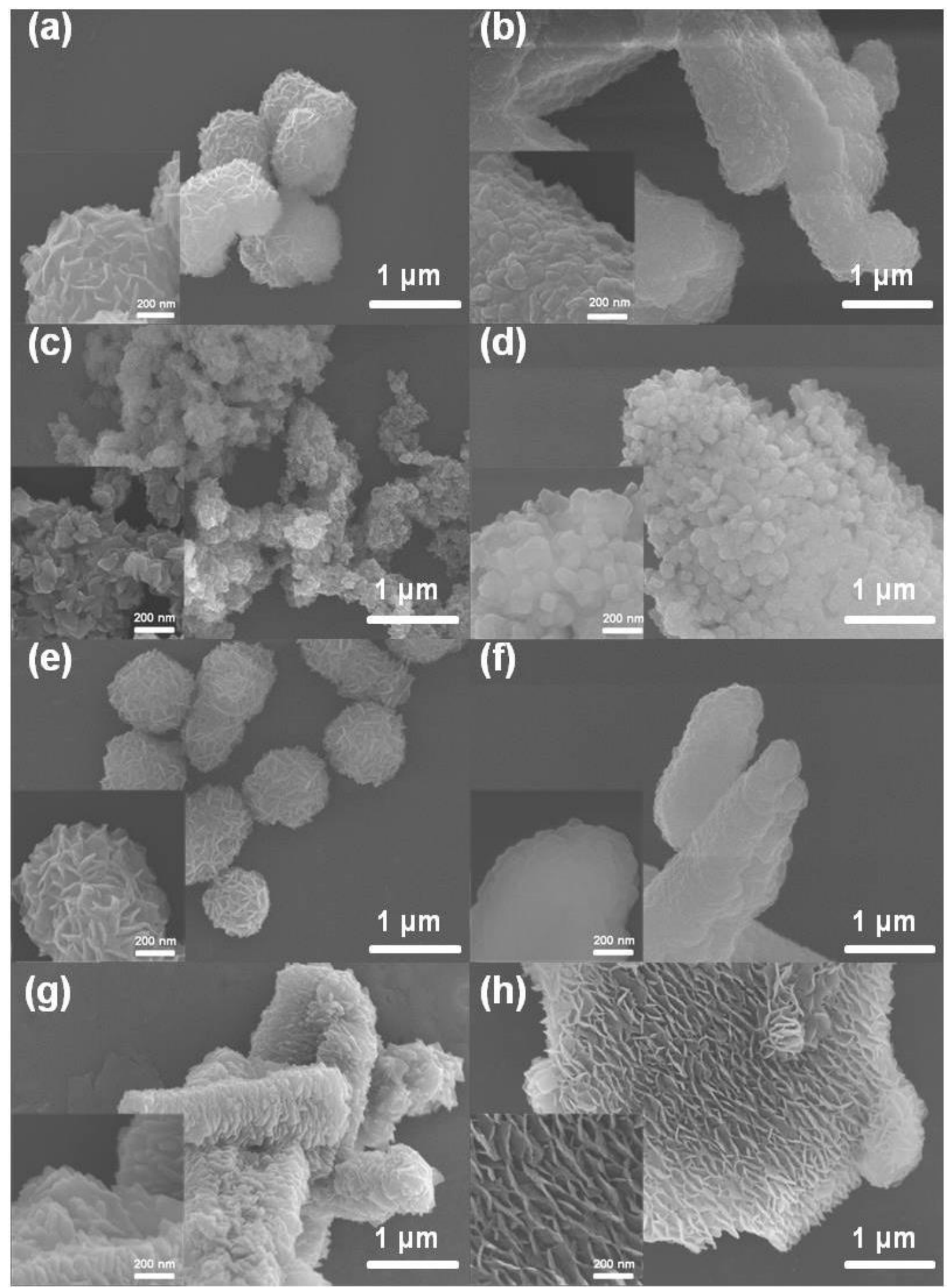

Figure S6. SEM images of $\mathrm{Py}-\mathrm{COF}$ powders synthesized in different solvents, (a) $\mathrm{Py}-\mathrm{COF}_{\mathrm{CHCl}}$, (b) Py-COFdcm, (c) Py-COFdmac, (d) Py-COFetoh, (e) Py-COFmecn, (f) Py-COFmeOh, (g) Py-COFth and

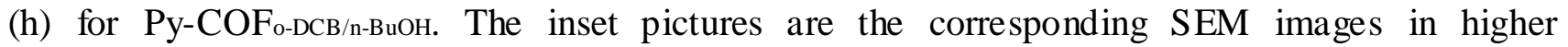
magnification. 


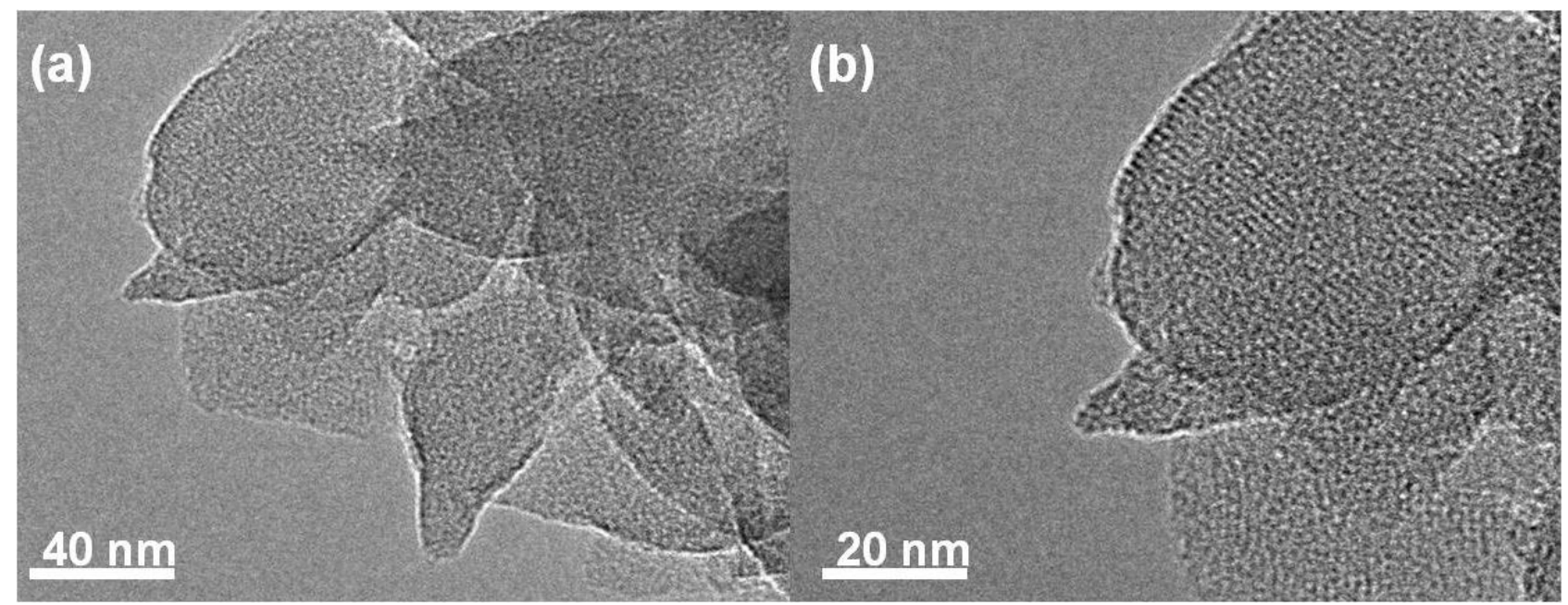

Figure S7. TEM images of Py-COF $\mathrm{DMAc}_{\text {. }}$

Section 8. UV-visible Spectral Profiles.

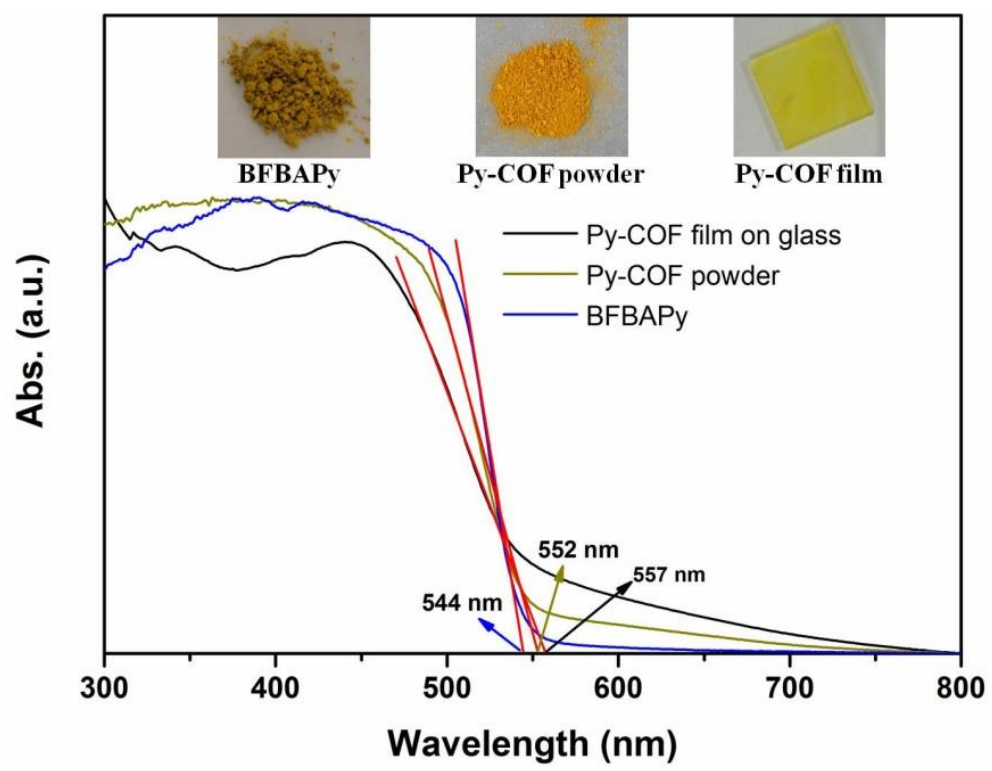

Figure S8. UV-visible spectra of BFBAPy (blue line), Py-COF powder (dark yellow line) and Py-COF film grown on glass (black line). 


\section{Section 9. Chemical Stability Tests}

(a)

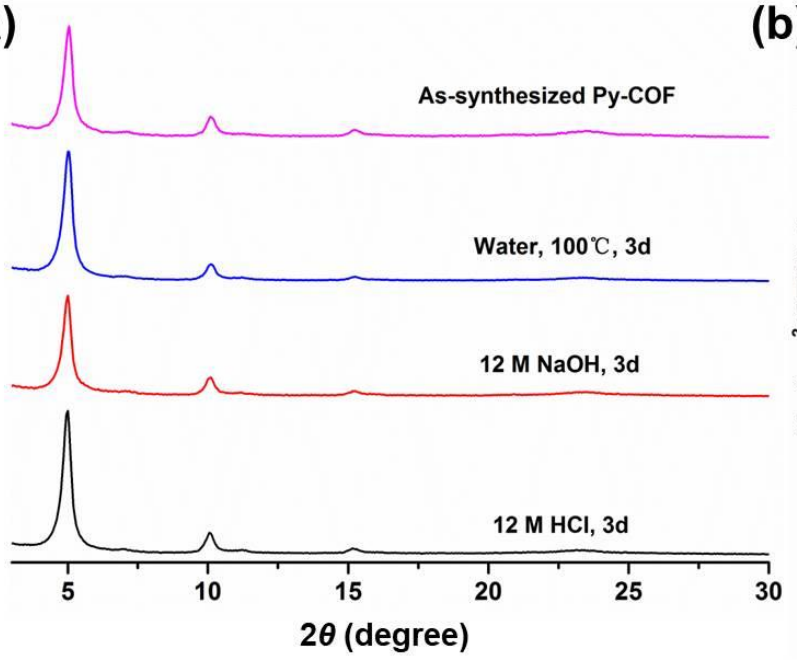

(b)

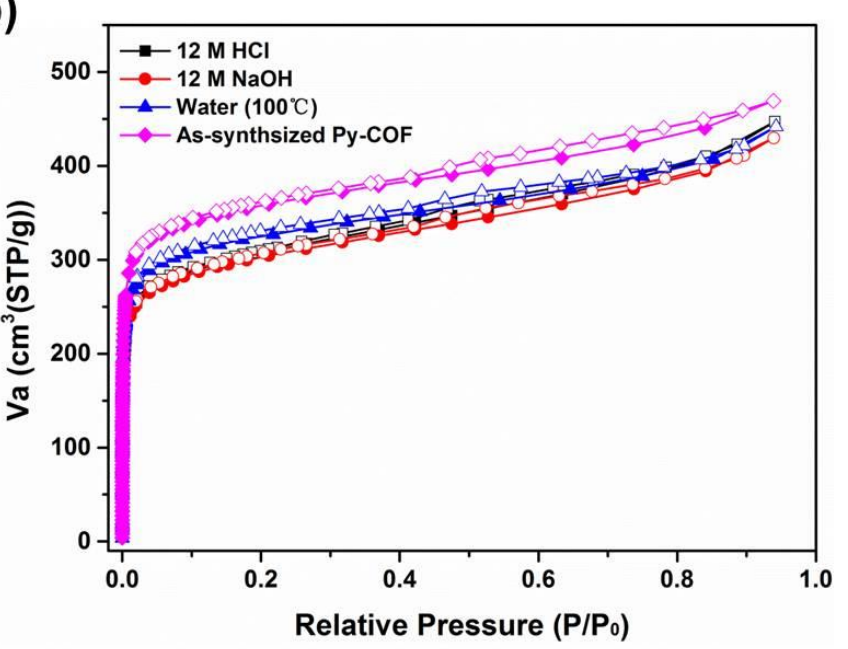

Figure S9. (a) PXRD patterns and (b) nitrogen adsorption (solid) and desorption (open) isotherms of $\mathrm{Py}-\mathrm{COF}_{\mathrm{DCM}}$ after acidic (black), alkaline (red) and boiling water (blue) treatments. The BET surface areas were 1280,1240 and $1310 \mathrm{~m}^{2} / \mathrm{g}$, which exhibited little changes comparing to $\mathrm{Py}-\mathrm{COF}_{\mathrm{DCM}}$ $\left(1370 \mathrm{~m}^{2} / \mathrm{g}\right)$.

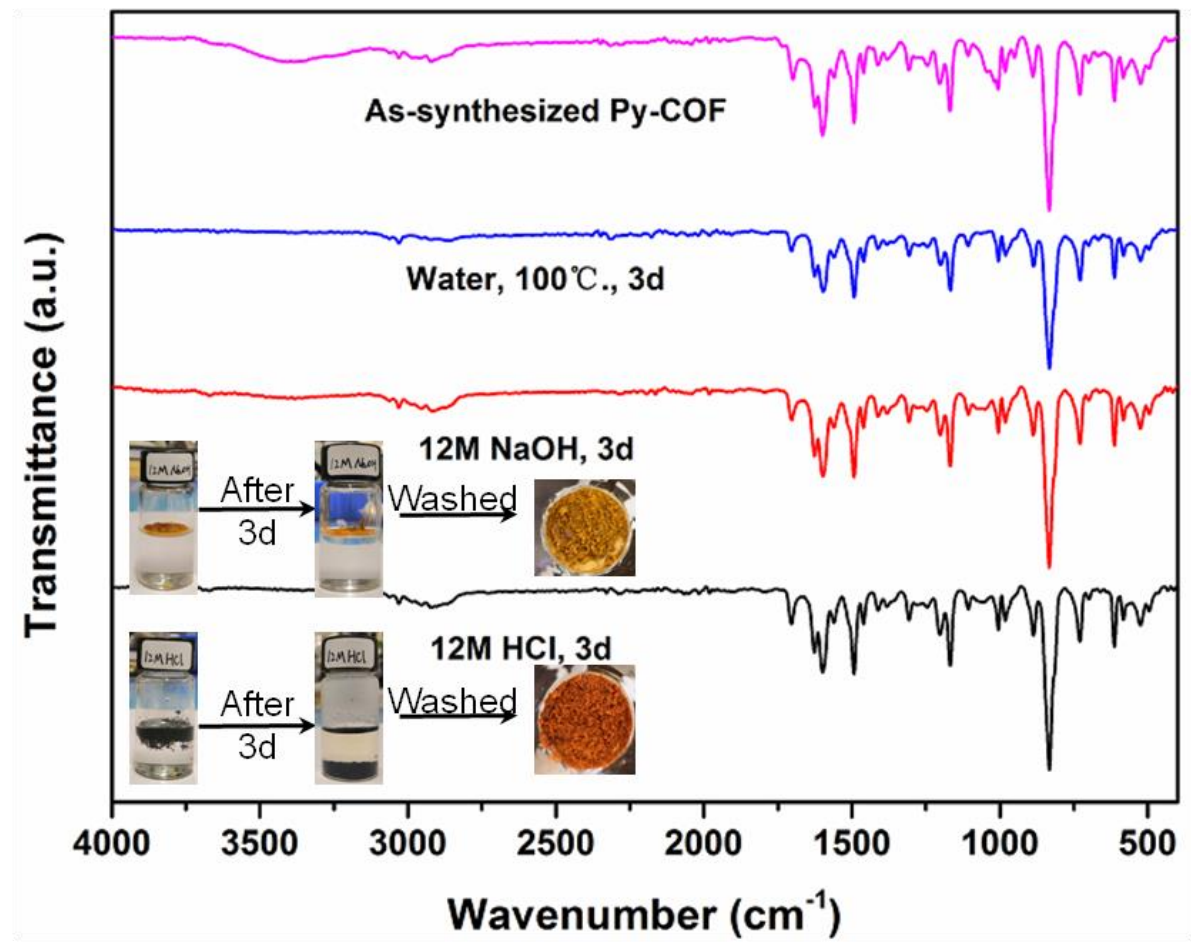

Figure S10. FT-IR spectra comparison of $\mathrm{Py}-\mathrm{COF}_{\mathrm{DCM}}$ before (pink) and after boiling water (blue), alkaline (red) and acidic (black) treatments. 
Section 10. The Influence of Reaction Conditions on Crystallinity and Porosity of Py-COFs

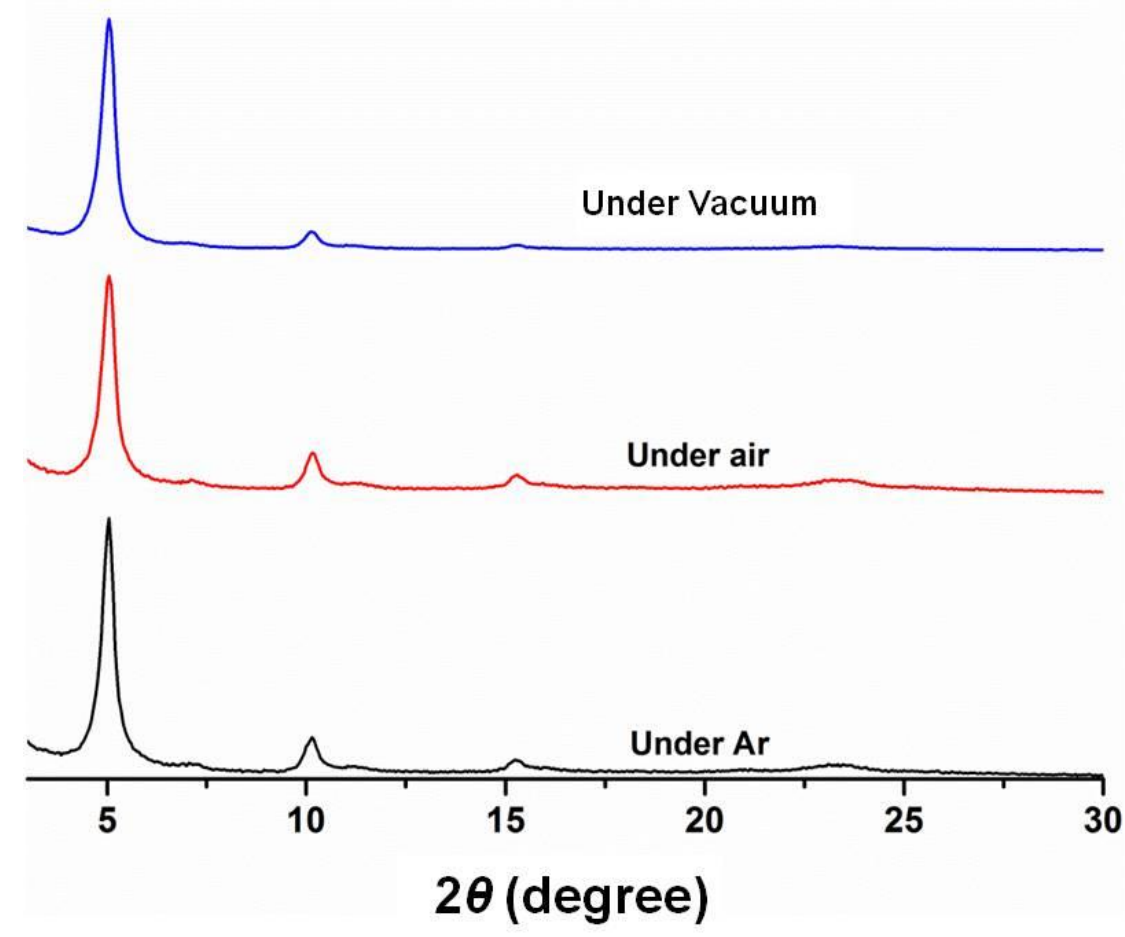

Figure S11. PXRD patterns of Py-COFDCm synthesized under Ar (black line), air (red line) and vacuum (blue line).

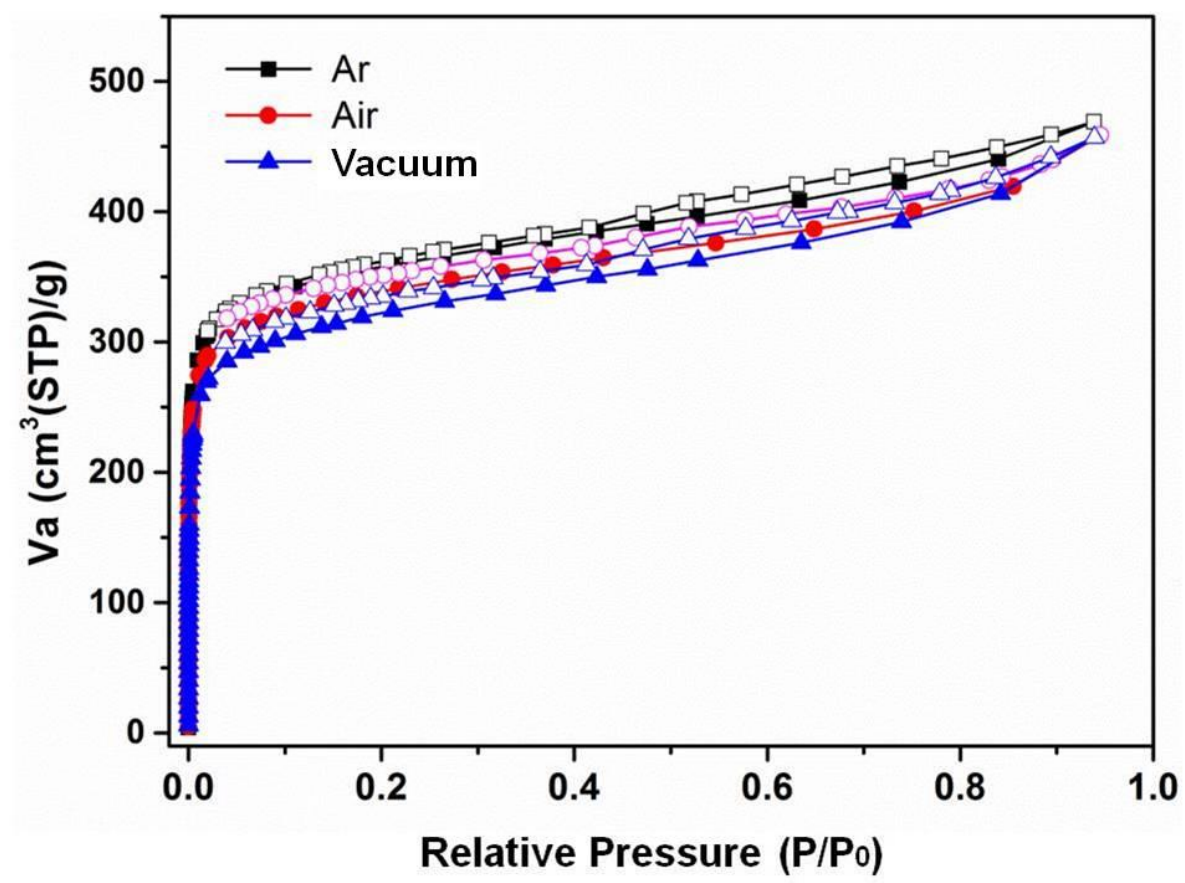

Figure S12. Nitrogen adsorption (solid) and desorption (open) isotherms of Py-COF $\mathrm{DCM}_{\text {synthesized }}$ under Ar, air and vacuum, the BET surface areas are 1370, 1295 and $1221 \mathrm{~m}^{2} / \mathrm{g}$, respectively. 


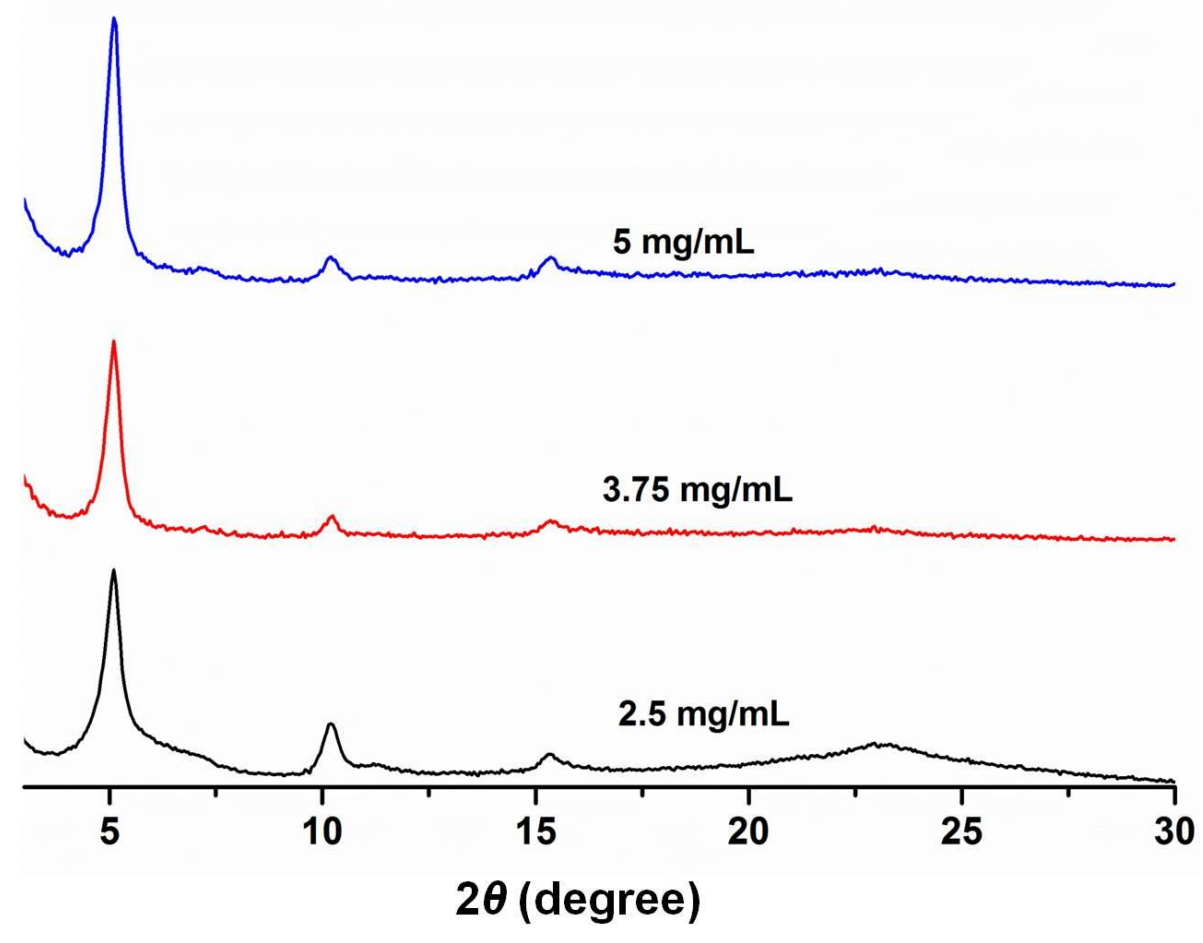

Figure S13. PXRD patterns of Рy-COFDCM synthesized at different concentrations.

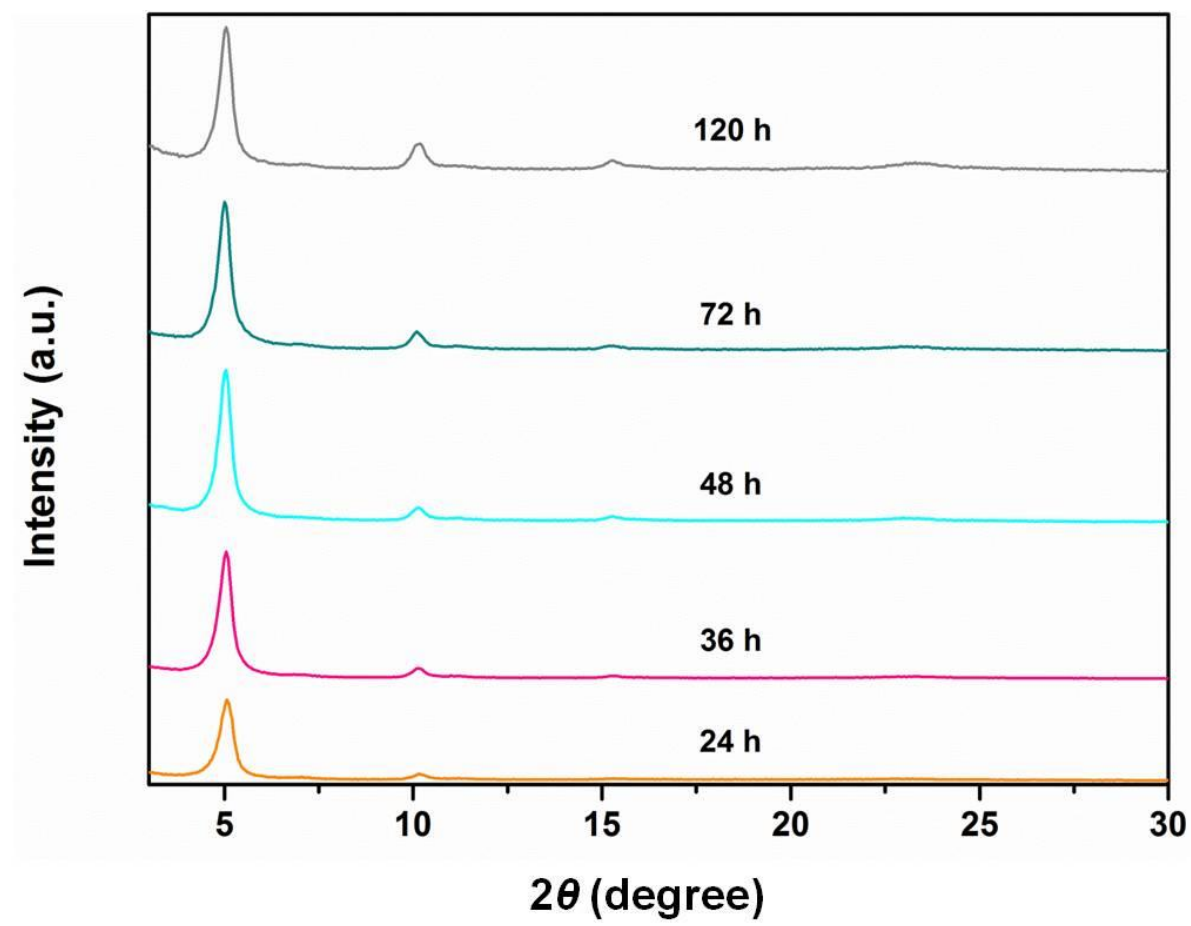

Figure S14. PXRD patterns of Py-COFDCM at different reaction times $(24 \sim 120 \mathrm{~h})$, the intensity exhibited no obvious enhancement after 36 hours. 


\section{of Py-COF}
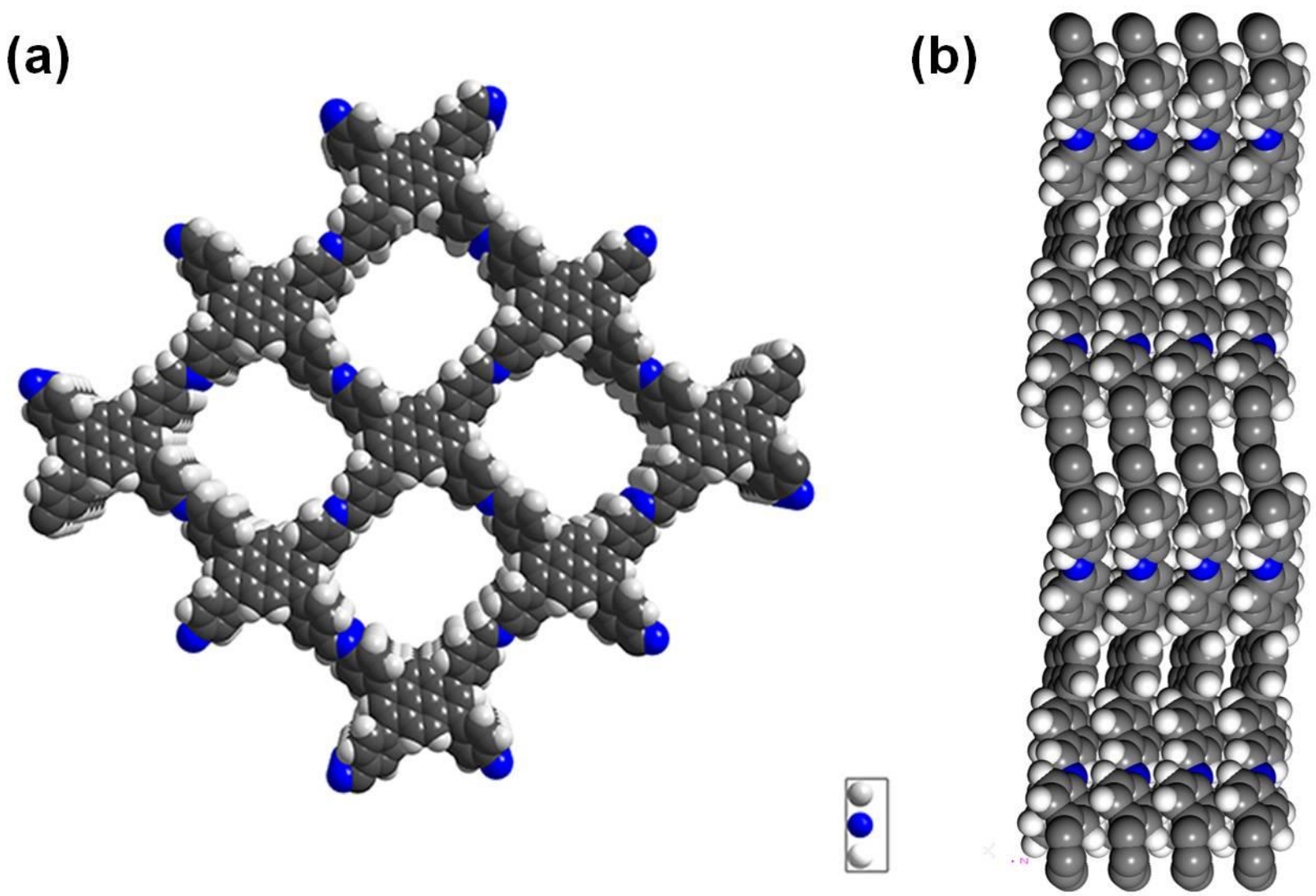

Figure S15. (a) Top-view and (b) Side-view for AA stacking model of Py-COF (gray, carbon; blue, nitrogen; white, hydrogen)

Table S2. Atomic coordinates of the AA-stacking mode of Py-COF using DFTB+ method

\begin{tabular}{lccc}
\hline \multicolumn{4}{c}{ Space group: $\boldsymbol{P 2 1}$} \\
\multicolumn{4}{c}{$\boldsymbol{a}=\mathbf{2 4 . 3 7 4 0} \AA, \boldsymbol{b}=\mathbf{2 6 . 2 1 3 4} \AA$, and $\boldsymbol{c}=\mathbf{4 . 0 2 8 7 \AA .}$} \\
$\boldsymbol{\alpha}=\boldsymbol{\gamma}=\mathbf{9 0} \mathbf{0}^{\circ}$ and $\boldsymbol{\beta}=\mathbf{7 2 . 1 ^ { \circ }}$ \\
\hline $\mathbf{C}$ & $\mathbf{Y}$ & $\mathbf{Z}$ \\
\hline $\mathbf{C 1}$ & 1.47938 & -7.71377 & 0.65708 \\
$\mathbf{C 3}$ & 1.47936 & -7.75531 & 0.47422 \\
$\mathbf{C 4}$ & 1.39431 & -7.86321 & 0.28948 \\
$\mathbf{C 5}$ & 1.43998 & -7.83064 & 0.27732 \\
$\mathbf{C 6}$ & 1.43025 & -7.78652 & 0.49286 \\
\hline & 1.37338 & -7.77504 & 0.71982 \\
\hline
\end{tabular}




\begin{tabular}{|c|c|c|c|}
\hline C7 & 1.32787 & -7.80803 & 0.73538 \\
\hline C8 & 1.13839 & -7.82145 & 0.34063 \\
\hline C9 & 1.0874 & -7.79477 & 0.37986 \\
\hline C10 & 1.03389 & -7.81345 & 0.61148 \\
\hline C11 & 1.03246 & -7.85888 & 0.80524 \\
\hline C12 & 1.08354 & -7.88524 & 0.76863 \\
\hline C13 & 1.36161 & -8.17838 & 0.65937 \\
\hline C14 & 1.4126 & -8.20506 & 0.62014 \\
\hline C15 & 1.46611 & -8.18638 & 0.38852 \\
\hline C16 & 1.46754 & -8.14095 & 0.19477 \\
\hline C17 & 1.41646 & -8.11459 & 0.23137 \\
\hline C18 & 1.10569 & -8.13662 & 0.71052 \\
\hline C19 & 1.06002 & -8.1692 & 0.72268 \\
\hline $\mathrm{C2O}$ & 1.06975 & -8.21332 & 0.50714 \\
\hline $\mathrm{C21}$ & 1.12662 & -8.22479 & 0.28018 \\
\hline $\mathrm{C} 22$ & 1.17213 & -8.1918 & 0.26461 \\
\hline $\mathrm{C} 23$ & 1.33784 & -7.85312 & 0.52647 \\
\hline $\mathrm{C} 24$ & 1.1371 & -7.86744 & 0.53037 \\
\hline $\mathrm{C} 25$ & 1.3629 & -8.13239 & 0.46963 \\
\hline $\mathrm{C26}$ & 1.16216 & -8.14671 & 0.47353 \\
\hline $\mathrm{C} 27$ & 1.28884 & -7.88767 & 0.5379 \\
\hline $\mathrm{C28}$ & 1.23805 & -7.86509 & 0.52448 \\
\hline $\mathrm{C29}$ & 1.19188 & -7.89458 & 0.50198 \\
\hline $\mathrm{C30}$ & 1.1982 & -7.94876 & 0.4692 \\
\hline C31 & 1.1573 & -7.97967 & 0.39199 \\
\hline C32 & 1.16207 & -8.03296 & 0.3816 \\
\hline $\mathrm{C} 33$ & 1.3427 & -8.02016 & 0.60801 \\
\hline C34 & 1.33793 & -7.96687 & 0.6184 \\
\hline C35 & 1.29216 & -7.94209 & 0.55074 \\
\hline C36 & 1.2476 & -7.97261 & 0.50485 \\
\hline C37 & 1.26195 & -8.13474 & 0.47552 \\
\hline C38 & 1.30812 & -8.10526 & 0.49802 \\
\hline C39 & 1.3018 & -8.05107 & 0.5308 \\
\hline $\mathrm{C} 40$ & 1.2524 & -8.02722 & 0.49515 \\
\hline C41 & 1.20784 & -8.05775 & 0.44926 \\
\hline $\mathrm{C} 42$ & 1.21116 & -8.11216 & 0.4621 \\
\hline N43 & 1.97936 & -7.74452 & 0.47422 \\
\hline C44 & 1.97938 & -7.78606 & 0.65709 \\
\hline H45 & 1.43985 & -7.69851 & 0.84835 \\
\hline H46 & 1.40314 & -7.89623 & 0.11192 \\
\hline H47 & 1.48326 & -7.83961 & 0.09658 \\
\hline H48 & 1.36333 & -7.74133 & 0.88956 \\
\hline H49 & 1.28482 & -7.79833 & 0.91402 \\
\hline H50 & 1.17884 & -7.80604 & 0.16088 \\
\hline
\end{tabular}




\begin{tabular}{llll}
\hline H51 & 1.08994 & -7.75969 & 0.22756 \\
H52 & 0.99183 & -7.87362 & 0.98966 \\
H53 & 1.08122 & -7.91925 & 0.93064 \\
H54 & 1.32116 & -8.19379 & 0.83911 \\
H55 & 1.41006 & -8.24014 & 0.77245 \\
H56 & 1.50817 & -8.12621 & 0.01035 \\
H57 & 1.41878 & -8.08058 & 0.06936 \\
H58 & 1.09686 & -8.1036 & 0.88809 \\
H59 & 1.01674 & -8.16022 & 0.90342 \\
H60 & 1.13667 & -8.2585 & 0.11044 \\
H61 & 1.21518 & -8.2015 & 0.08598 \\
H62 & 1.23429 & -7.82358 & 0.53258 \\
H63 & 1.12168 & -7.96299 & 0.3312 \\
H64 & 1.12994 & -8.0544 & 0.31227 \\
H65 & 1.37832 & -8.03684 & 0.6688 \\
H66 & 1.37006 & -7.94543 & 0.68773 \\
H67 & 1.26571 & -8.17625 & 0.46742 \\
H68 & 1.93985 & -7.80132 & 0.84836 \\
\hline
\end{tabular}




\section{Section 12. Single-Crystal Structure and Crystal Data of BFBAPy}

(a)

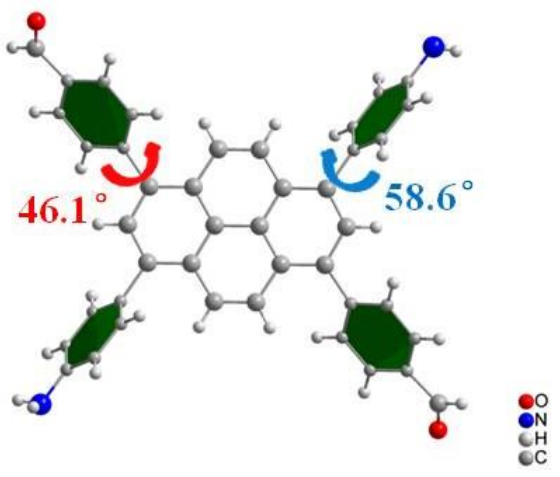

(c)

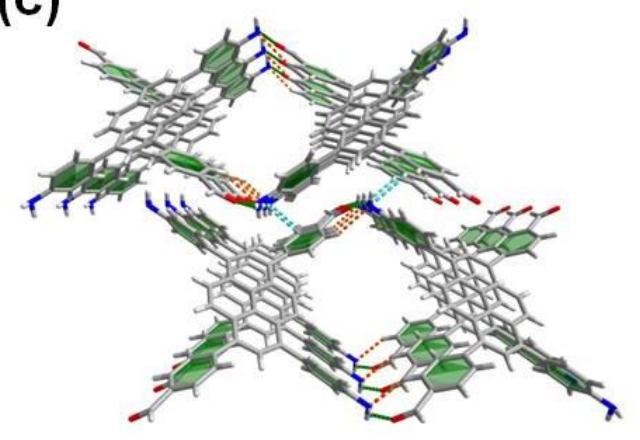

(b)

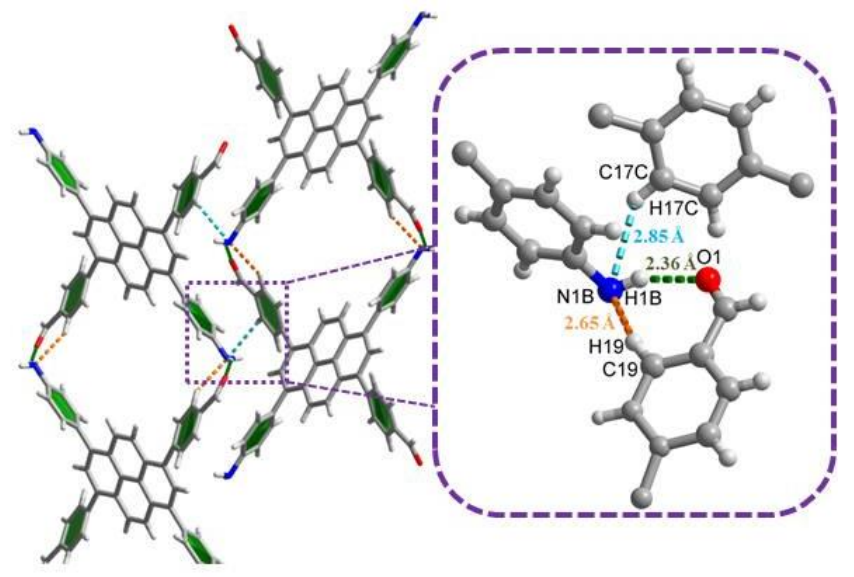

(d)

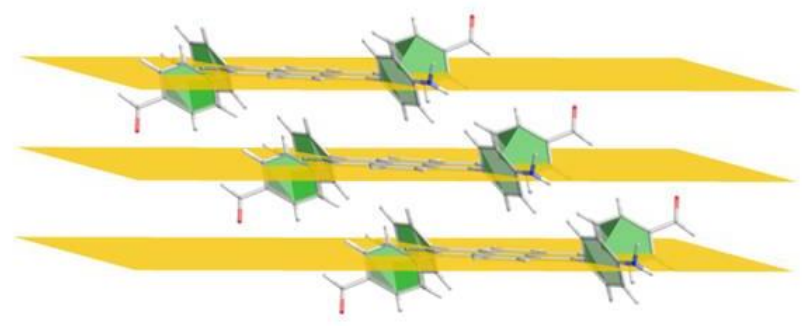

Figure S16. (a) Ball and stick representation of the asymmetric structural unit of the monomer. C: Grey; O: Red; N: Blue; H: White. (b) The hydrogen bonding interactions in the monomer. Aqua dashed: C17C-H17C $\bullet$ N1B; Orange dashed: C19-H19••N1B; Green dashed: N1B-H1B・•O1. B: $\mathrm{x}, \mathrm{y}+1, \mathrm{z} ; \mathrm{C}:-\mathrm{x}+0.5, \mathrm{y}+0.5,-\mathrm{z}+0.5$; (c) $3 \mathrm{D} \mathrm{H}$-bonded supramolecular network constitutes via hydrogen bonds interactions between the adjacent monomer units. (d) The layered structure of BFBAPy. Yellow layer represents the plane of pyrene center and the interlayer spacing is $4.38 \AA$. 
Table S3. Crystal data (CCDC No.: 1845638) and structure refinement details for BFBAPy.

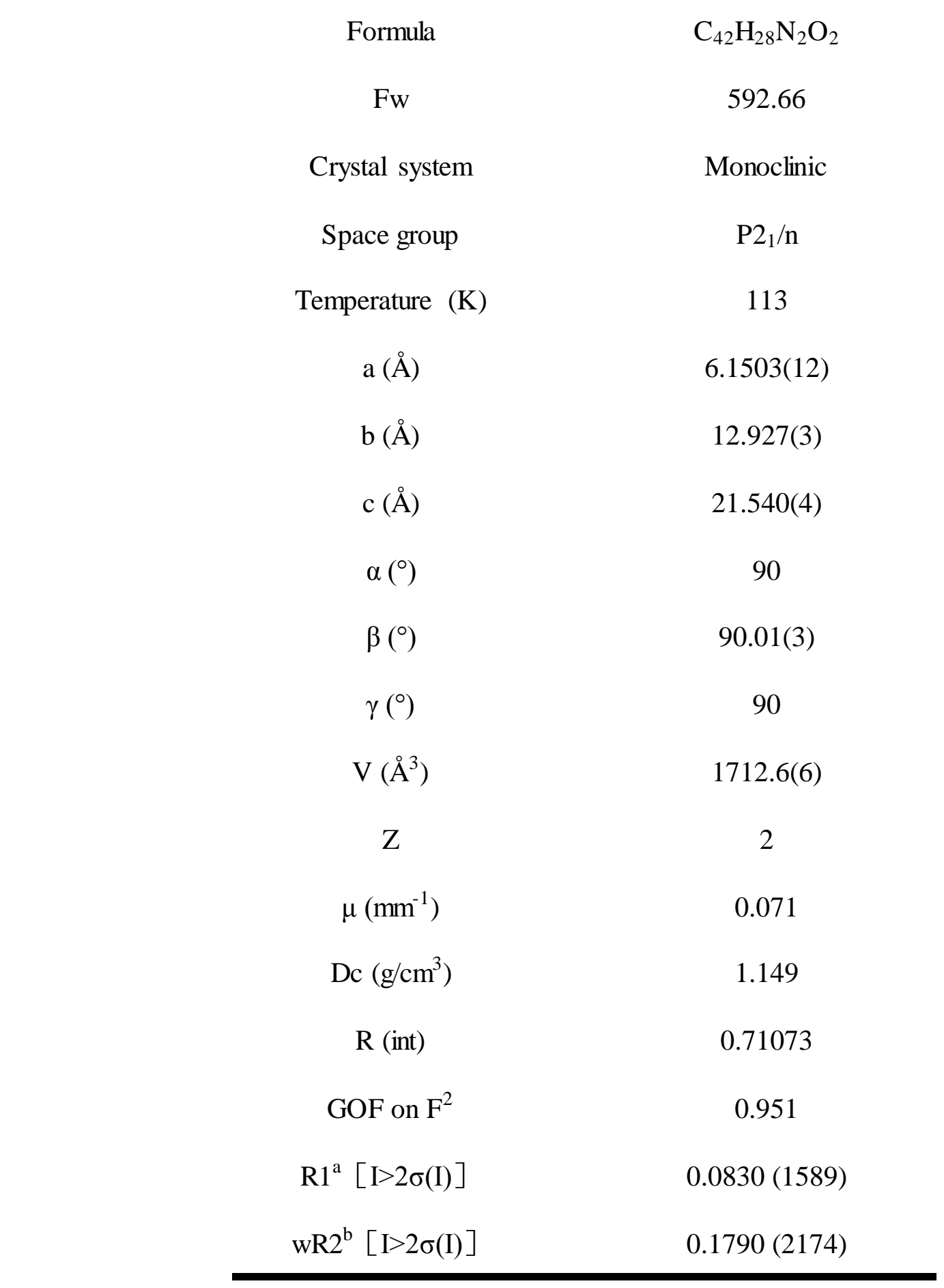

${ }^{\mathrm{a}} \mathrm{R}_{1}=\Sigma|| \mathrm{F}_{\mathrm{o}}|-| \mathrm{F}_{\mathrm{c}}|| / \Sigma\left|\mathrm{F}_{\mathrm{o}}\right| ;{ }^{\mathrm{b}} \mathrm{wR}_{2}=\left[\Sigma\left[\mathrm{w}\left(\mathrm{F}_{\mathrm{o}}{ }^{2}-\mathrm{F}_{\mathrm{c}}{ }^{2}\right)^{2}\right] / \Sigma \mathrm{w}\left(\mathrm{F}_{\mathrm{o}}{ }^{2}\right]^{2}\right]^{1 / 2}$ 


\section{Section 13. BET Plots of $\mathrm{N}_{2}$ Isotherms for Py-COFs}
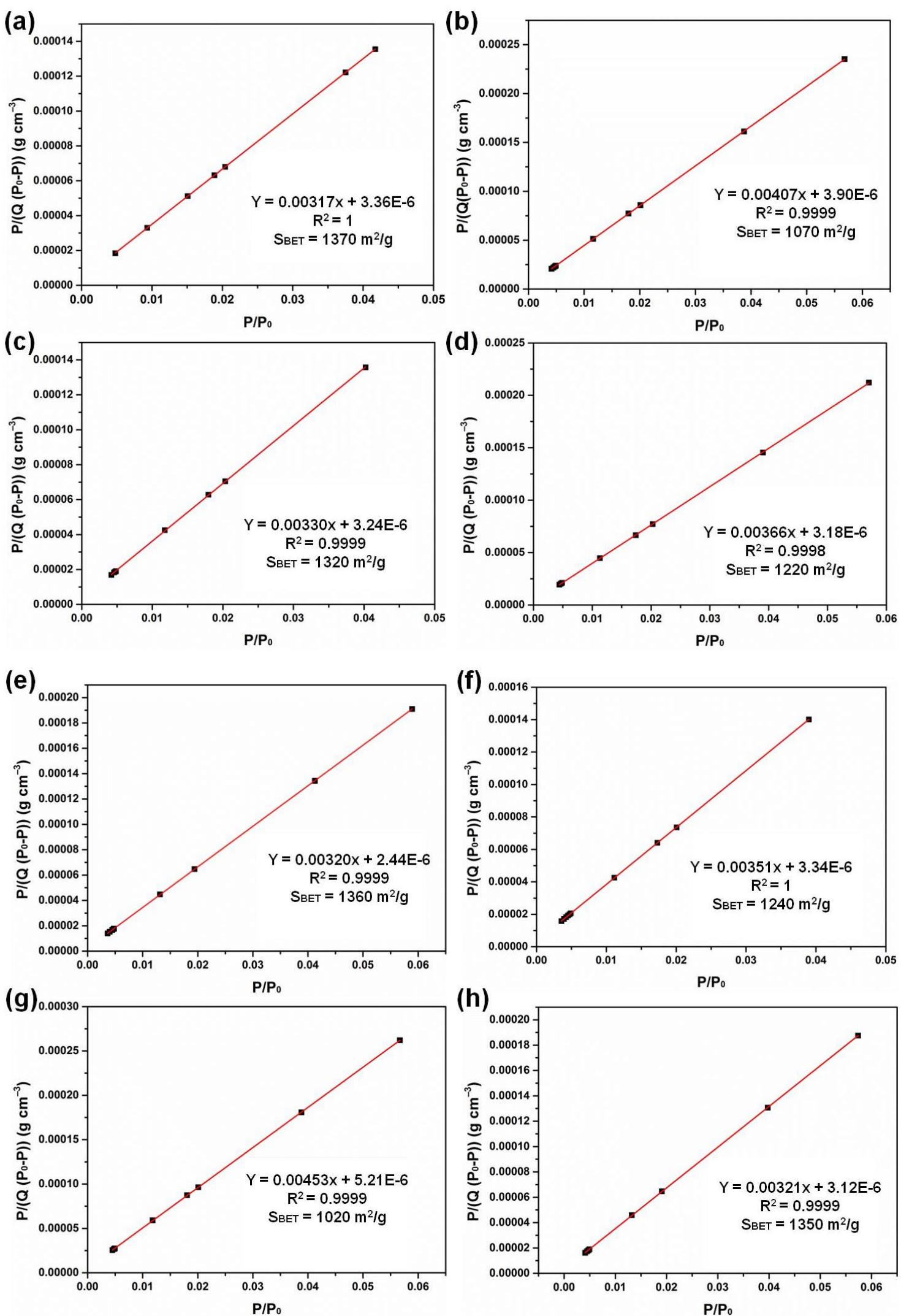

Figure S17. BET plots for (a) $\mathrm{Py}-\mathrm{COF}$ dem, (b) $\mathrm{Py}-\mathrm{COF}_{\mathrm{CHCl}}$, (c) $\mathrm{Py}-\mathrm{COF}_{\mathrm{DMAc}}$, (d) $\mathrm{Py}-\mathrm{COF}_{\mathrm{EtOH}}$, (e) Py-COFthғ, (f) Py-COFmeon, (g) Py-COFmecn, (h) Py-COFo-DCB/n-BuoH. 
Section 14. AFM Images of Py-COF Thin Films.
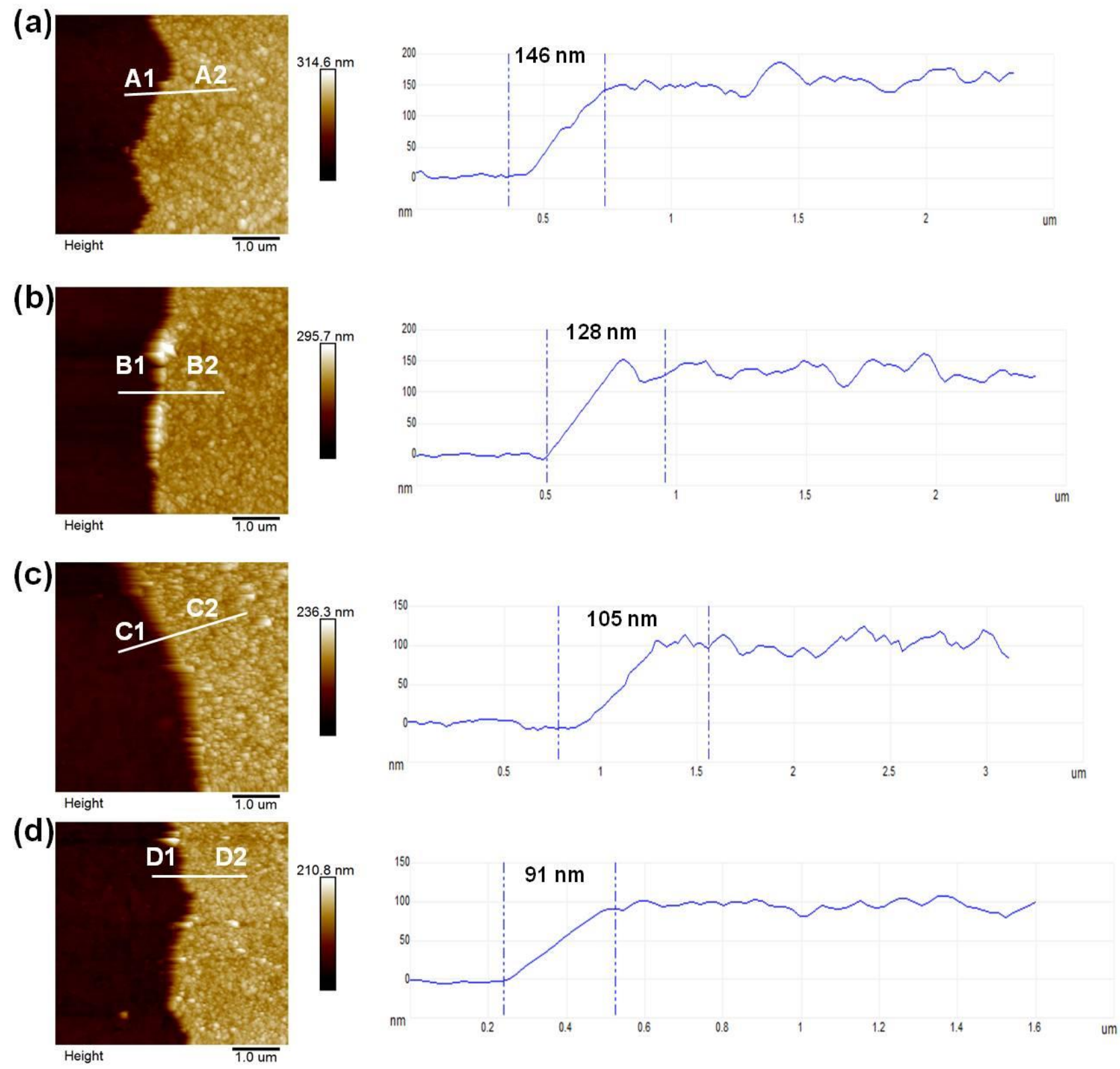

Figure S18. AFM images of Py-COF films (after $24 \mathrm{~h}$ growth) with their corresponding height profiles. The initial concentrations of the monomer are (a) 7.5 , (b) 5.0 , (c) 3.75 and (d) $2.5 \mathrm{mg} / \mathrm{mL}$, respectively. 

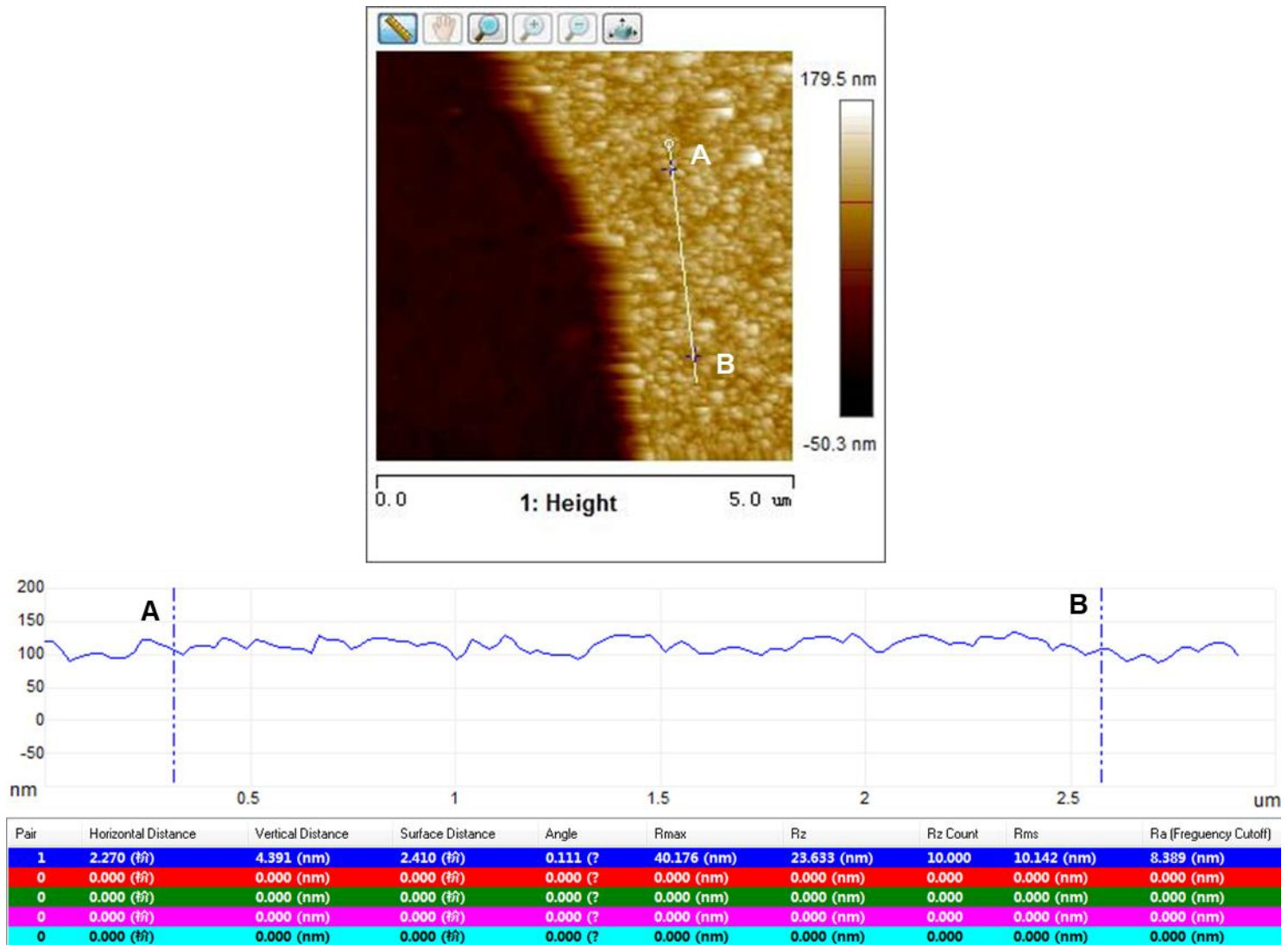

Figure S19. The root-mean-square (RMS) roughness of Py-COF film (3.75 mg/mL) is about 10.14 nm.

Section 15. The Solvent Dependence Tests and Transparency of Py-COF Films

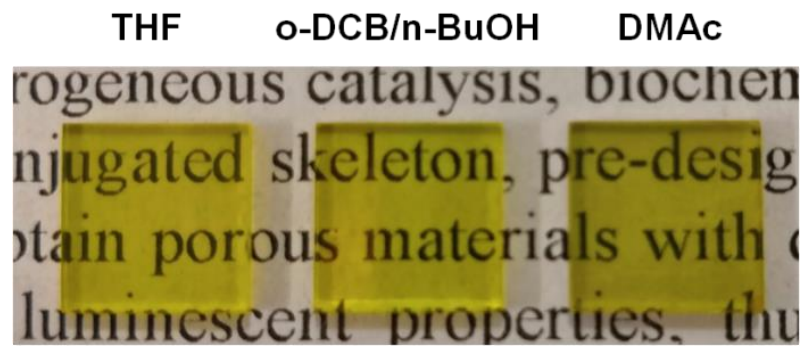

Figure S20. The solvent dependence test of Py-COF films. Py-COF films can be facilely grown in THF, o-DCB/n-BuOH and DMAc. 


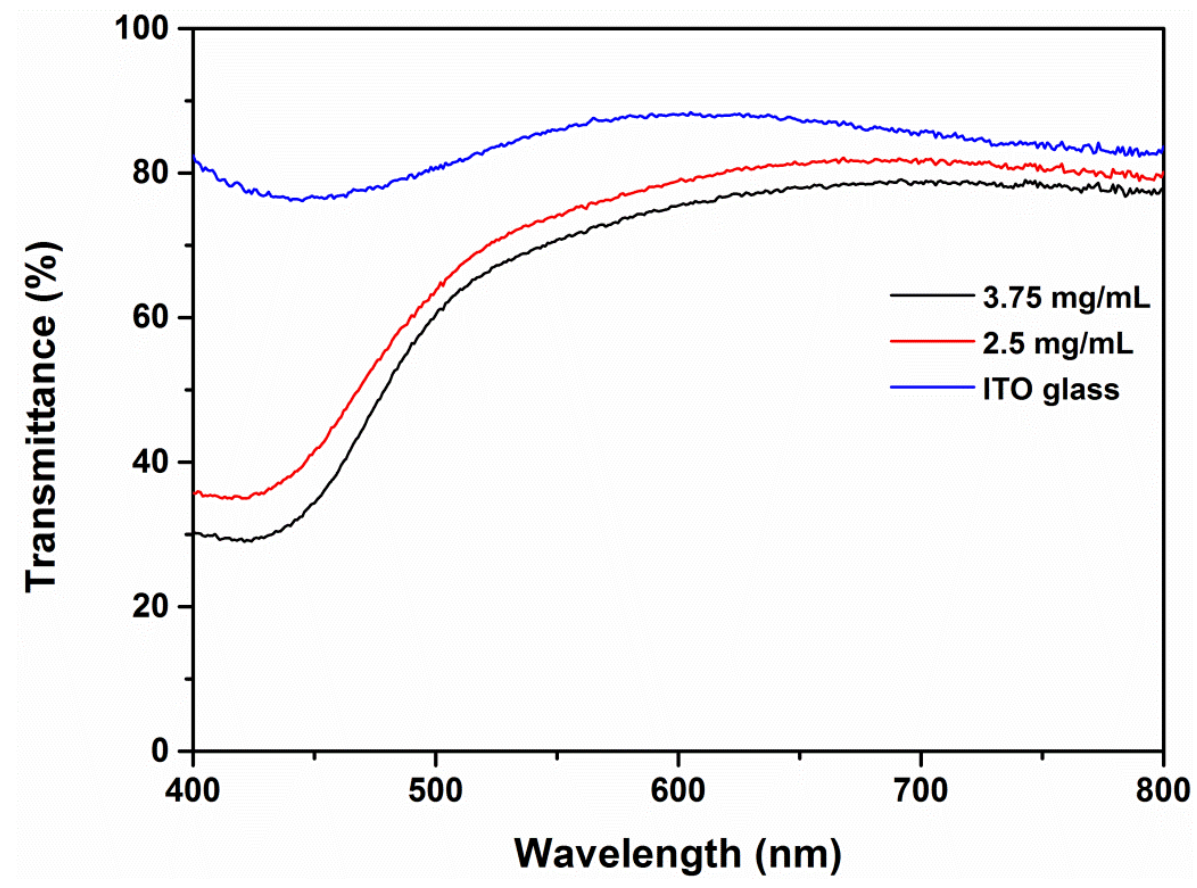

Figure S21. The transmittance of Py-COF films synthesized at the concentration of 3.75 (black) and $2.5 \mathrm{mg} / \mathrm{mL}$ (red), which only displayed little attenuation comparing with ITO substrate (blue) in the $500-800 \mathrm{~nm}$. 


\section{Section 16. General Procedure for the Synthesis Py-COFs}

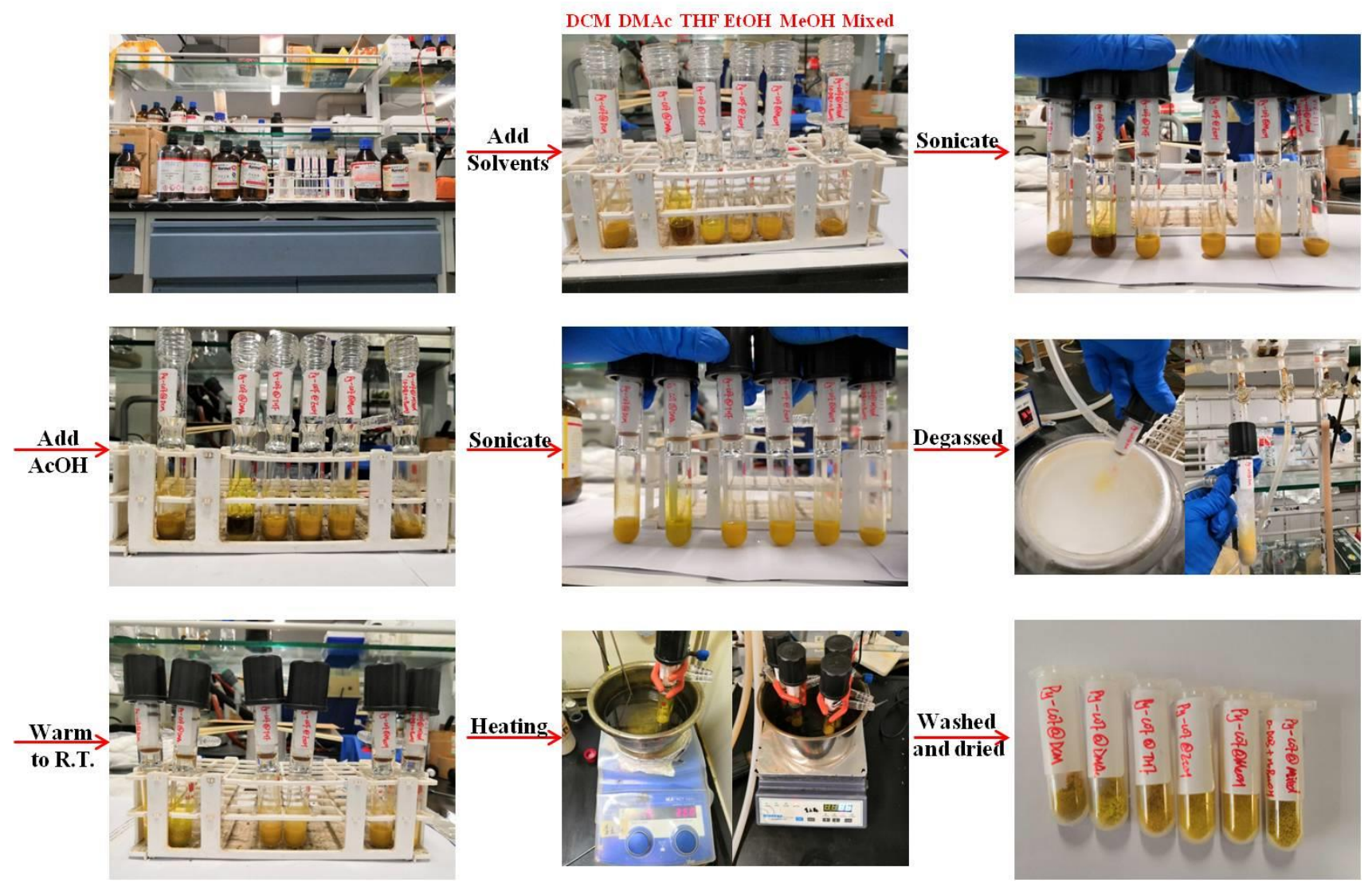

Figure S22. Pictorial illustration of the general procedure of Py-COFs synthesis.

\section{Section 17. Contact Angle Images for Py-COF Film and Powder}

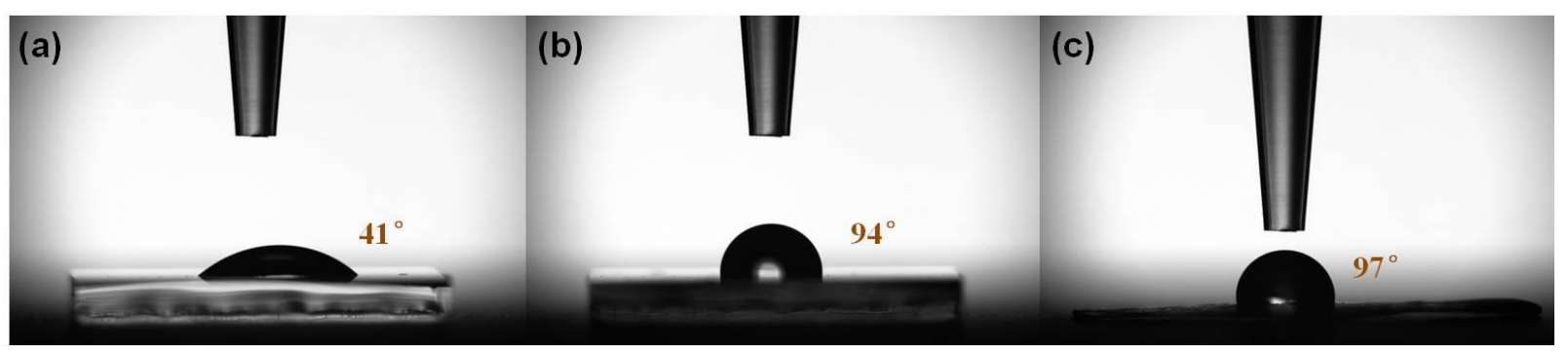

Figure S23. Contact angle images for (a) ITO glass, (b) Py-COF film on ITO glass and (c) Py-COF powder. 


\section{Section 18. PXRD, BET and IR Patterns of Py-COF $6 \mathrm{MAcOH}$ and $\mathrm{Py}-\mathrm{COF}_{12 \mathrm{MHCl}}$}
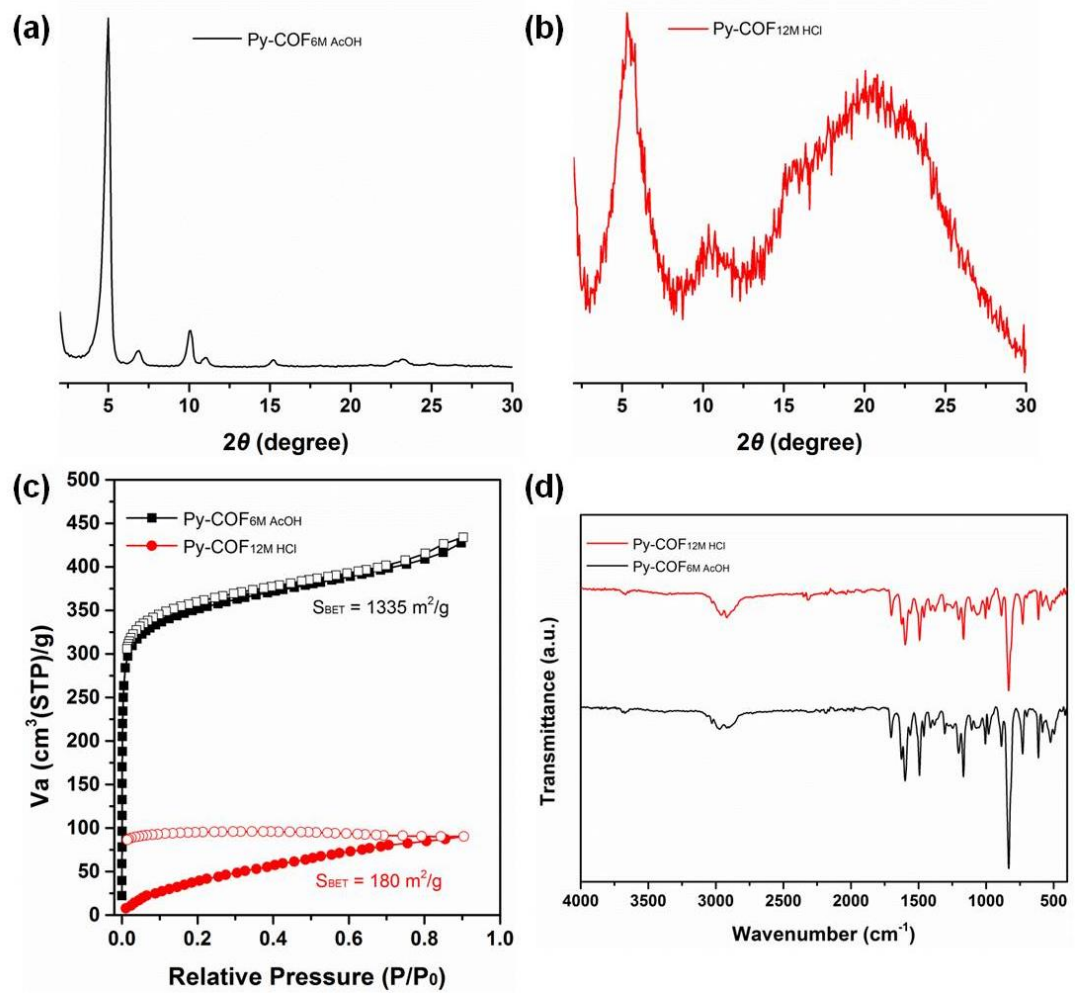

Figure S24. (a) and (b) PXRD patterns of $\mathrm{Py}-\mathrm{COF}_{6 \mathrm{M}} \mathrm{AcOH}$ and $\mathrm{Py}-\mathrm{COF}_{12 \mathrm{M} \mathrm{HCl}}$; (c) Nitrogen adsorption (solid) and desorption (open) isotherms at $77 \mathrm{~K}$ for $\mathrm{Py}_{-} \mathrm{COF}_{6 \mathrm{M}} \mathrm{AcOH}$ (black) and Py- $\mathrm{COF}_{12 \mathrm{M} \mathrm{HCl}}$ (red); (d) IR spectra of $\mathrm{Py}-\mathrm{COF}_{6 \mathrm{M} \mathrm{AcOH}}$ (black) and $\mathrm{Py}-\mathrm{COF}_{12 \mathrm{M} \mathrm{HCl}}$ (red); $\mathrm{Py}-\mathrm{COF}_{6 \mathrm{M}}$

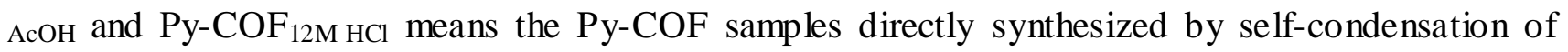
BFBAPy in $6 \mathrm{M} \mathrm{AcOH}$ or $12 \mathrm{M} \mathrm{HCl}$ without adding any organic solvents.

\section{Section 19. UPS Spectrum of Py-COF Film}

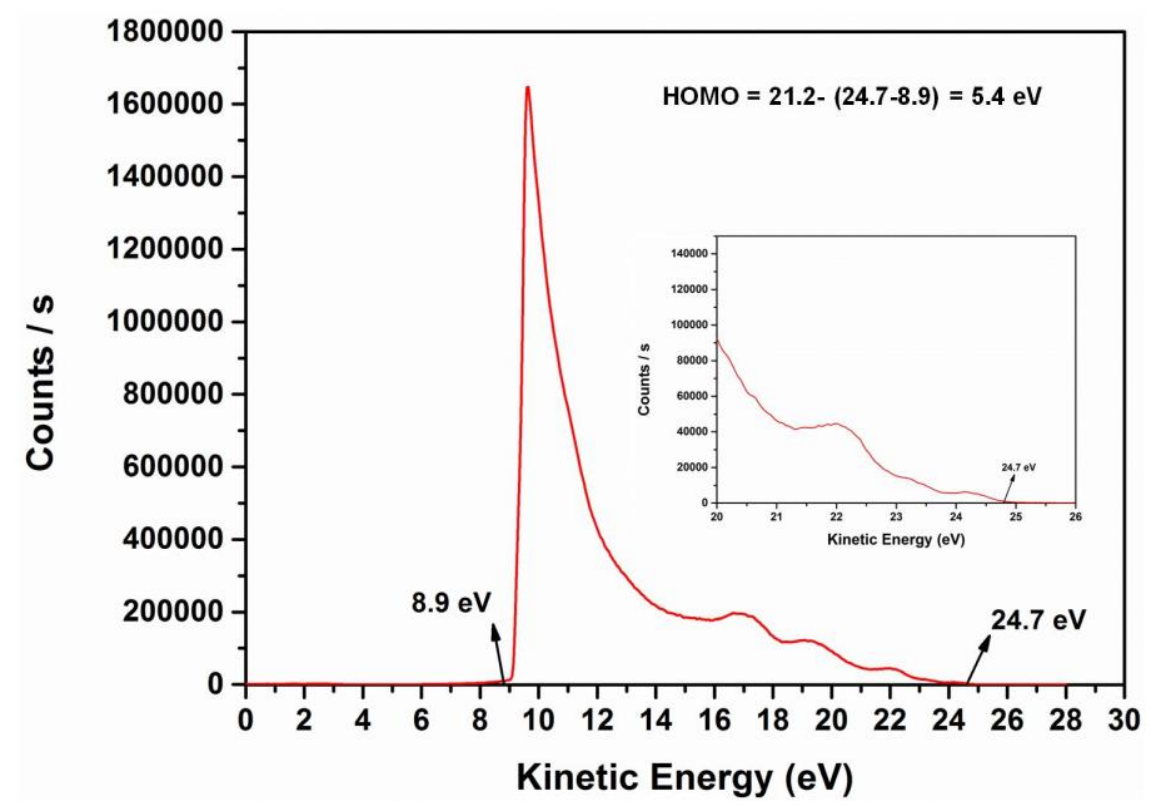

Figure S25. UPS spectrum of Py-COF film (ca. $100 \mathrm{~nm}$ thick), which indicated the HOMO energy level of Py-COF is ca. $5.4 \mathrm{eV}$ 


\section{Section 20. Optical Images for Py-COF Film on ITO Glass with PEDOT/PSS}

\section{Coating}

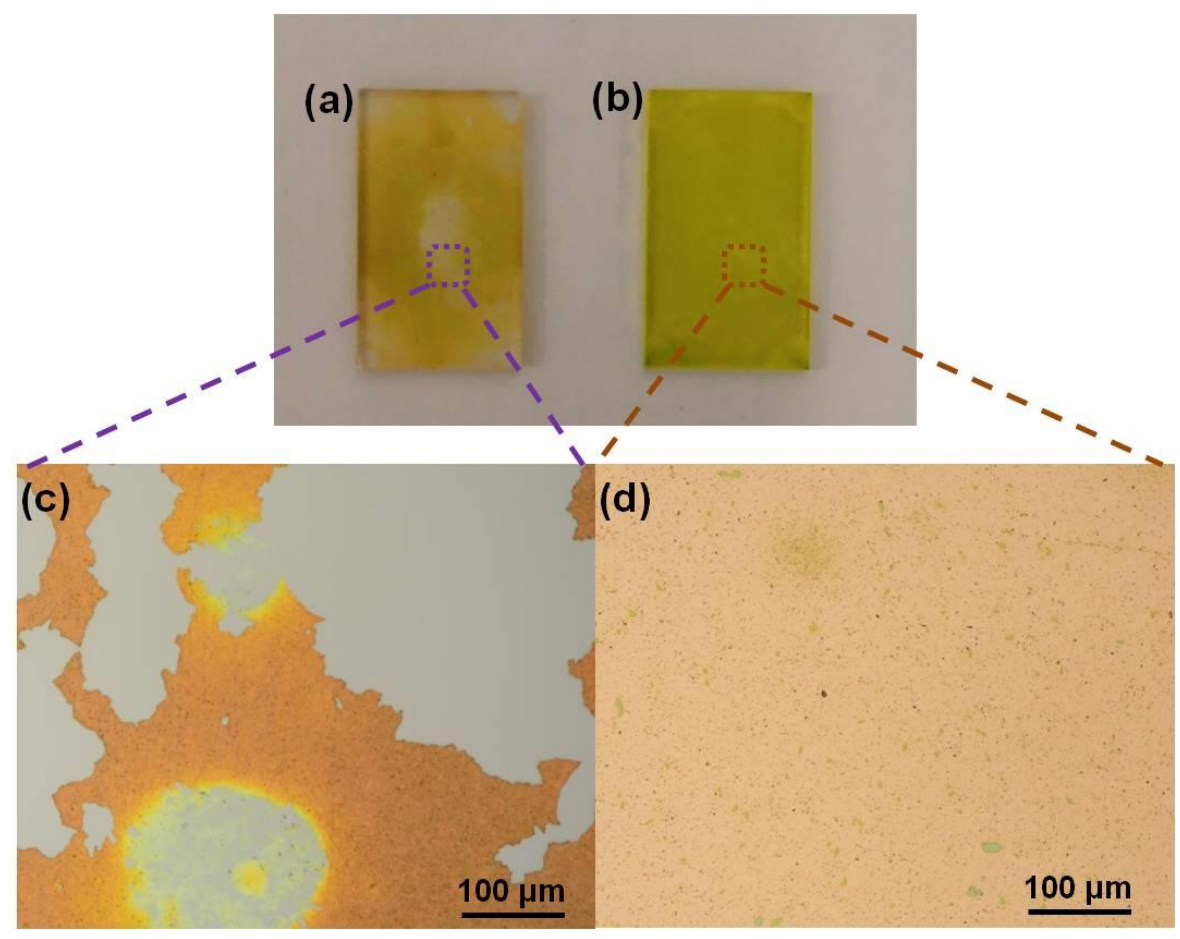

Figure S26. The optical images of Py-COF film grown on PEDOT/PSS coating ITO glass: (a) a fragmentized film obtained by in-situ growth in o-DCB/n-BuOH; (b) a high quality Py-COF film generated by in-situ growth in DCM; (c) and (d) are the high magnification image of selected area of (a) and (b). 


\section{Section 21. Generality and Tolerance of Two-in-one Strategy}
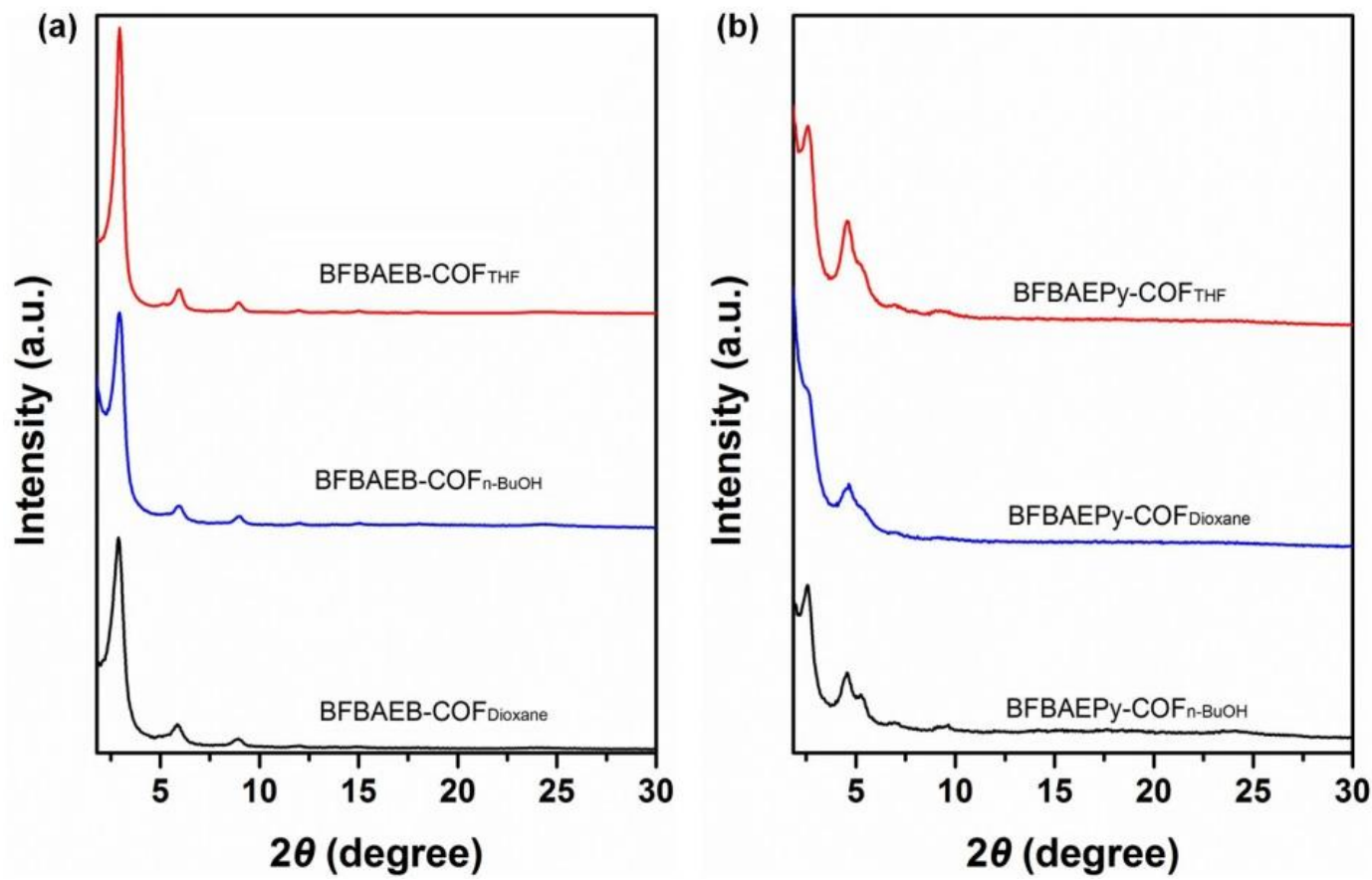

Figure S27. (a) PXRD patterns of BFBAEB-COF synthesized in dioxane (black), n-BuOH (blue) and THF (red); (b) PXRD patterns of BFBAEPy-COF synthesized in n-BuOH (black), dioxane (blue) and THF (red).

(a)
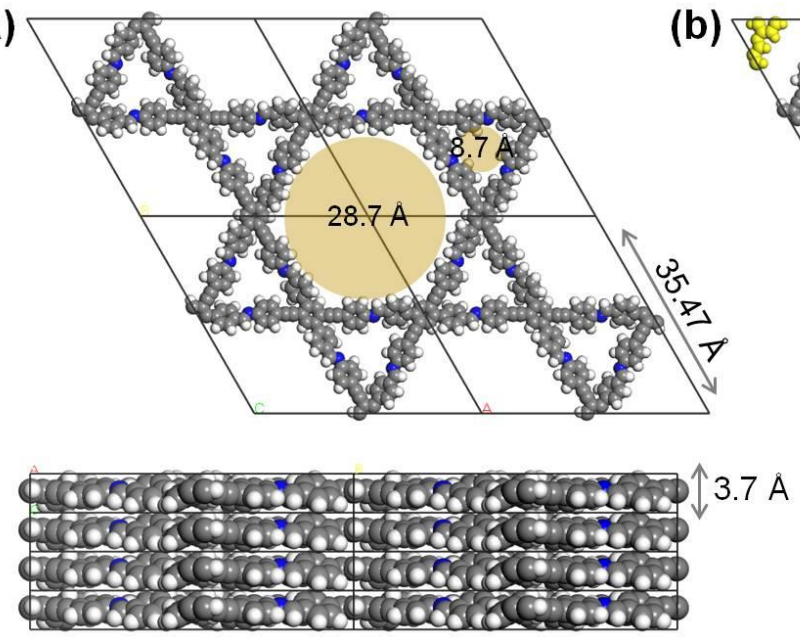

(b)
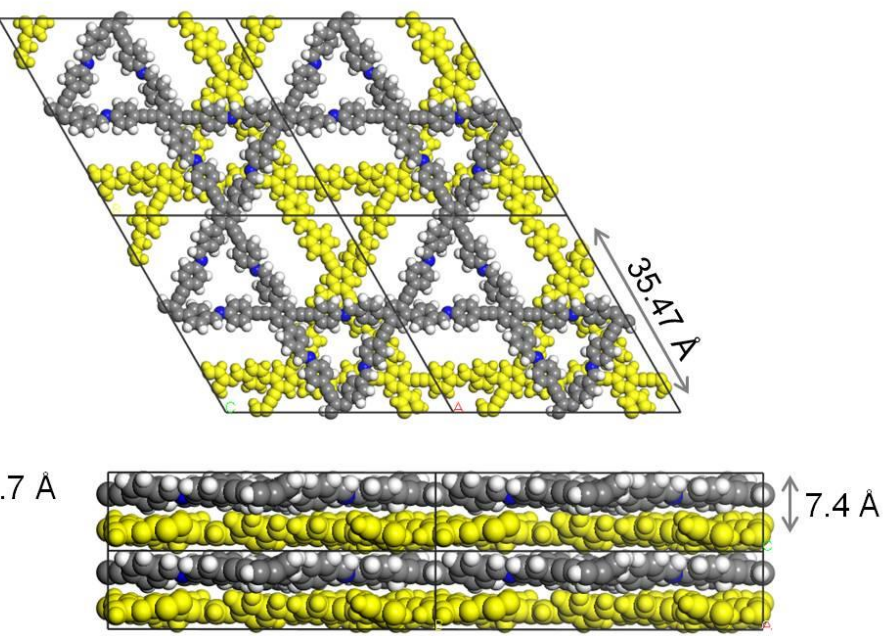

Figure S28. (a) AA-Stacking model and (b) AB-Stacking model of BFBAEB-COF. 
Table S4. Atomic coordinates of the AA-stacking mode of BFBAEB-COF using DFTB+ method

\begin{tabular}{|c|c|c|c|}
\hline \multicolumn{4}{|c|}{$\begin{array}{c}\text { Space group: } P 6 \\
a=b=35.7672 \AA \text {, and } c=3.6823 \AA . \\
\alpha=\beta=90^{\circ}, \text { and } \gamma=120^{\circ}\end{array}$} \\
\hline & $\mathbf{X}$ & $\mathbf{Y}$ & $\mathbf{Z}$ \\
\hline $\mathrm{C1}$ & 0.5032 & 0.54182 & 0.45314 \\
\hline $\mathrm{C} 2$ & 0.46208 & 0.50311 & 0.45905 \\
\hline $\mathrm{C3}$ & 0.45942 & 0.46242 & 0.44296 \\
\hline $\mathrm{C} 4$ & 0.50871 & 0.58668 & 0.47198 \\
\hline C5 & 0.42163 & 0.50321 & 0.49162 \\
\hline C6 & 0.54503 & 0.62053 & 0.65167 \\
\hline C7 & 0.55063 & 0.66232 & 0.67414 \\
\hline C8 & 0.51941 & 0.67121 & 0.52927 \\
\hline C9 & 0.48332 & 0.63798 & 0.34696 \\
\hline C10 & 0.4788 & 0.59671 & 0.30901 \\
\hline C11 & 0.61229 & 0.49679 & 0.50865 \\
\hline $\mathrm{C} 12$ & 0.65262 & 0.49646 & 0.51527 \\
\hline C13 & 0.65319 & 0.45834 & 0.42889 \\
\hline C14 & 0.69269 & 0.45858 & 0.41615 \\
\hline C15 & 0.73198 & 0.49674 & 0.49089 \\
\hline C16 & 0.73114 & 0.53506 & 0.57777 \\
\hline C17 & 0.6916 & 0.53473 & 0.59048 \\
\hline C18 & 0.80997 & 0.52504 & 0.57438 \\
\hline N19 & 0.7717 & 0.49531 & 0.46395 \\
\hline H20 & 0.42742 & 0.43367 & 0.42819 \\
\hline H21 & 0.56864 & 0.61465 & 0.78751 \\
\hline H22 & 0.57868 & 0.68738 & 0.81733 \\
\hline $\mathrm{H} 23$ & 0.45926 & 0.6442 & 0.22322 \\
\hline H24 & 0.45262 & 0.57344 & 0.13996 \\
\hline H25 & 0.62321 & 0.42861 & 0.36658 \\
\hline H26 & 0.69278 & 0.42899 & 0.34536 \\
\hline H27 & 0.7606 & 0.5655 & 0.62898 \\
\hline H28 & 0.6915 & 0.56451 & 0.65401 \\
\hline H29 & 0.81448 & 0.55391 & 0.7121 \\
\hline H27 & 0.7606 & 0.5655 & 0.62898 \\
\hline H28 & 0.6915 & 0.56451 & 0.65401 \\
\hline H29 & 0.81448 & 0.55391 & 0.7121 \\
\hline
\end{tabular}


(a)
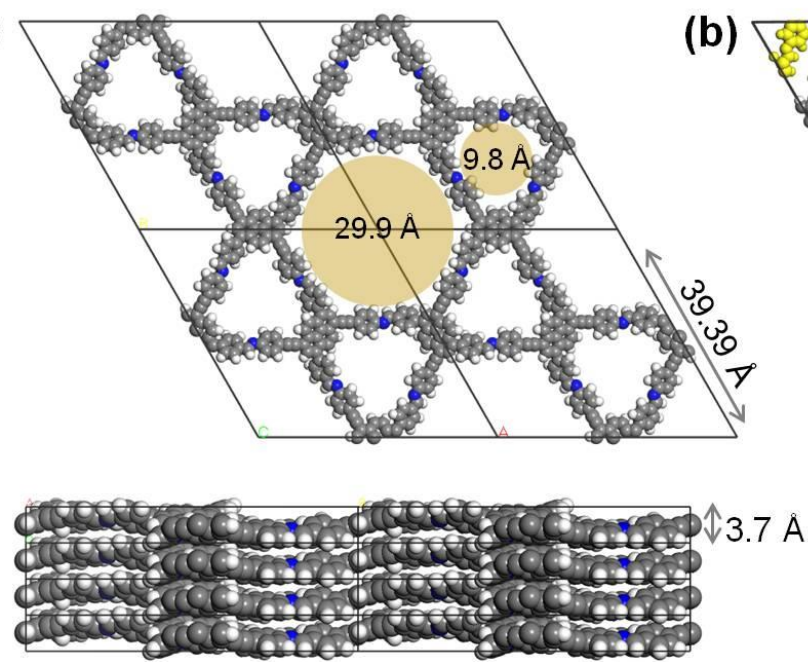
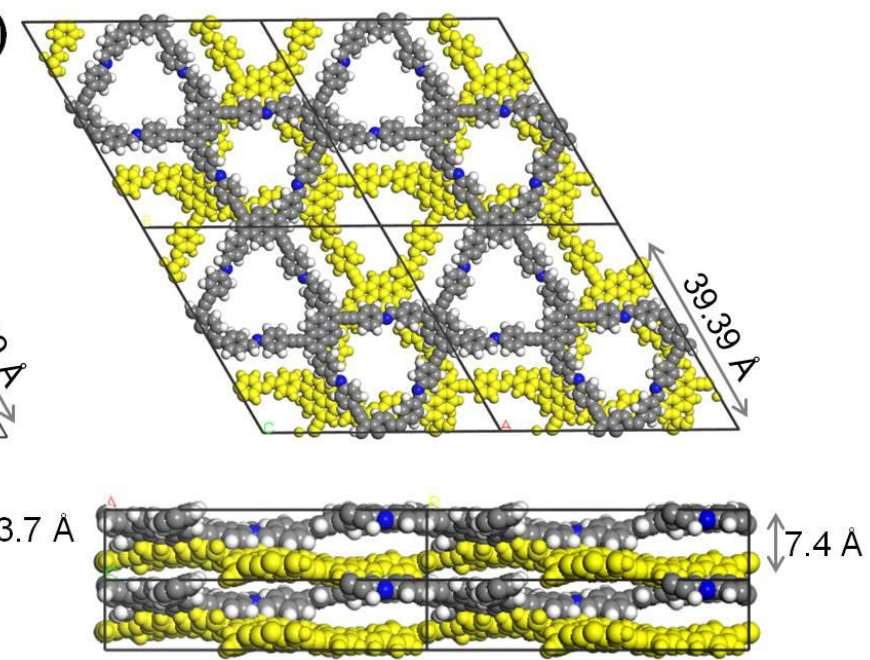

Figure S29. (a) AA-Stacking model and (b) AB-Stacking model of BFBAEPy-COF.

Table S5. Atomic coordinates of the AA-stacking mode of BFBAEPy-COF using DFTB+ method

\begin{tabular}{|c|c|c|c|}
\hline & \multicolumn{3}{|c|}{$\begin{array}{c}\text { Space group: } P 3 \\
a=b=39.3932 \AA \text {, and } c=3.7002 \AA . \\
\alpha=\beta=90^{\circ}, \text { and } \gamma=120^{\circ}\end{array}$} \\
\hline & $\mathbf{X}$ & $\mathbf{Y}$ & $\mathbf{Z}$ \\
\hline $\mathrm{C1}$ & 0.55644 & 0.58951 & 0.58253 \\
\hline $\mathrm{C} 2$ & 0.5202 & 0.55351 & 0.60694 \\
\hline C3 & 0.51813 & 0.51798 & 0.4945 \\
\hline C4 & 0.55234 & 0.5182 & 0.37508 \\
\hline C5 & 0.58854 & 0.55342 & 0.3812 \\
\hline C6 & 0.59012 & 0.58839 & 0.4765 \\
\hline C7 & 0.51384 & 0.44836 & 0.25187 \\
\hline C8 & 0.54949 & 0.48322 & 0.25052 \\
\hline C9 & 0.56063 & 0.62889 & 0.65455 \\
\hline C10 & 0.62503 & 0.55419 & 0.31534 \\
\hline C11 & 0.59407 & 0.65827 & 0.83294 \\
\hline C12 & 0.59939 & 0.6958 & 0.88197 \\
\hline C13 & 0.57121 & 0.70481 & 0.75828 \\
\hline C14 & 0.53789 & 0.6758 & 0.57839 \\
\hline C15 & 0.53319 & 0.63867 & 0.51983 \\
\hline C16 & 0.65537 & 0.55412 & 0.27777 \\
\hline C17 & 0.6913 & 0.55321 & 0.25219 \\
\hline C18 & 0.30829 & 0.48095 & 0.65345 \\
\hline C19 & 0.27302 & 0.48128 & 0.65029 \\
\hline $\mathrm{C20}$ & 0.23775 & 0.44761 & 0.74176 \\
\hline C21 & 0.23836 & 0.41334 & 0.84098 \\
\hline $\mathrm{C22}$ & 0.27375 & 0.41307 & 0.84386 \\
\hline
\end{tabular}




\begin{tabular}{llll}
\hline $\mathbf{N 2 3}$ & 0.4493 & 0.24706 & 0.28659 \\
$\mathbf{C 2 4}$ & 0.42286 & 0.25551 & 0.18344 \\
$\mathbf{H 2 5}$ & 0.61821 & 0.6152 & 0.4641 \\
$\mathbf{H 2 6}$ & 0.51347 & 0.42315 & 0.13501 \\
$\mathbf{H 2 7}$ & 0.57477 & 0.48265 & 0.14321 \\
$\mathbf{H 2 8}$ & 0.61615 & 0.65226 & 0.93764 \\
$\mathbf{H 2 9}$ & 0.62534 & 0.71768 & 1.02142 \\
$\mathbf{H 3 0}$ & 0.51594 & 0.68205 & 0.47352 \\
$\mathbf{H 3 1}$ & 0.50829 & 0.61787 & 0.36331 \\
$\mathbf{H 3 2}$ & 0.33512 & 0.5071 & 0.57484 \\
$\mathbf{H 3 3}$ & 0.27301 & 0.50771 & 0.57033 \\
$\mathbf{H 3 4}$ & 0.21188 & 0.38651 & 0.90867 \\
$\mathbf{H 3 5}$ & 0.27374 & 0.38638 & 0.91456 \\
$\mathbf{H 3 6}$ & 0.39632 & 0.23397 & 0.05065 \\
\hline
\end{tabular}
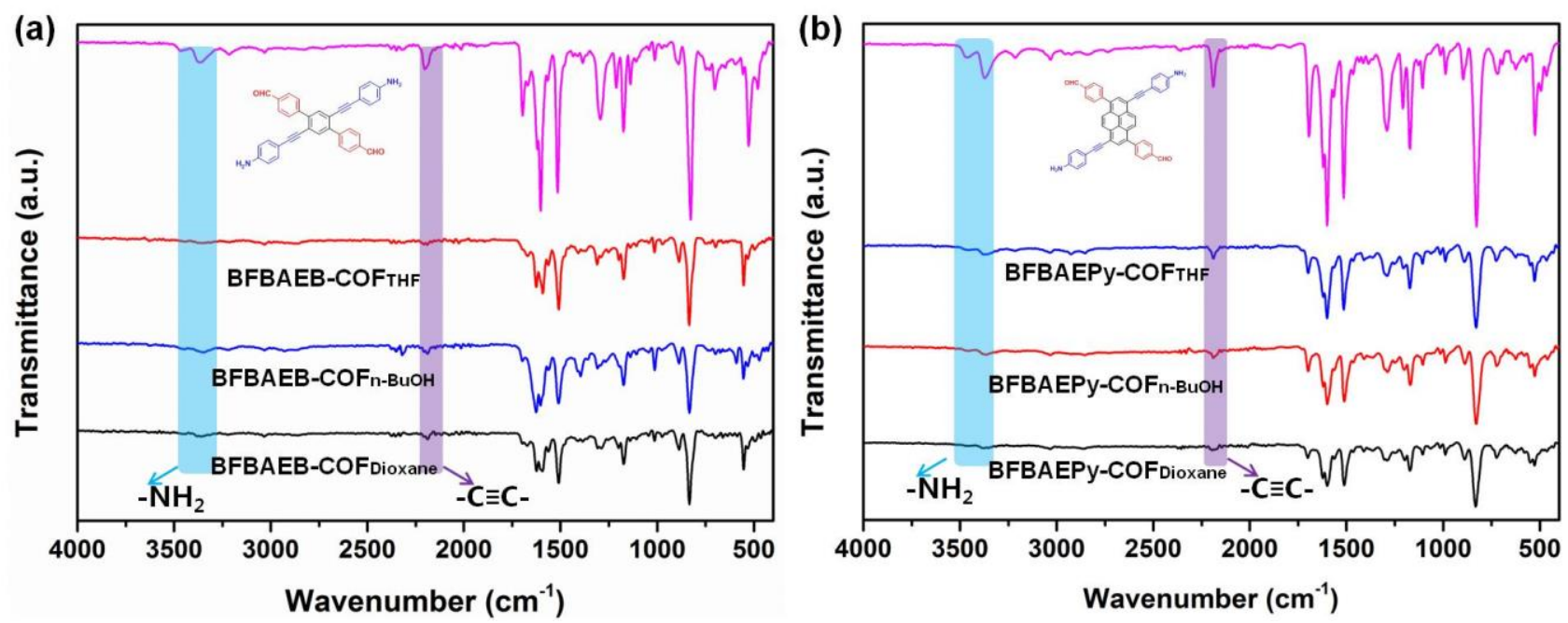

Figure S30. (a) FT-IR spectra of BFBAEB-COF Dioxane $_{\text {(black line), BFBAEB-COF }}$-BuOH (blue line) BFBAEB-COF THF $_{\text {(red line) and BFBAEB (purple line); (b) FT-IR spectra of BFBAEPy-COF }}$ Dioxane (black line), BFBAEPy-COF $\mathrm{n}_{\mathrm{n}-\mathrm{BuOH}}$ (red line) BFBAEPy-COF ${ }_{\mathrm{THF}}$ (blue line) and BFBAEPy (purple line). The characteristic vibration of amino group $\left(3270 \sim 3500 \mathrm{~cm}^{-1}\right)$ is obviously weakened and the vibration of the alkyne group $\left(2200 \mathrm{~cm}^{-1}\right)$ still remaining in BFBAEB-COF and BFBAEPy-COF. 

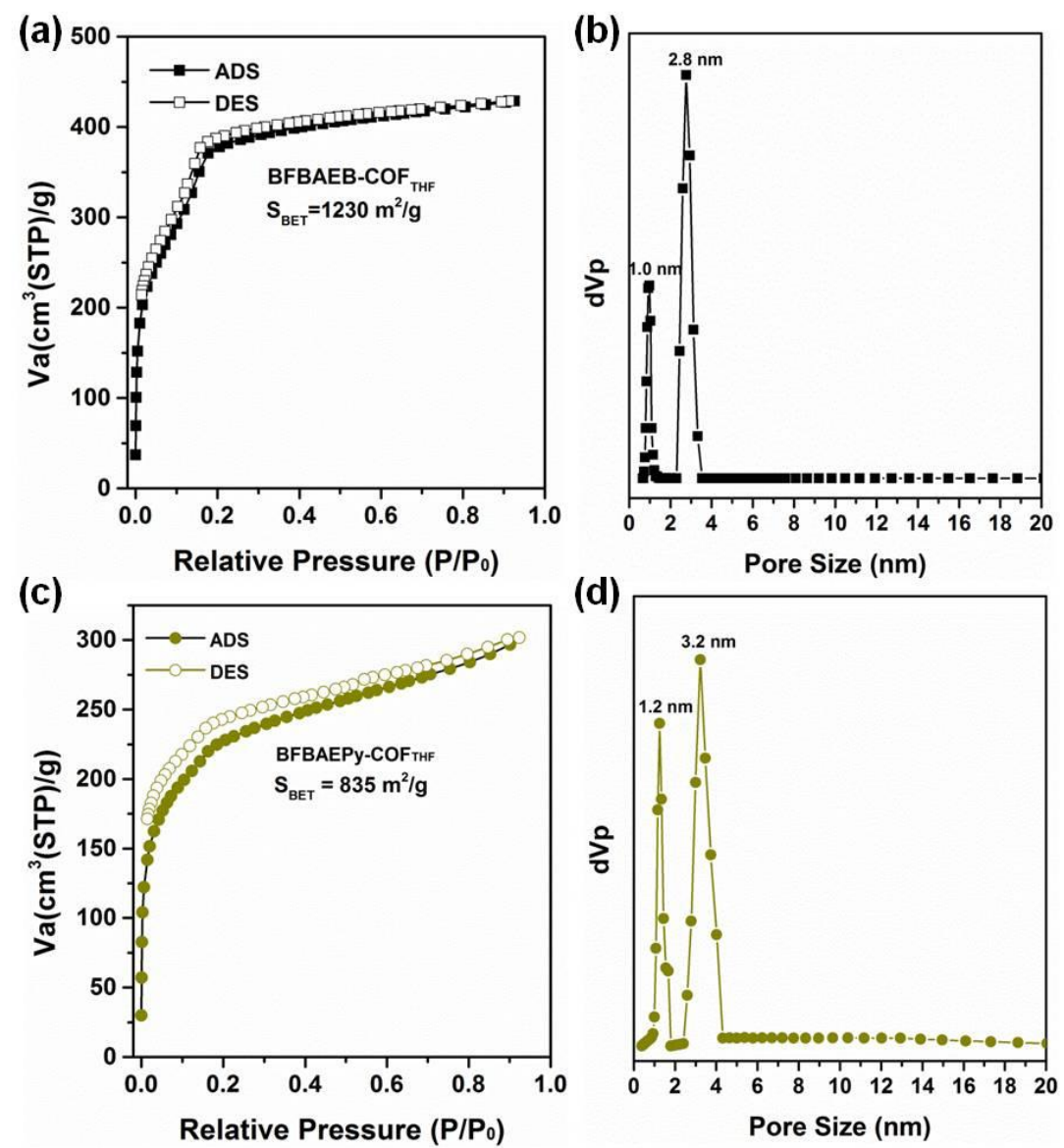

Figure S31. (a) and (c) Nitrogen adsorption (solid) and desorption (open) isotherms at $77 \mathrm{~K}$ for BFBAEB-COF $\mathrm{THF}_{\mathrm{THF}}$ and BFBAEPy- $\mathrm{COF}_{\mathrm{THF}}$; (b) and (d) Pore size distribution profiles based on NLDFT calculation for BFBAEB-COF $\mathrm{THF}_{\mathrm{T}}$ and BFBAEPy-COF $\mathrm{THF}_{\mathrm{TH}}$

\section{Section 22. 2D-GIWAXS of Py-COF Film}
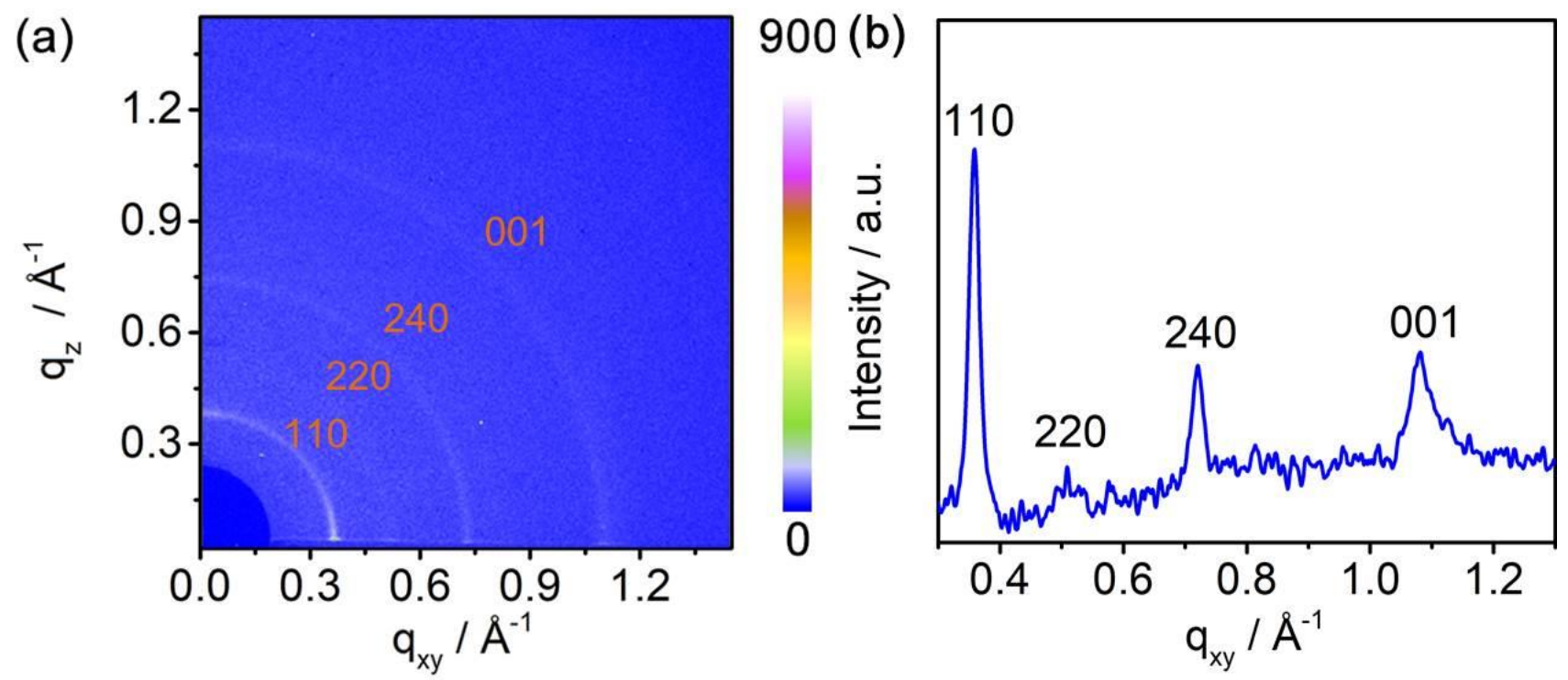

Figure S32. (a) 2D-GIWAXS pattern of Py-COF film grown on silicon wafer; (b) projections of GIWAXS data of Py-COF films sets near $\mathrm{q}_{\mathrm{z}}=0$. 


\section{Section 23. The Investigation of Stoichiometric Imbalance in $\mathrm{Py}-\mathrm{COF}_{\mathrm{DCM}}$ System}

The investigation was proceed by adding different equivalents $(5 \%, 10 \%, 25 \%$ and $50 \%)$ of $\mathrm{Py}\left(\mathrm{NH}_{2}\right)_{4}$ or aniline into the reaction system of Py-COF were filtered, washed and dried, then examined by PXRD measurements.

(a)
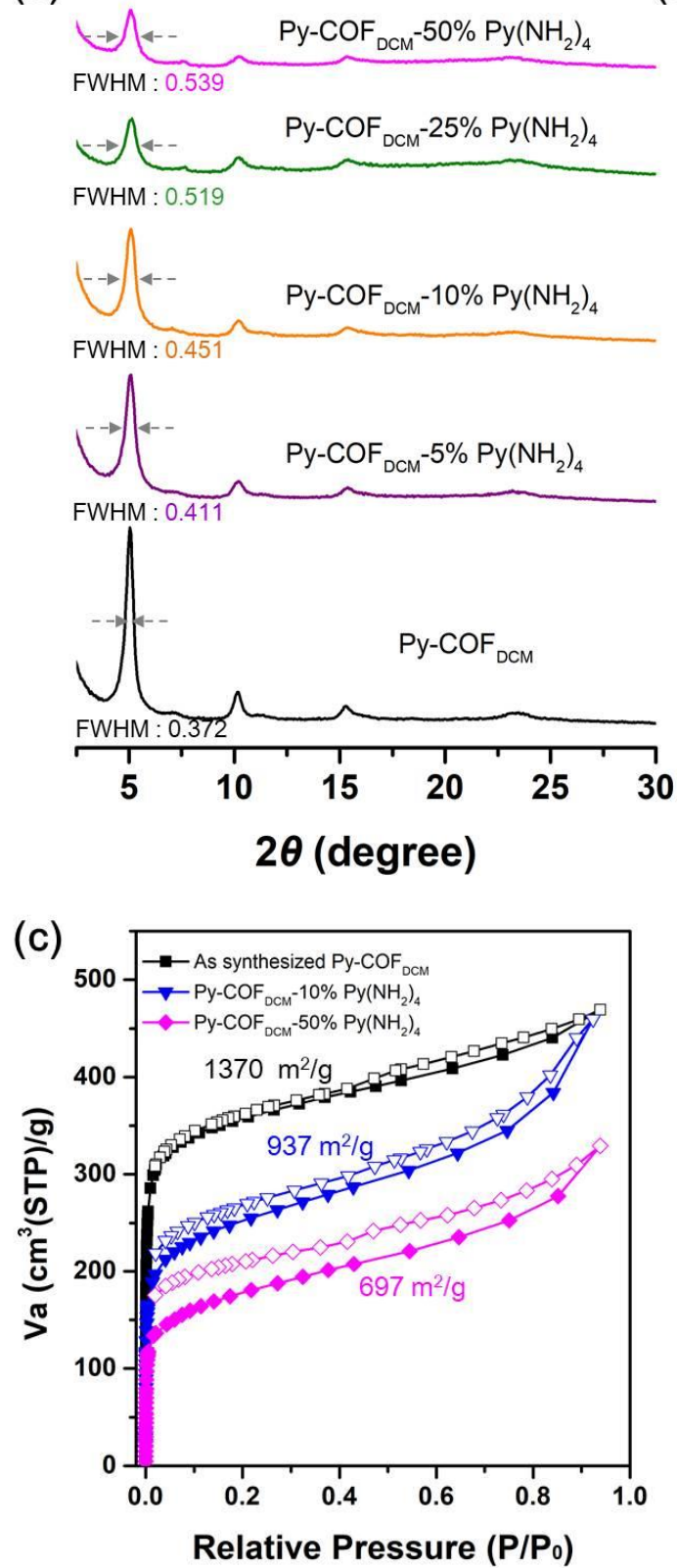

(b)
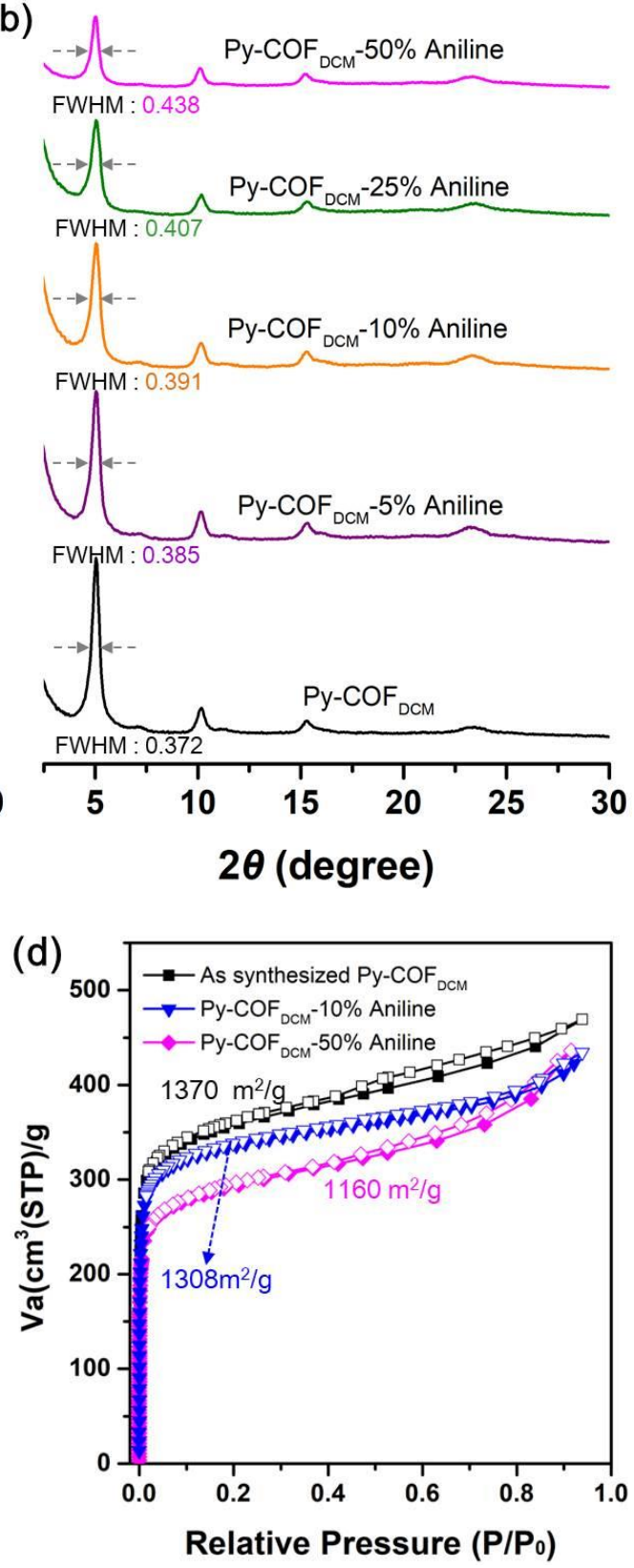

Figure S33. The influence of (a) monofunctional monomer $\left(\mathrm{Py}\left(\mathrm{NH}_{2}\right)_{4}\right)$ and (b) modulator (aniline)

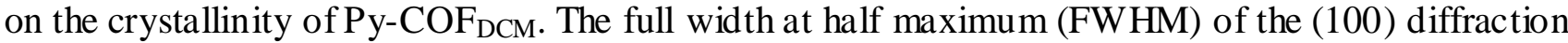
peak at $5.02^{\circ}$ in the PXRD patterns of $\mathrm{Py}-\mathrm{COF}_{\mathrm{DCM}}$ exhibited gradual increase when $\mathrm{Py}\left(\mathrm{NH}_{2}\right)_{4}$ or aniline were added into the reaction system, which indicated a decreased crystallinity. (c) and (d) Nitrogen adsorption (solid) and desorption (open) isotherms at $77 \mathrm{~K}$ for Py-COF ${ }_{\mathrm{DCM}}$ and some stoichometrically imbalanced $\mathrm{Py}-\mathrm{COF}_{\mathrm{DCM}}$. 


\section{Section 24. The Comparison of PXRD Patterns for Co- and Self-Condensation COFs}

The co-condensation Py-Py COF was synthesized according to the literature. ${ }^{\mathrm{S} 4} \mathrm{We}$ compared the PXRD patterns of Py-Py COF with Py-COF, and observed that our Py-COF exhibited stronger diffraction peaks than Py-Py COF. In addition, we tried to synthesize Py-Py COF in five different solvent combinations, the resultes indicated Py-Py COF exhibited poorer solvent adaptability (Figure S34).
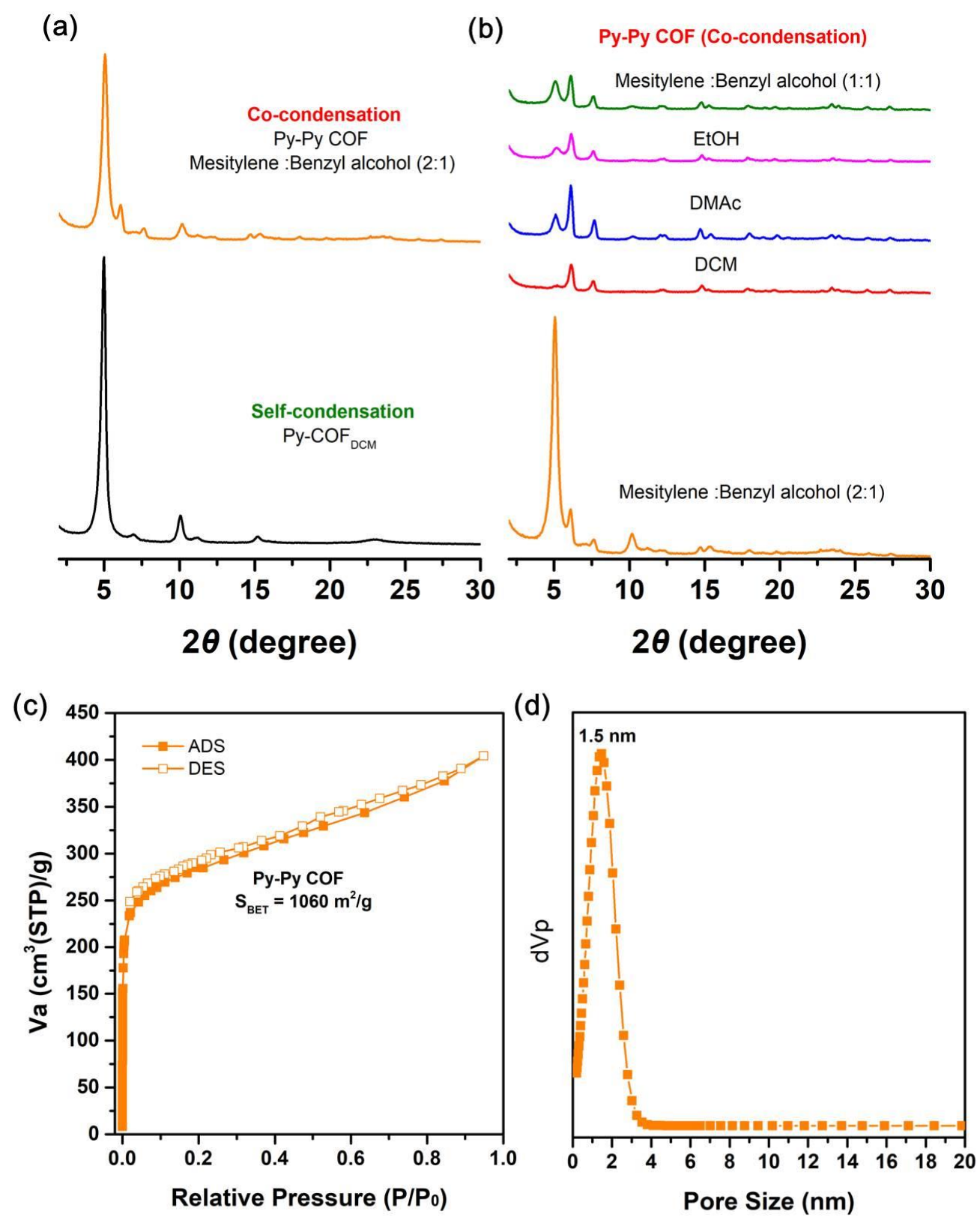

Figure S34. (a) Comparison of PXRD patterns of the co-condensation Py-Py COF and self-condensation $\mathrm{Py}-\mathrm{COF}_{\mathrm{DCM}}$; (b) PXRD patterns of Py-Py COF synthesized in different solvents. (c) Nitrogen adsorption (solid) and desorption (open) isotherms at $77 \mathrm{~K}$ for Py-Py COF; (d) Pore size distribution profiles based on NLDFT calculation for Py-Py COF. 

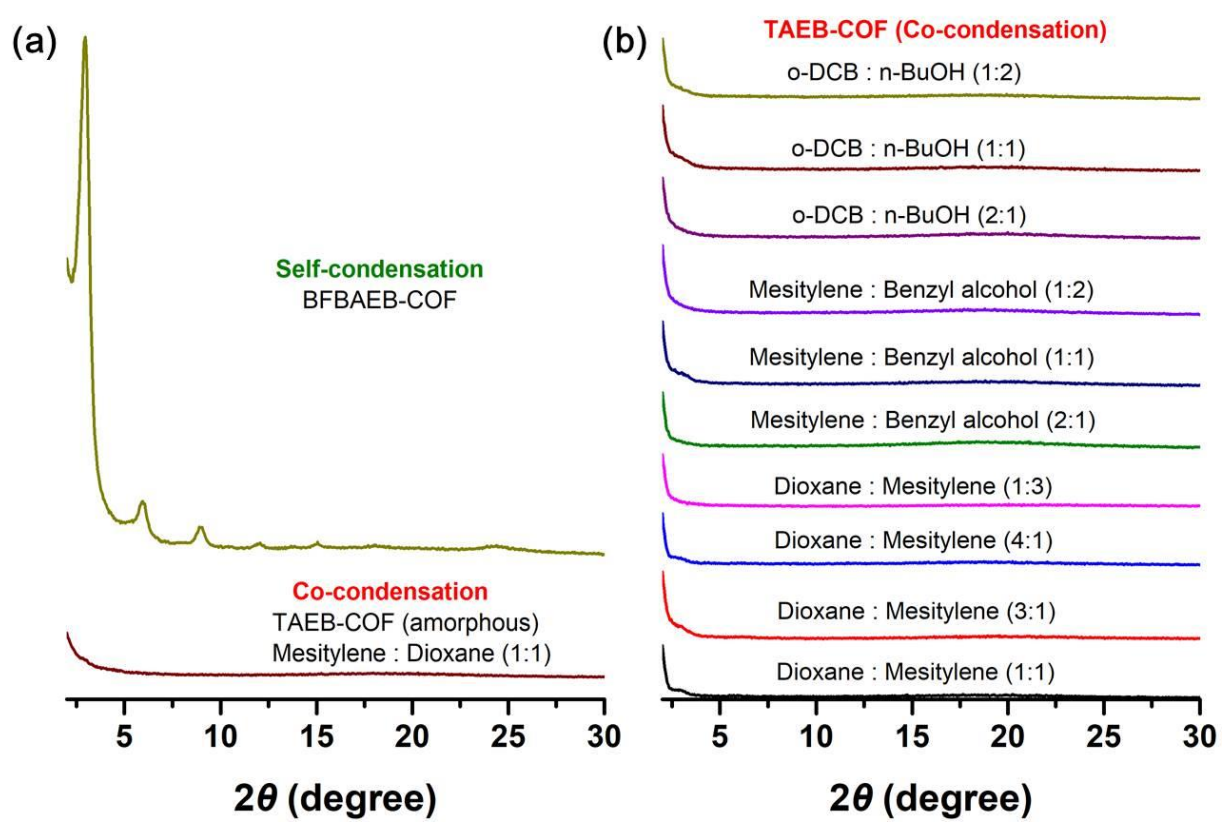

Figure S35. (a) Comparison of PXRD patterns of the co-condensation TAEB-COF and self-condensation BFBAEB-COF; (b) PXRD patterns of TAEB-COF synthesized in different solvents, only amorphous powders were obtained.

(a)

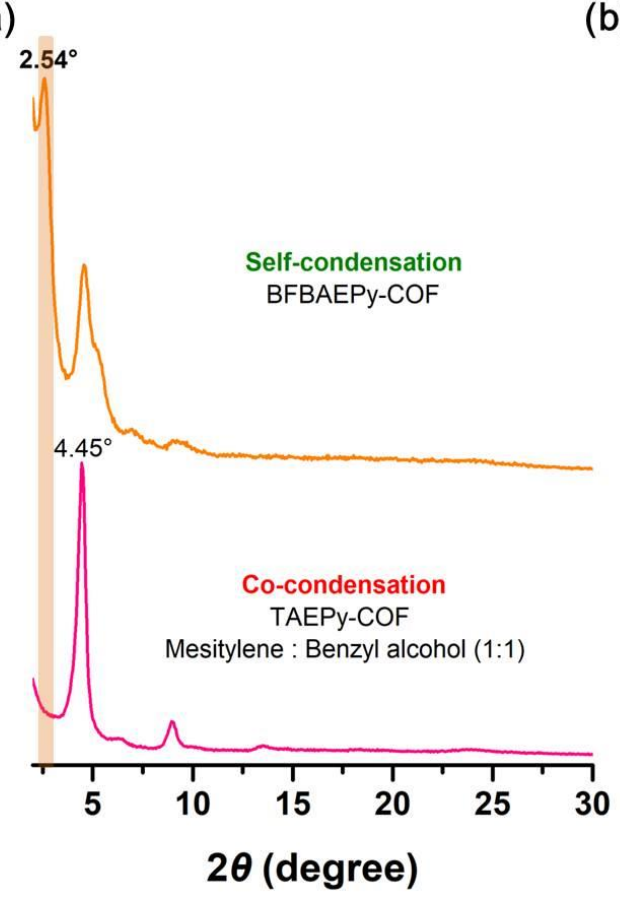

(b)

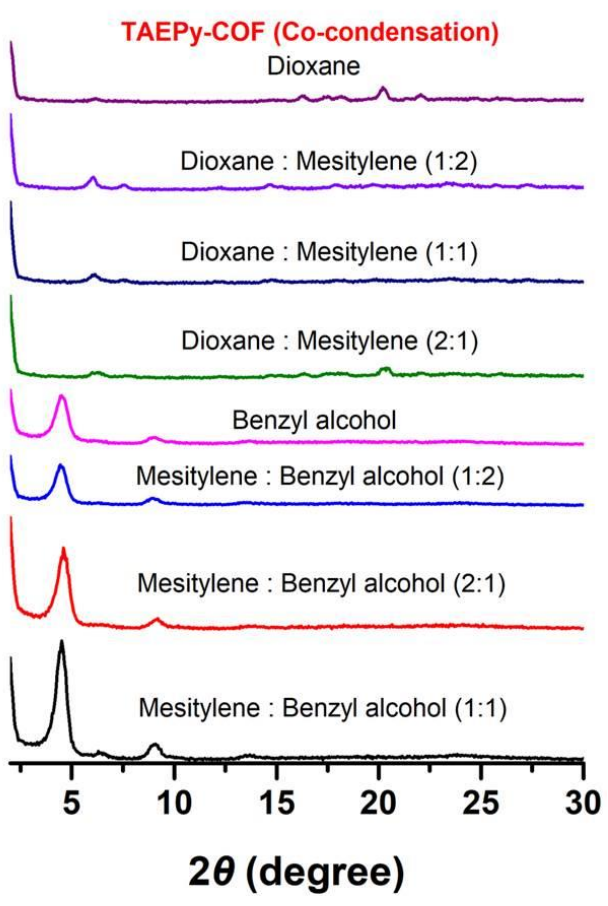



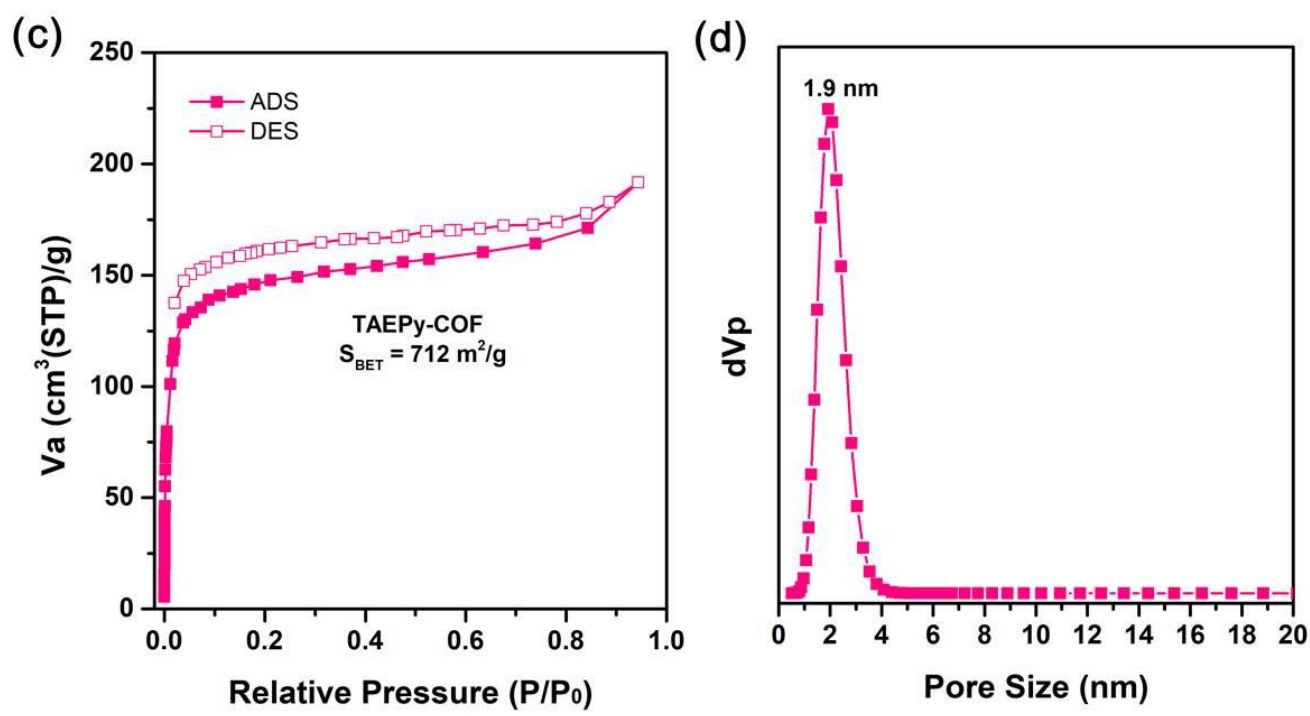

Figure S36. (a) Comparison of PXRD patterns of the co-condensation TAEPy-COF and self-condensation BFBAEPy-COF, the first peaks are distinctly different indicating they have different structures; (b) PXRD patterns of TAEPy-COF synthesized in different solvents; (c) Nitrogen adsorption (solid) and desorption (open) isotherms at $77 \mathrm{~K}$ for TAEPy-COF; (d) Pore size distribution profiles based on NLDFT calculation for TAEPy-COF.
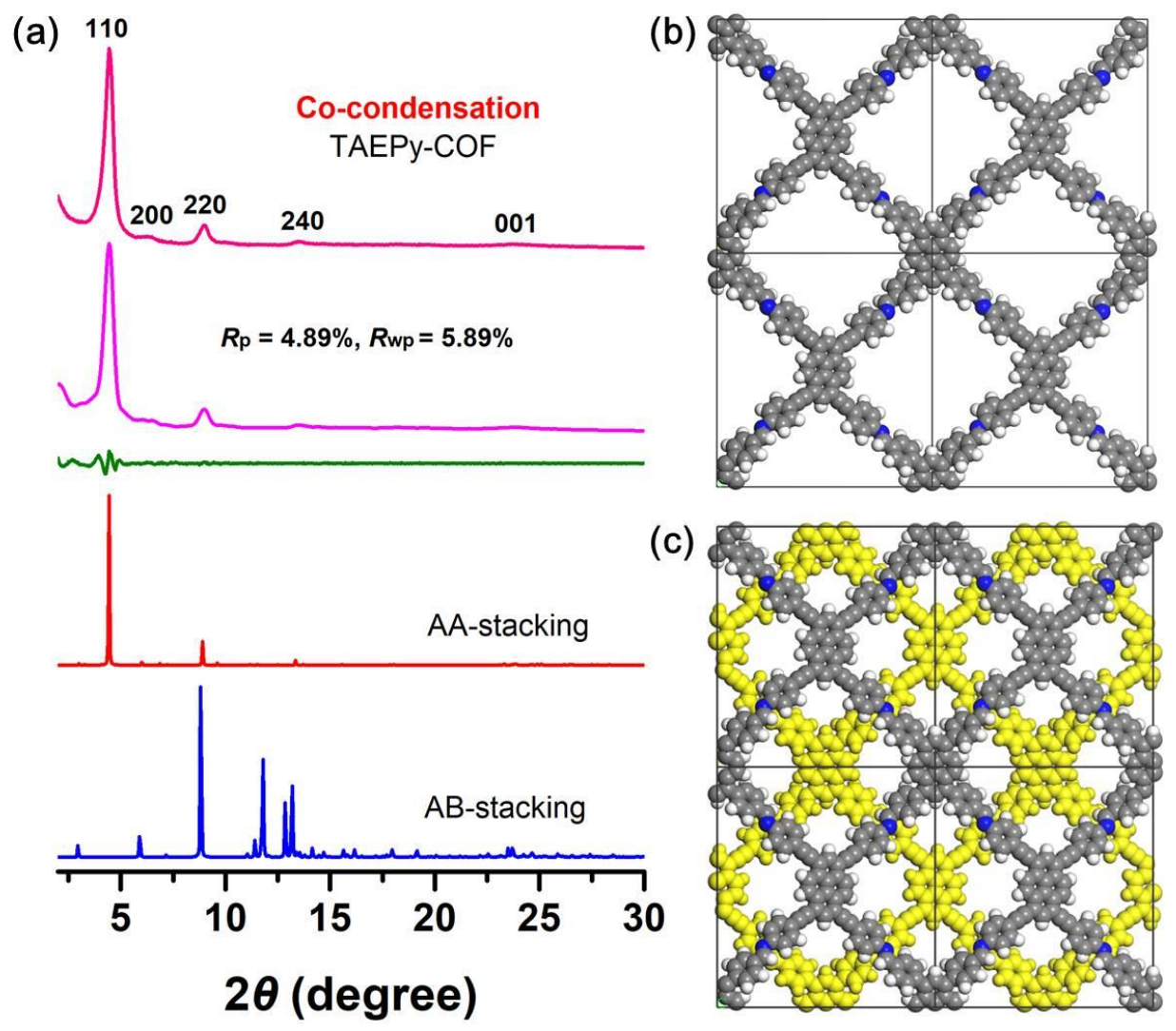

Figure S37. (a) Experimental PXRD pattern (pink), Pawley refinement (purple), their difference (green), simulated profiles using AA-stacking (red) and AB-stacking (blue) modes for co-condensation TAEPy-COF; (b) and (c) AA-stacking and AB-stacking structures of TAEPy-COF. 


\section{Section 25. Comparison of the Performance of Some Hole Transport Materials}

Table S6. Comparison of the performance of some hole transport materials

\begin{tabular}{|c|c|c|}
\hline $\begin{array}{c}\text { Hole transport material } \\
\text { (HTM) }\end{array}$ & $\begin{array}{c}\text { PCE of perovs kite } \\
\text { solar cells }\end{array}$ & References \\
\hline $\begin{array}{c}\text { lithium iodide/triiodide } \\
2,2^{\prime}, 7,7^{\prime} \text {-tetrakis- } \\
\text { (N,N-di-4-methoxyphenylamino)-9,9'- } \\
\text { spirobifluorene (spiro-MeOTAD) }\end{array}$ & $3.8 \%$ & J. Am. Chem. Soc. 2009, 131, \\
6050.
\end{tabular}


Section 26. The ${ }^{1} \mathrm{H}$ and ${ }^{13} \mathrm{C}$ NMR Spectra of the Intermediates and Monomers
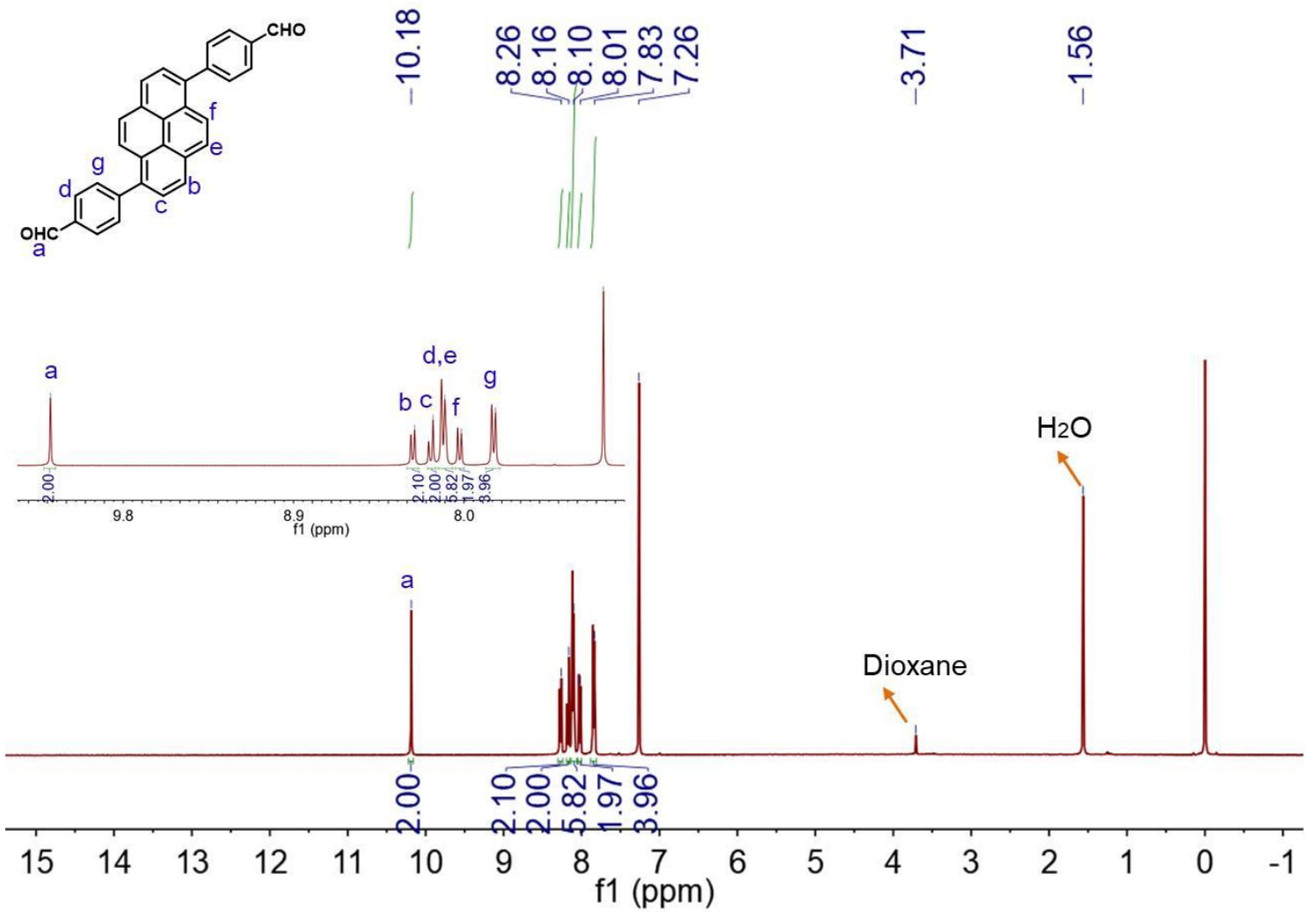

Figure S38. The ${ }^{1} \mathrm{H}$ NMR spectrum of 4,4'-(pyrene-1,6-diyl)dibenzaldehyde (2) in $\mathrm{CDCl}_{3}$.
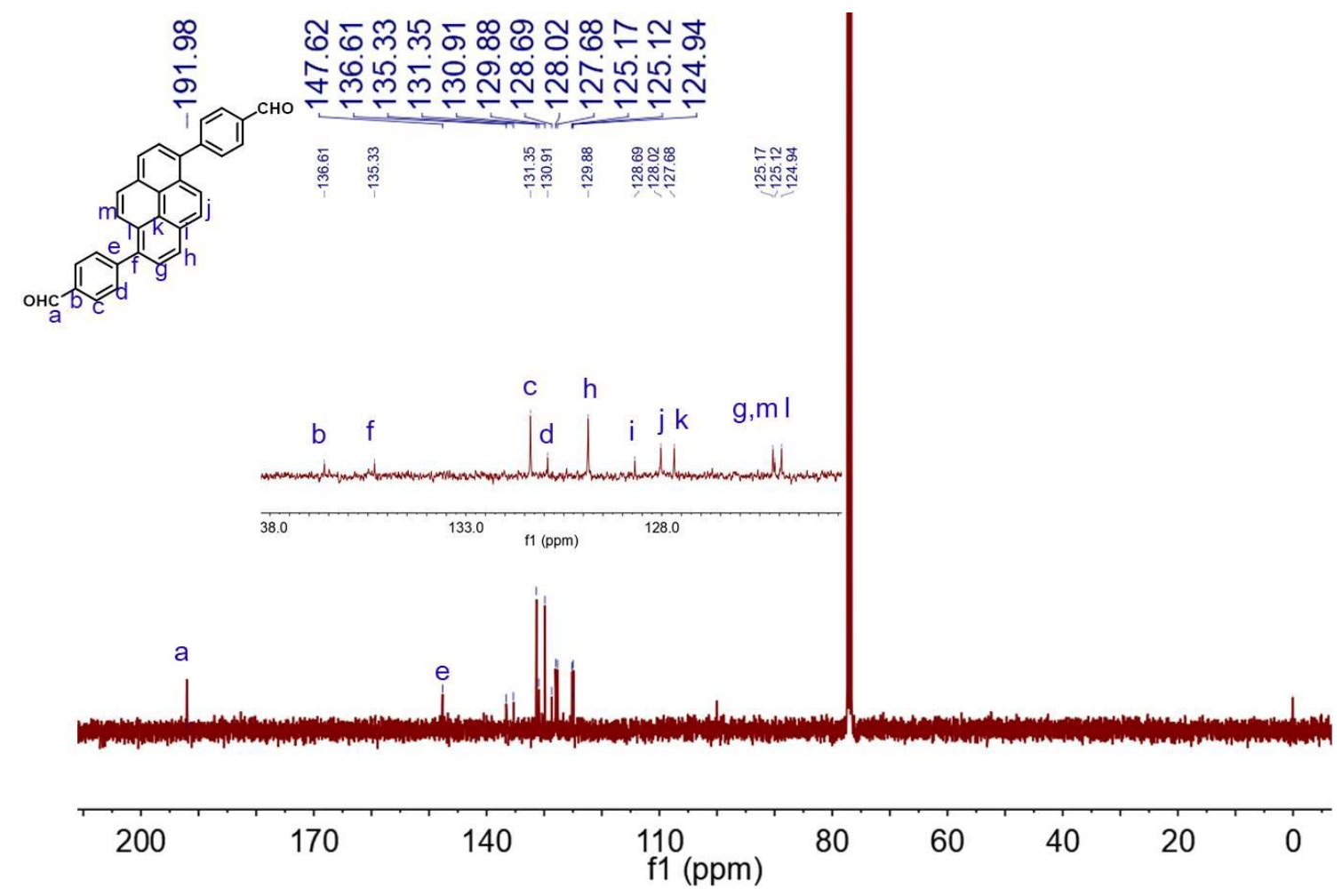

Figure S39. The ${ }^{13} \mathrm{C}$ NMR spectrum of 4,4'-(pyrene-1,6-diyl)dibenzaldehyde (2) in $\mathrm{CDCl}_{3}$. 


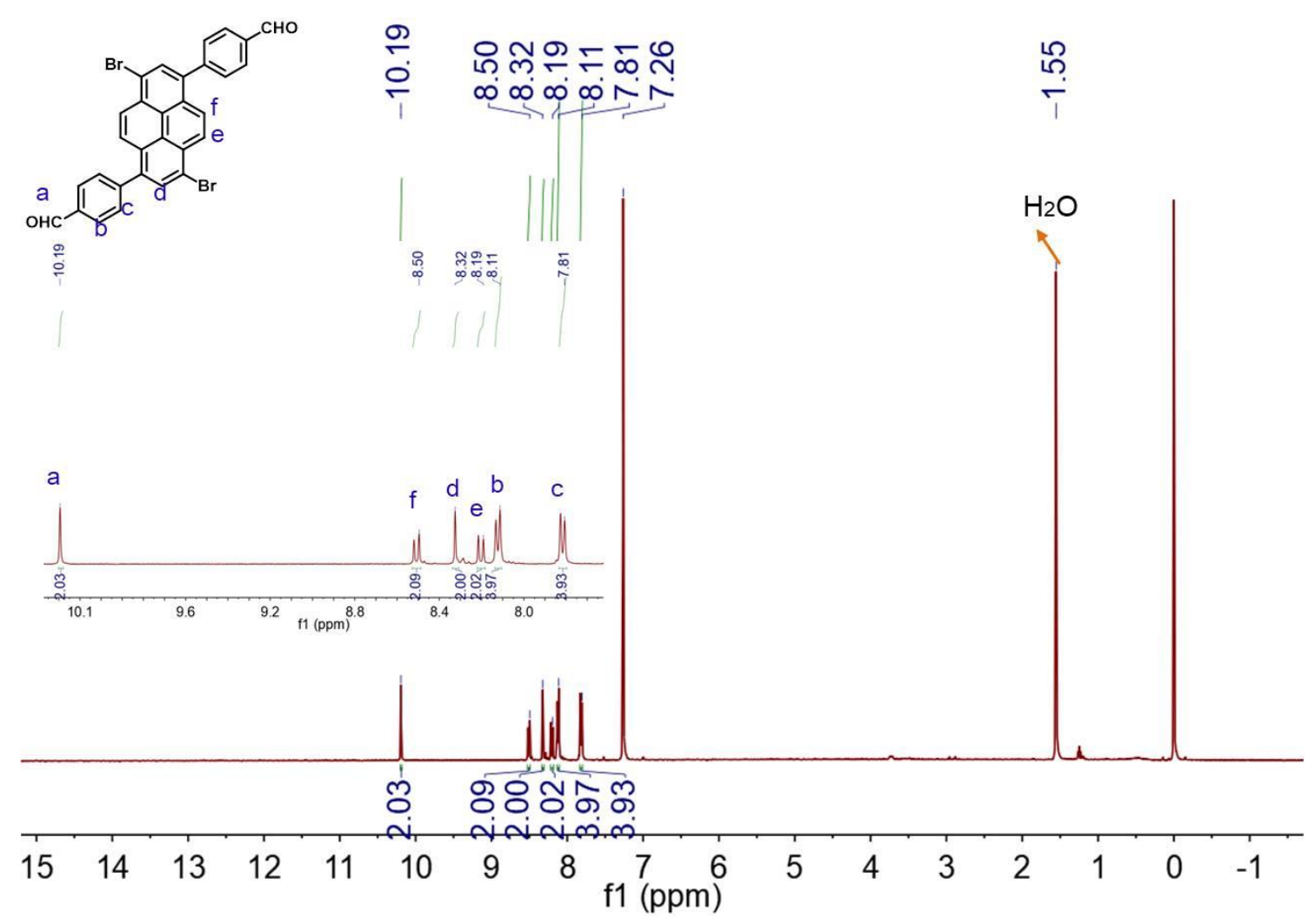

Figure S40. The ${ }^{1}$ H NMR spectrum of 4,4'-(3,8-dibromopyrene-1,6-diyl)dibenzaldehyde (3) in $\mathrm{CDCl}_{3}$.

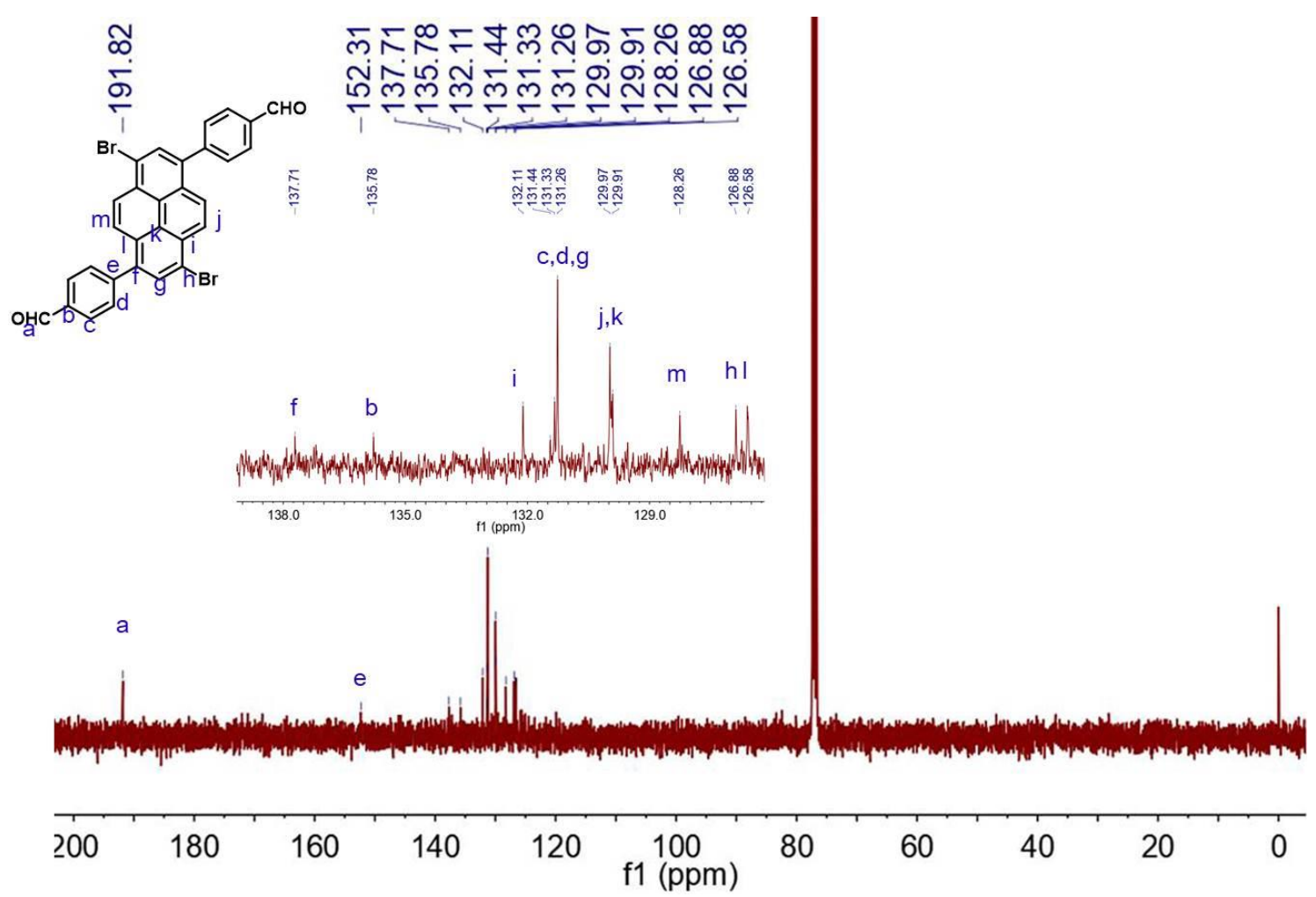

Figure S41. The ${ }^{13} \mathrm{C}$ NMR spectrum of 4,4'-(3,8-dibromopyrene-1,6-diyl)dibenzaldehyde (3) in $\mathrm{CDCl}_{3}$. 


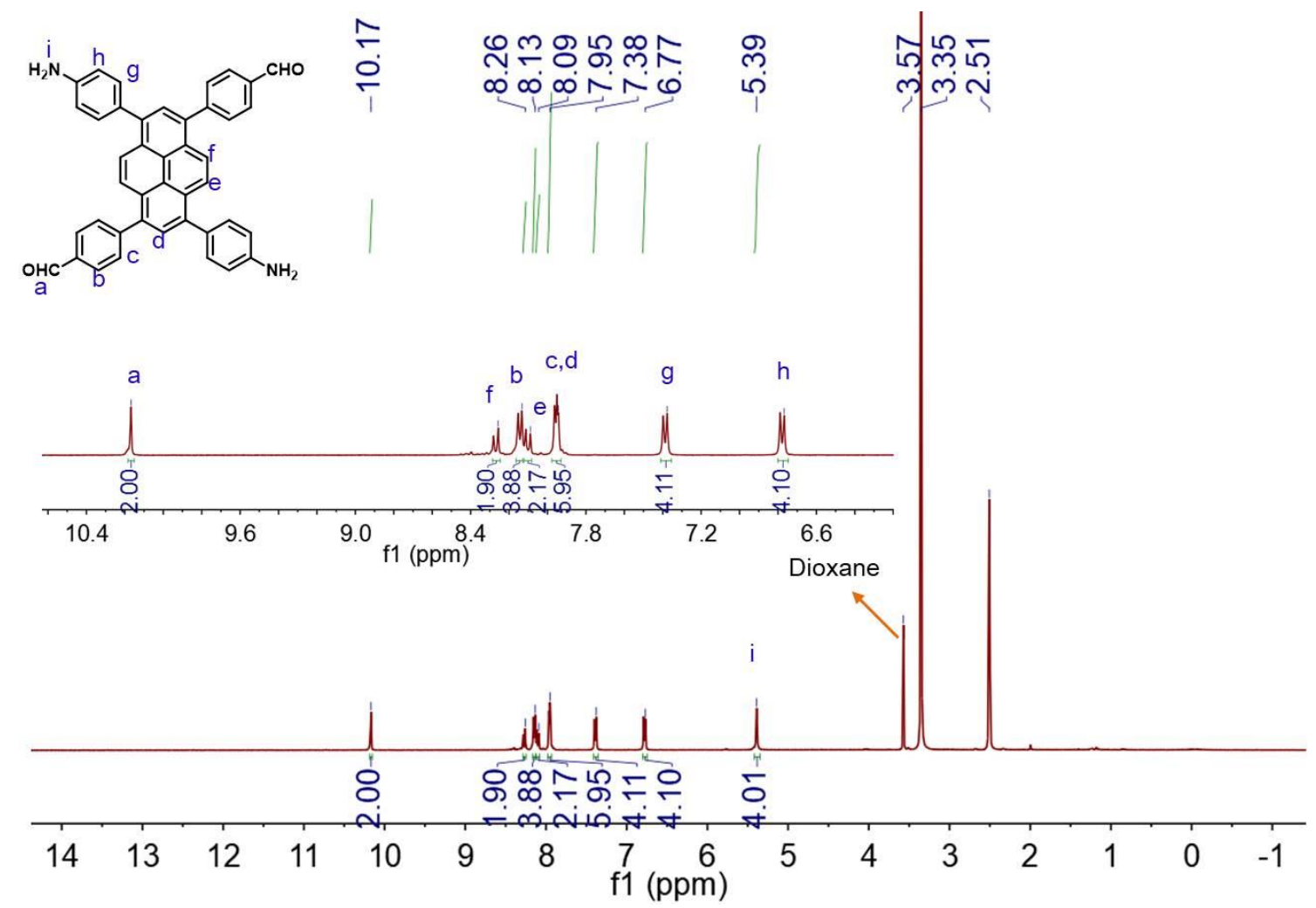

Figure S42. The ${ }^{1} \mathrm{H}$ NMR spectrum of BFBAPy in DMSO- $\mathrm{d}_{6}$.
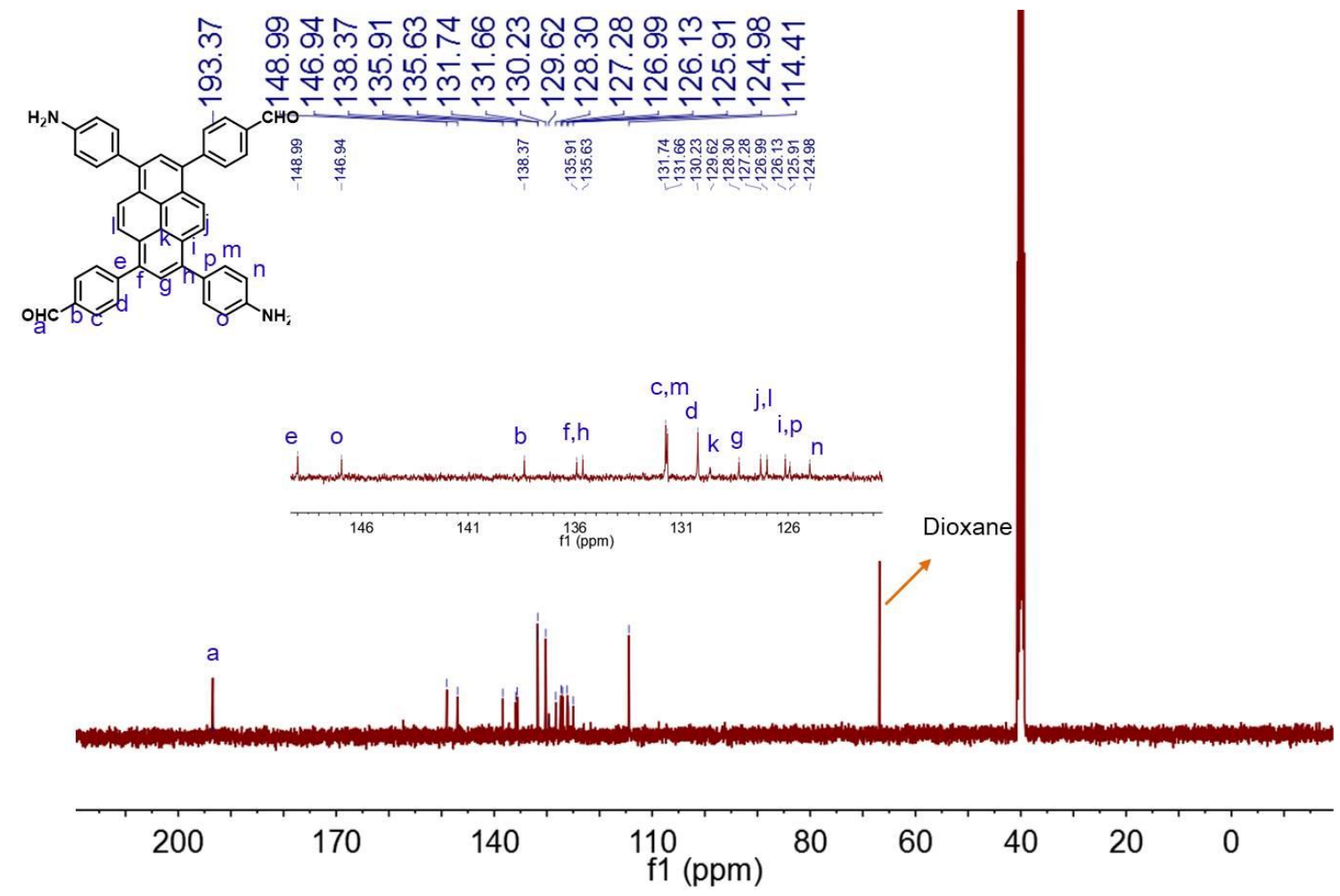

Figure S43. The ${ }^{13} \mathrm{C}$ NMR spectrum of BFBAPy in DMSO- $\mathrm{d}_{6}$. 


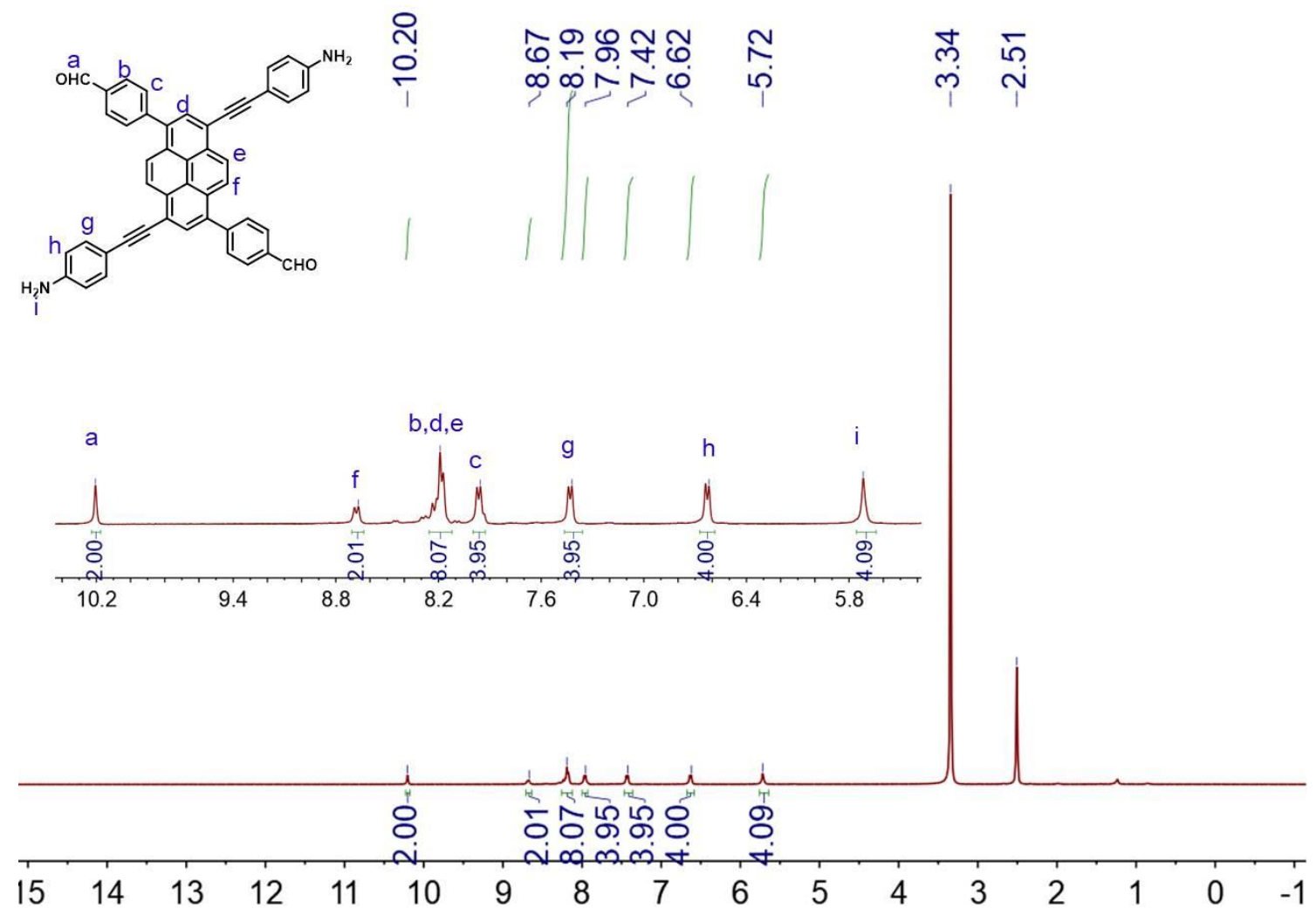

Figure S44. The ${ }^{1} \mathrm{H}$ NMR spectrum of BFBAEPy in DMSO- $\mathrm{d}_{6}$.
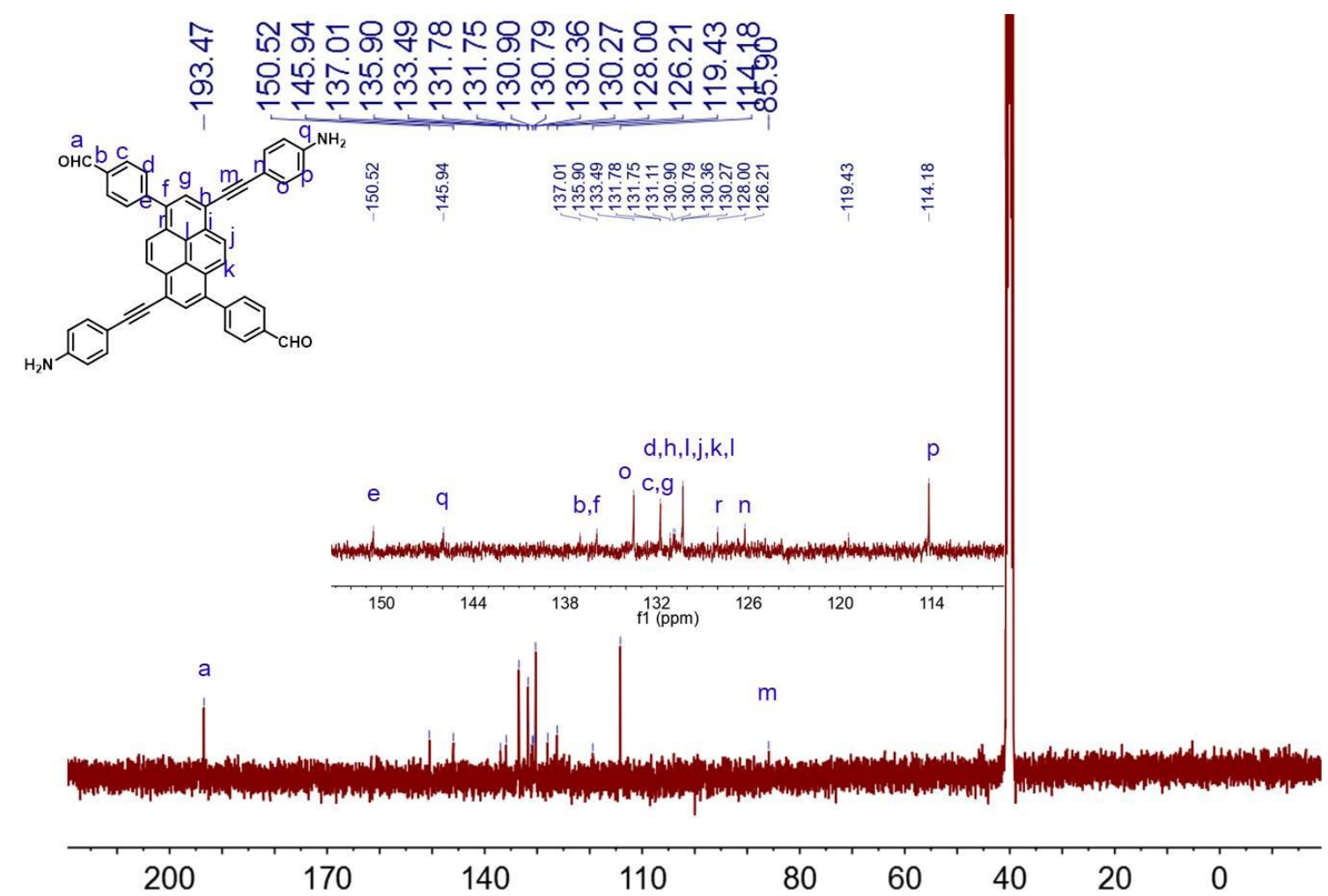

Figure S45. The ${ }^{13} \mathrm{C}$ NMR spectrum of BFBAEPy in DMSO- $\mathrm{d}_{6}$. 

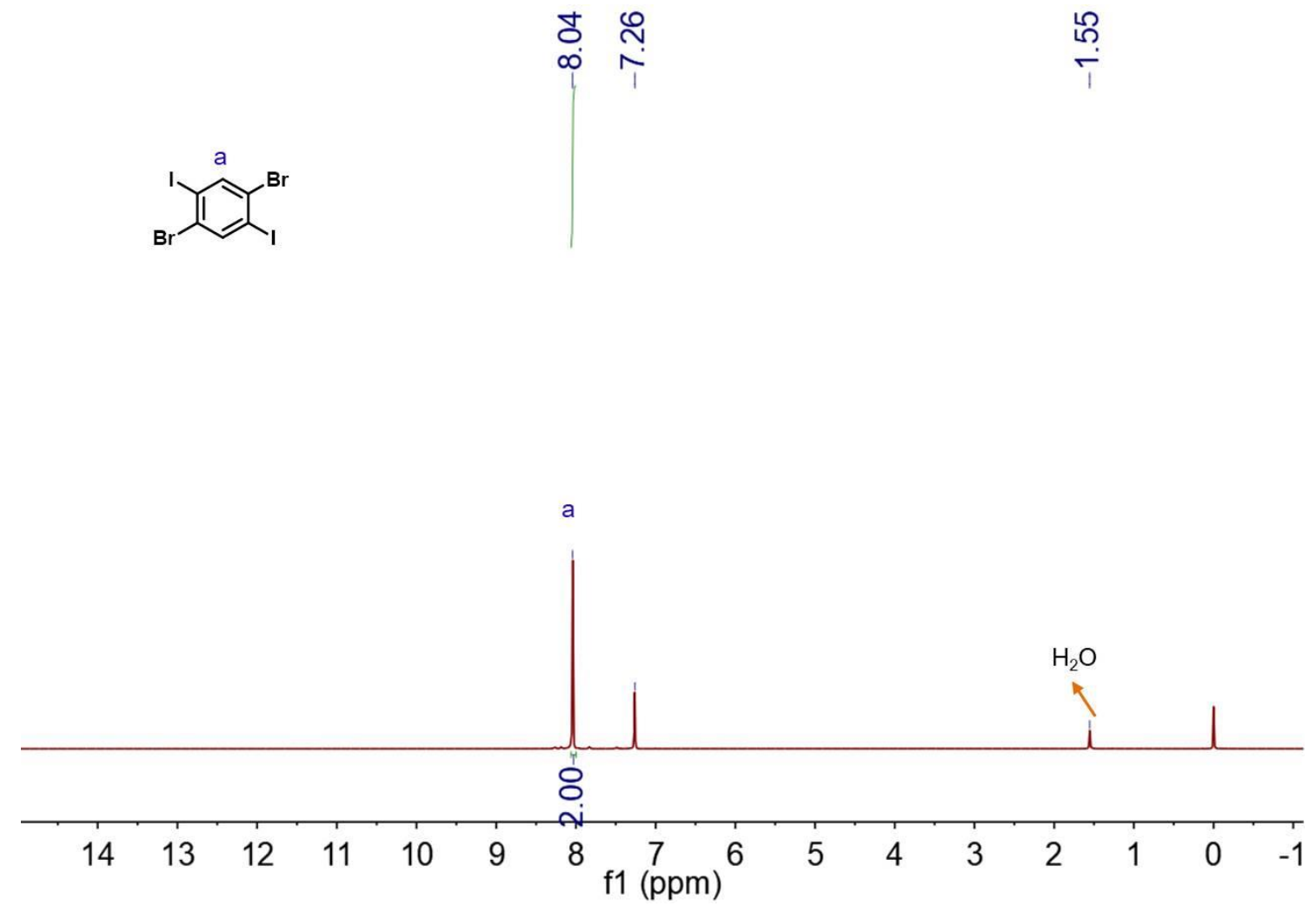

Figure S46. The ${ }^{1} \mathrm{H}$ NMR spectrum of 1,4-dibromo-2,5-diiodobenzene (4) in $\mathrm{CDCl}_{3}$.
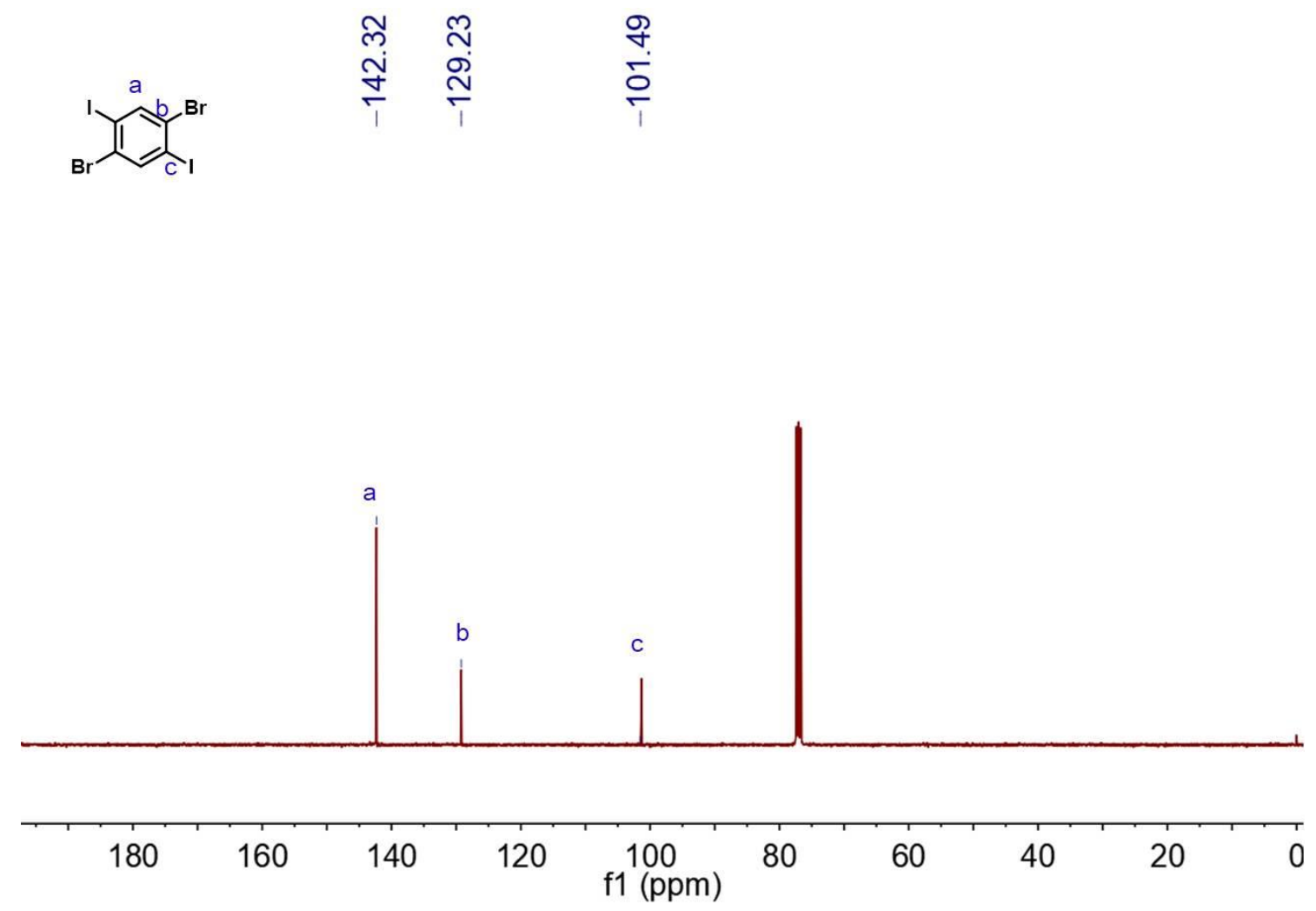

Figure S47. The ${ }^{13} \mathrm{C}$ NMR spectrum of 1,4-dibromo-2,5-diiodobenzene (4) in $\mathrm{CDCl}_{3}$. 


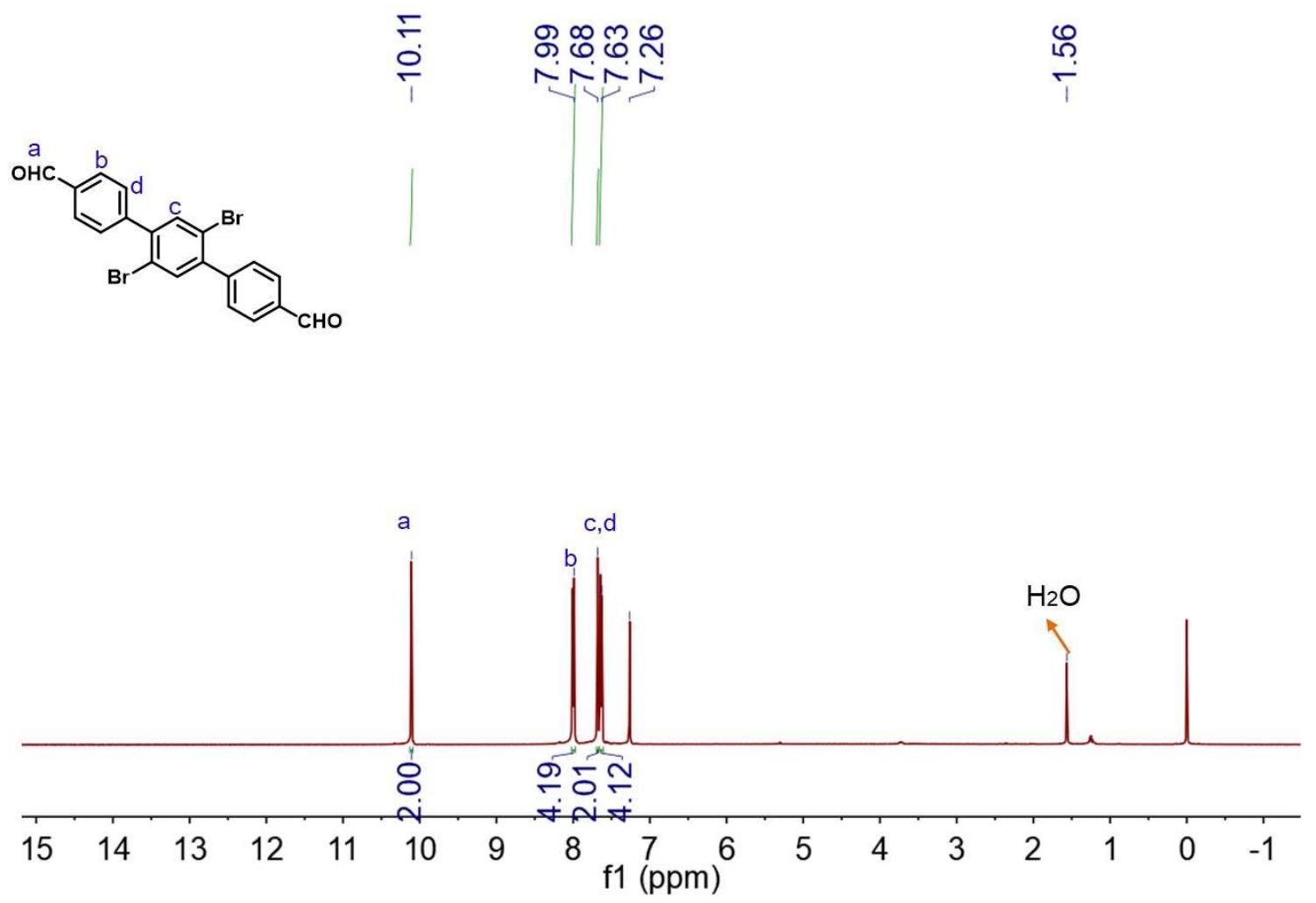

Figure S48. The ${ }^{1} \mathrm{H}$ NMR spectrum of 1,4-Dibromo-2,5-bis(4-formylphenyl)benzene (5) in $\mathrm{CDCl}_{3}$.

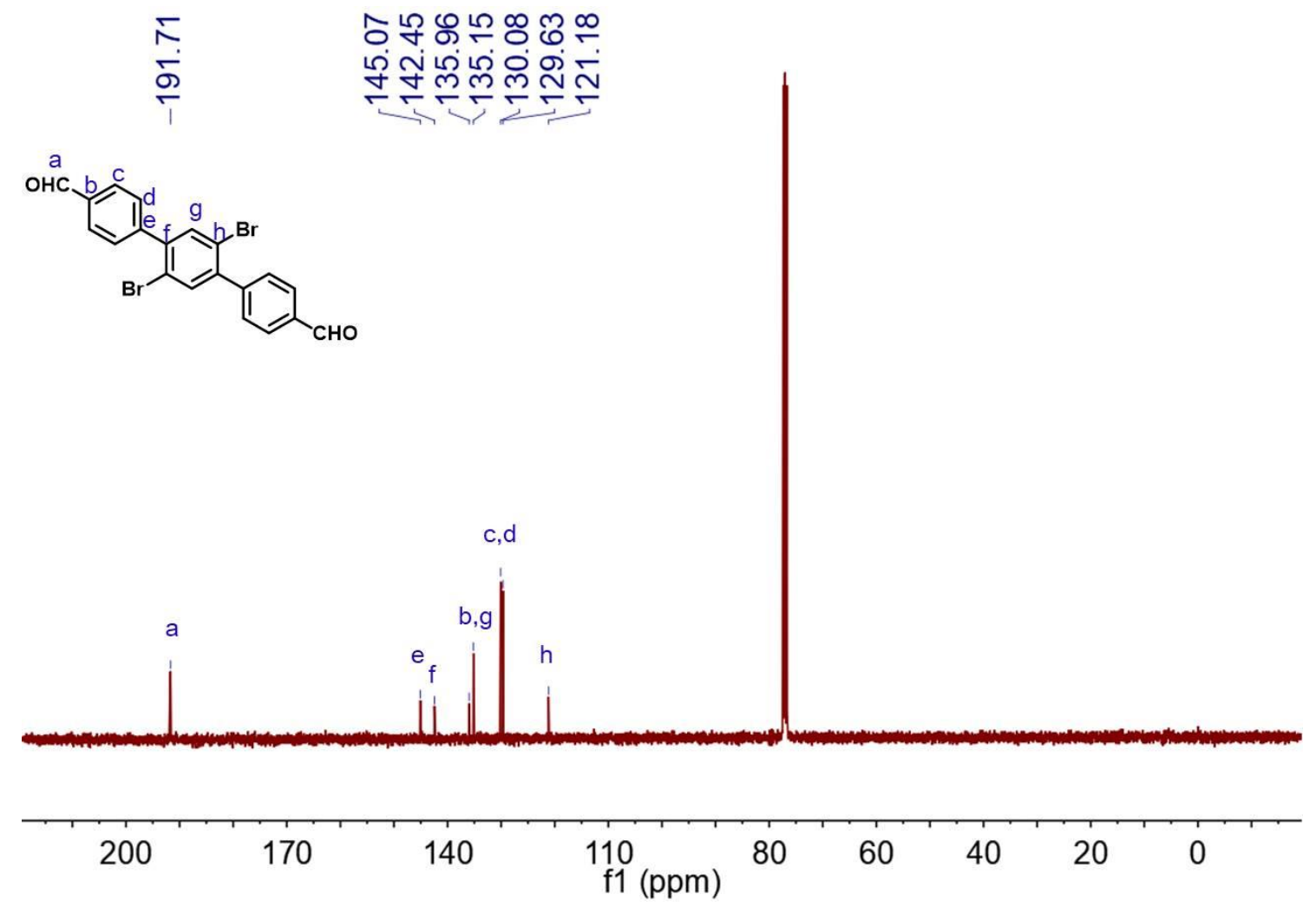

Figure S49. The ${ }^{13} \mathrm{C}$ NMR spectrum of 1,4-Dibromo-2,5-bis(4-formylphenyl)benzene (5) in $\mathrm{CDCl}_{3}$. 

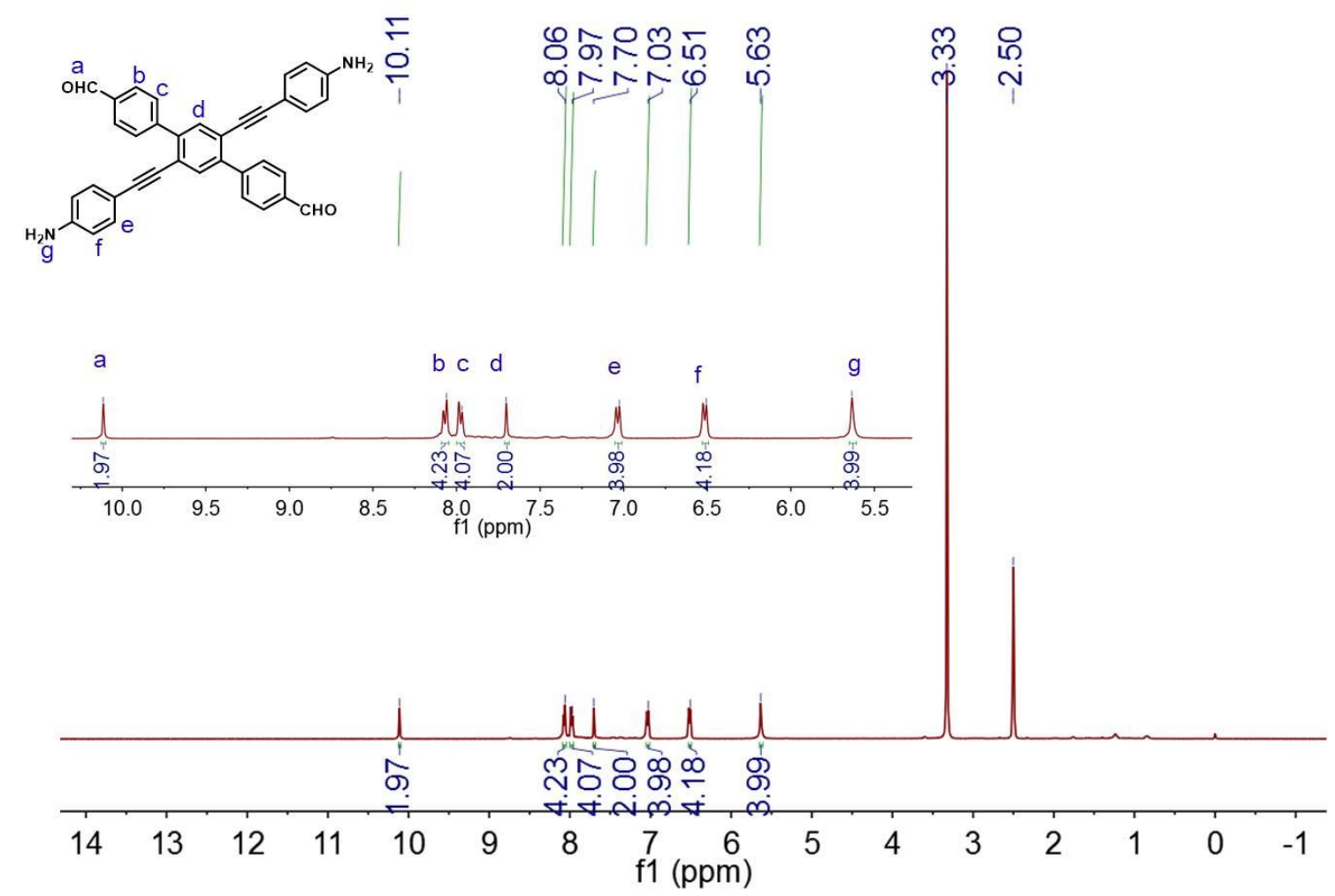

Figure S50. The ${ }^{1} \mathrm{H}$ NMR spectrum of BFBAEB in DMSO- $\mathrm{d}_{6}$.
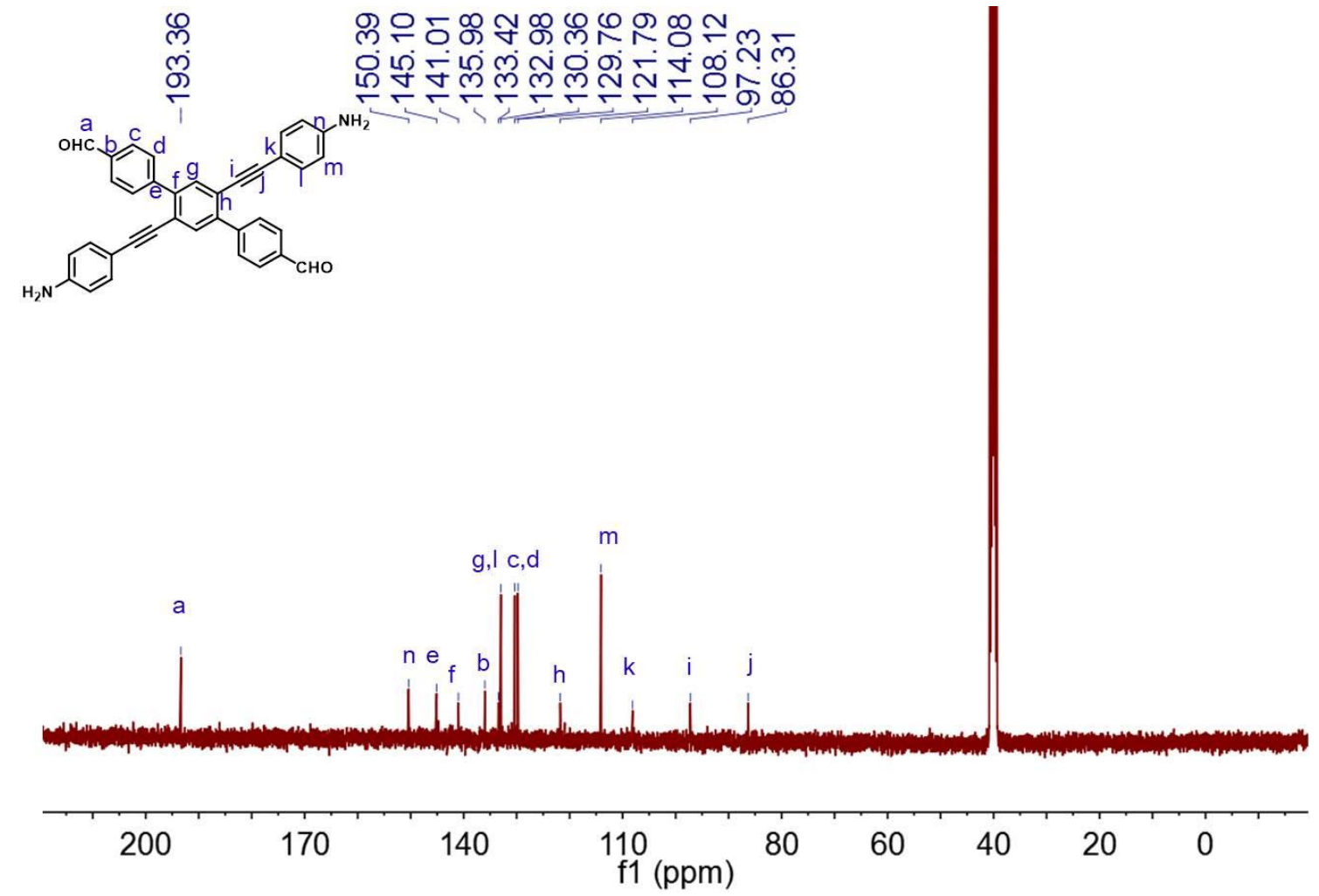

Figure S51. The ${ }^{13} \mathrm{C}$ NMR spectrum of BFBAEB in DMSO- $\mathrm{d}_{6}$. 

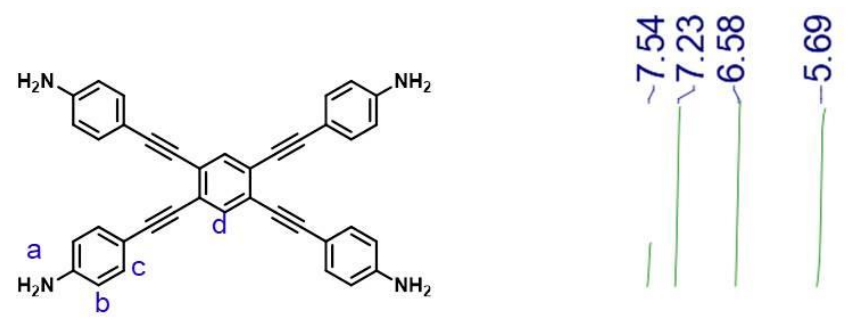

$\stackrel{\text { mై }}{\text { mं }}$
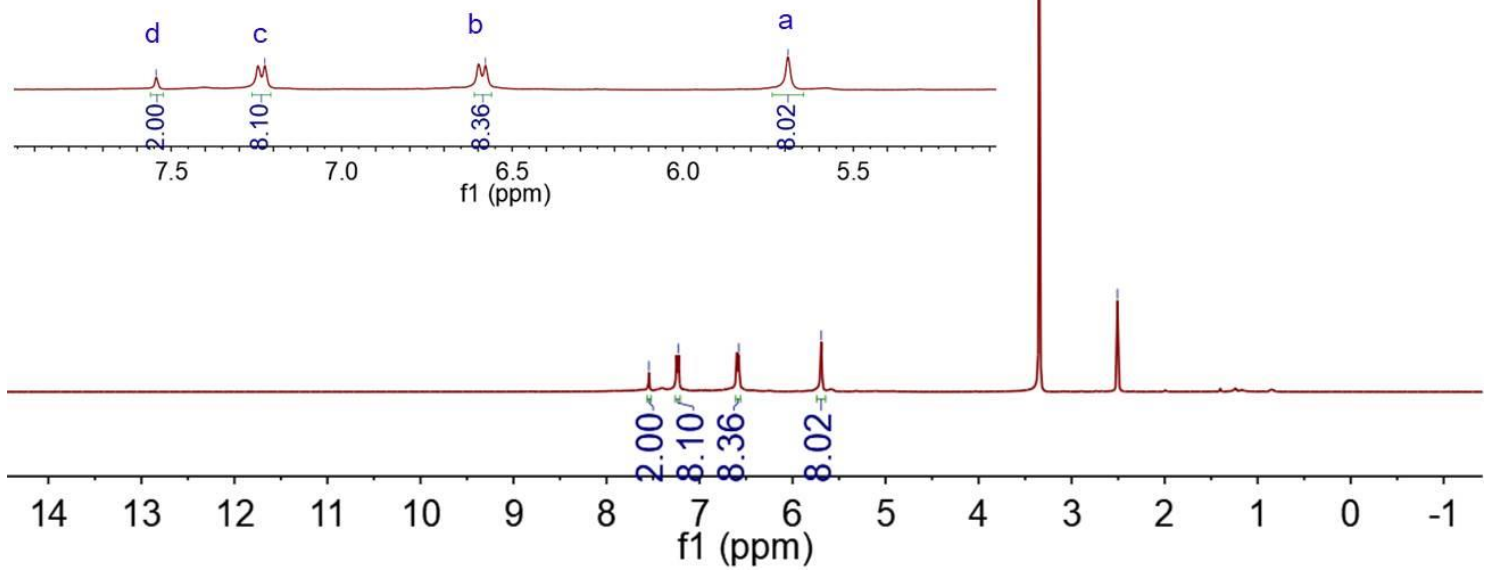

Figure S52. The ${ }^{1} \mathrm{H}$ NMR spectrum of TAEB in DMSO- $\mathrm{d}_{6}$.
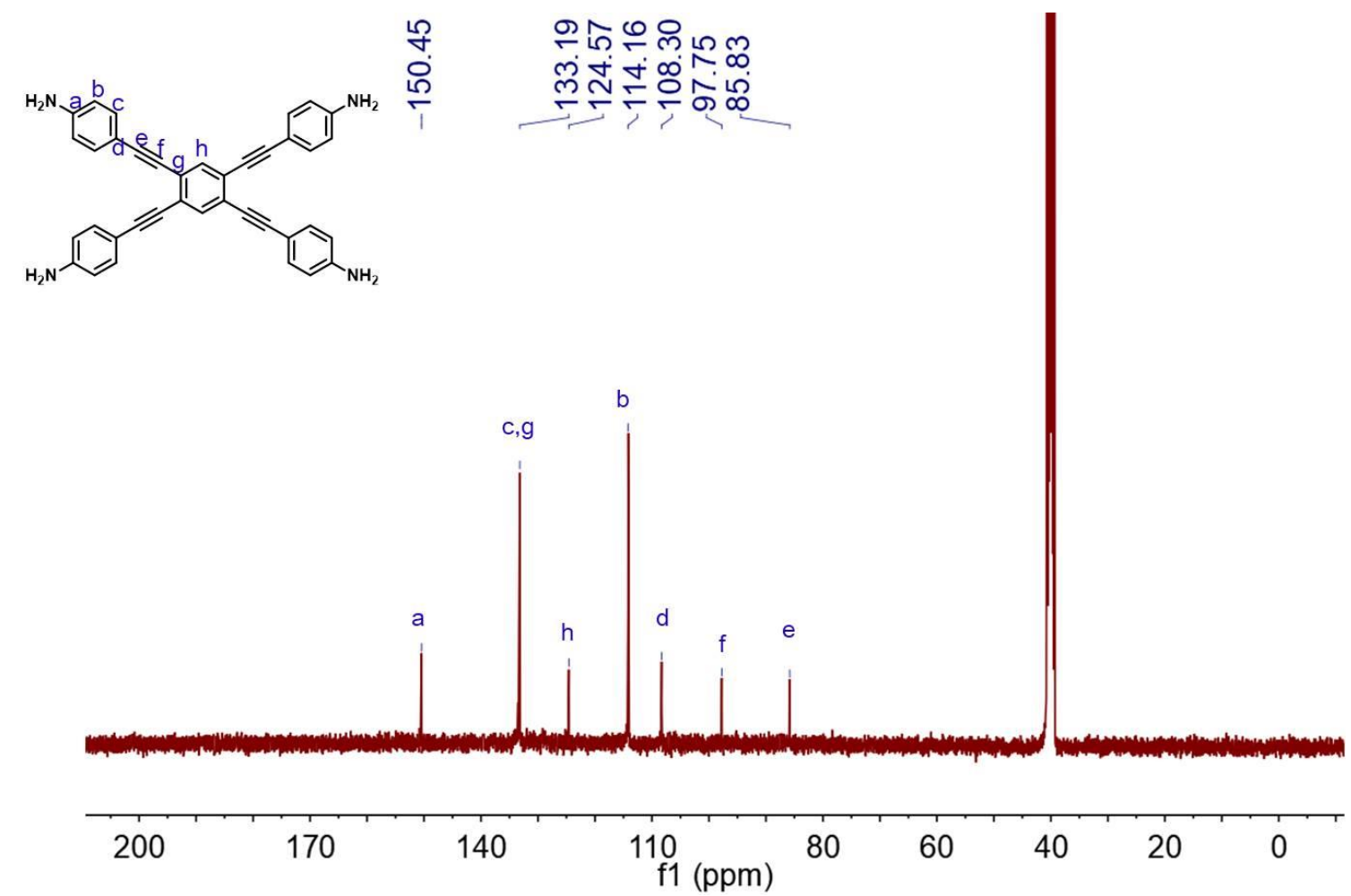

Figure S53. The ${ }^{13} \mathrm{C}$ NMR spectrum of TAEB in DMSO- $\mathrm{d}_{6}$. 


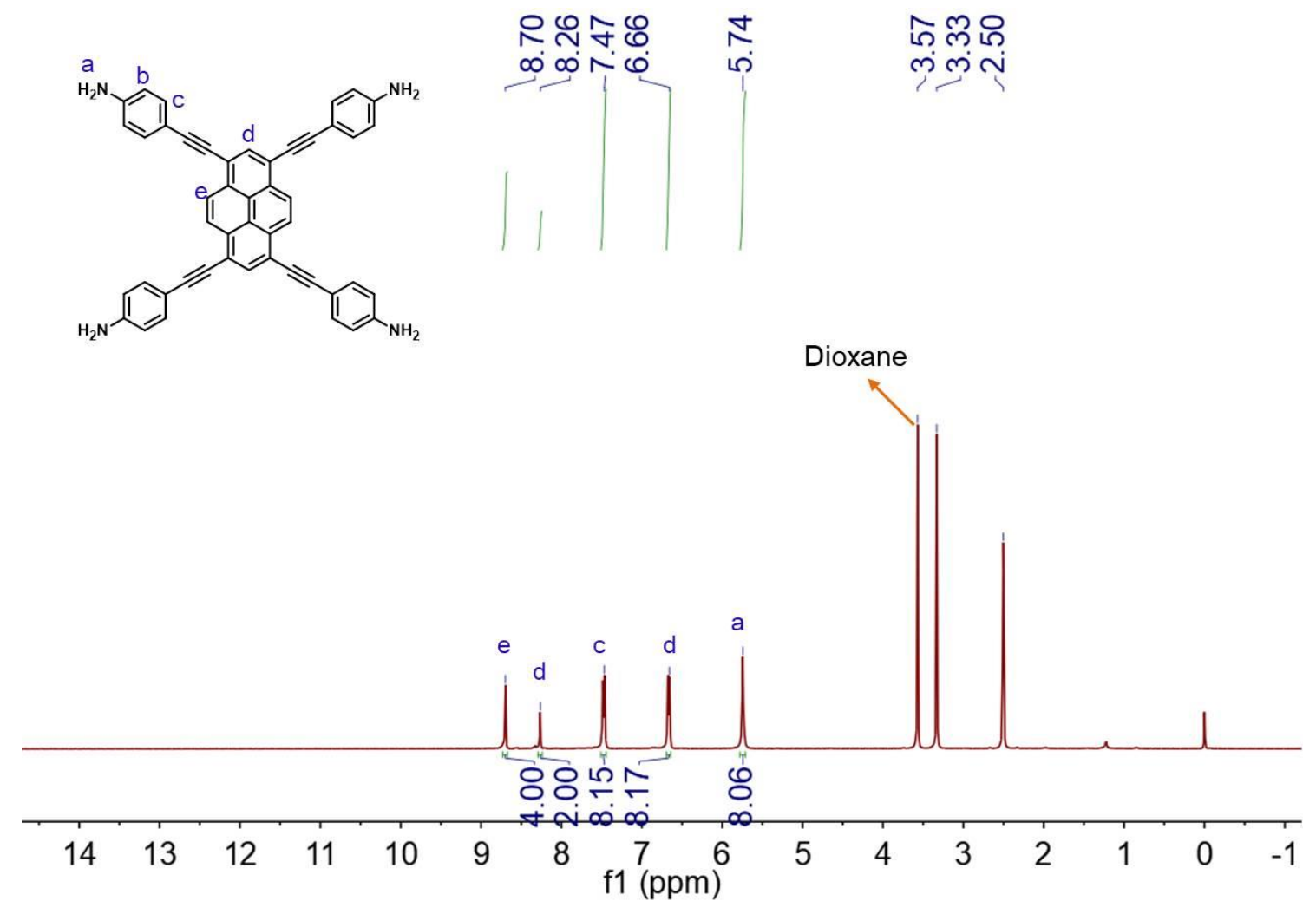

Figure S54. The ${ }^{1} \mathrm{H}$ NMR spectrum of TAEPy in DMSO- $\mathrm{d}_{6}$.

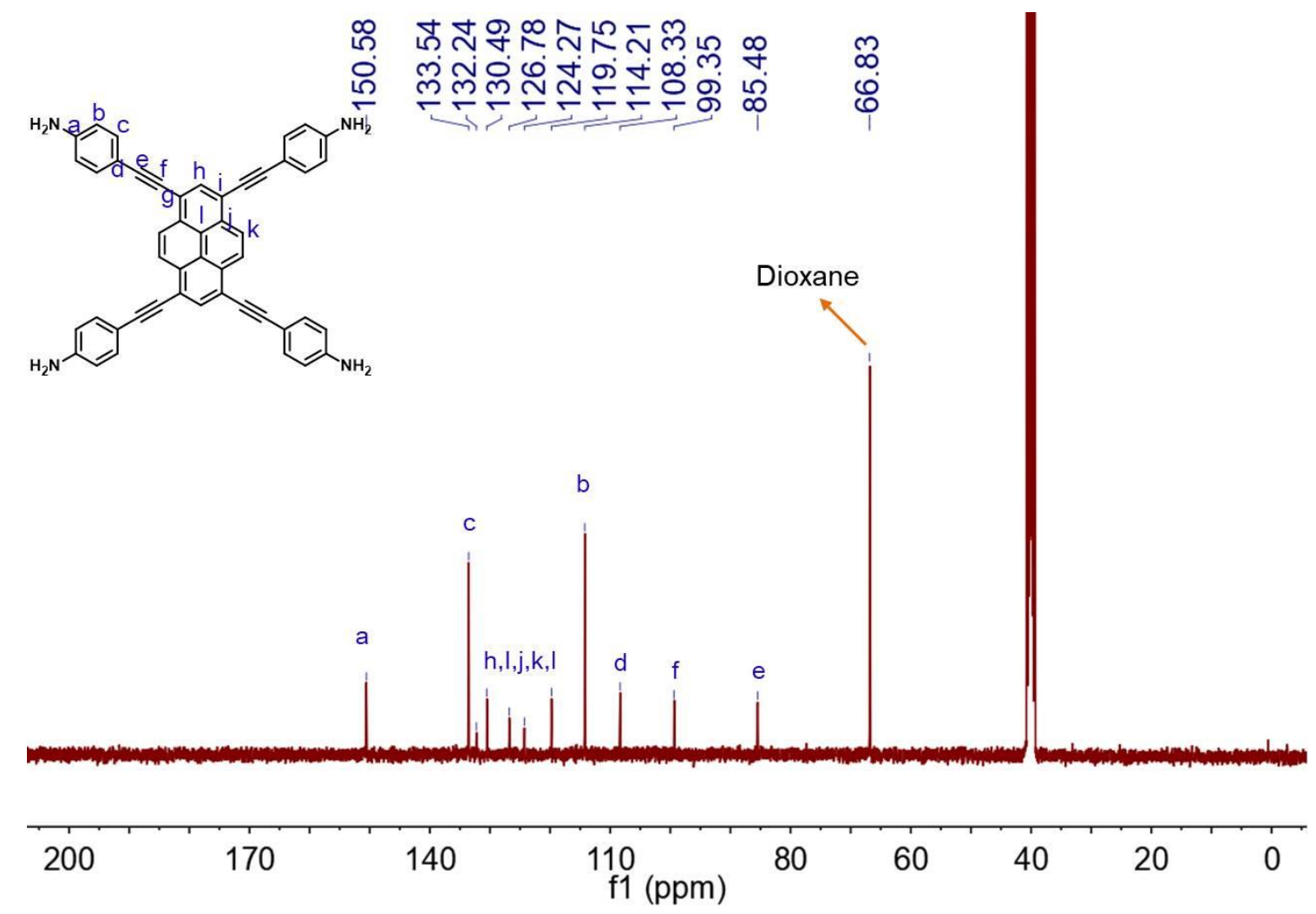

Figure S55. The ${ }^{13} \mathrm{C}$ NMR spectrum of TAEPy in DMSO- $\mathrm{d}_{6}$. 


\section{Section 27. Supporting References}

S1. Zhang, R.; Zhang, T.; Xu, L.; Han, F.; Zhao, Y.; Ni, Z. A New Series of Short Axially Symmetrically and Asymmetrically 1,3,6,8-Tetrasubstituted Pyrenes with Two Types of Substituents: Syntheses, Structures, Photophysical Properties and Electroluminescence. J. Mol. Struct., 2017, 1127, 237-246.

S2. He, F.; Wang, W.; Chen, W.; Xu, T.; Darling, S. B.; Strzalka, J.; Liu, Y.; Yu, L. Tetrathienoanthracene-Based Copolymers for Efficient Solar Cells. J. Am. Chem. Soc. 2011, 133, 3284-3287.

S3. Altarawneh, S., Behera, S., Jena, P., El-Kaderi, H. M. New Insights into Carbon Dioxide Interactions with Benzimidazole-linked Polymers. Chem. Commun., 2014, 50, 3571-3574.

S4. Ascherl, L., Evans, E. W., Hennemann, M., Nuzzo, D. D., Hufnagel, A. G., Beetz, M., Friend, R. H., Clark, T., Bein, T., Auras, F. Solvatochromic Covalent Organic Frameworks. Nat. Commun. 2018, 9, 3802 . 